UNIVERSIDADE DE SÃO PAULO

ESCOLA DE ENFERMAGEM DE RIBEIRÃO PRETO

SARA PINTO BARBOSA

Intervenção com familiares, usuários de álcool e álcool mais outras drogas: um estudo clínico

RIBEIRÃO PRETO 


\section{SARA PINTO BARBOSA}

Intervenção com familiares, usuários de álcool e álcool mais outras drogas: um estudo clínico

Tese apresentada à Escola de Enfermagem de Ribeirão Preto da Universidade de São Paulo, para obtenção do título de Doutor em Ciências, Programa de Pós-Graduação Enfermagem Psiquiátrica.

Linha de pesquisa: Uso e Abuso de Álcool e Drogas

Orientador: Margarita A. Villar Luis

RIBEIRÃO PRETO 
Autorizo a reprodução e divulgação total ou parcial deste trabalho, por qualquer meio convencional ou eletrônico, para fins de estudo e pesquisa, desde que citada a fonte.

\section{Barbosa, Sara}

Intervenção com familiares, usuários de álcool e álcool mais outras drogas: um estudo clínico. Ribeirão Preto, 2017.

119 p. : il. ; $30 \mathrm{~cm}$

Tese de Doutorado, apresentada à Escola de Enfermagem de Ribeirão Preto/USP. Área de concentração: Enfermagem Psiquiátrica.

Orientador: Margarita A. Villar Luis

1. Intervenção Breve. 2. Estudo clínico. 3.Usuários de álcool. 4.Atenção Primária à Saúde. 
Intervenção com familiares, usuários de álcool e álcool mais outras drogas: um estudo clínico

Tese apresentada à Escola de Enfermagem de Ribeirão Preto da Universidade de São Paulo, para obtenção do título de Doutor em Ciências, Programa de Pós-Graduação Enfermagem Psiquiátrica.

Aprovado em / / /

Comissão Julgadora

Prof. Dr.

Instituição:

Prof. Dr.

Instituição:

Prof. Dr.

Instituição:

Prof. Dr.

Instituição:

Prof. Dr.

Instituição:

Prof. Dr.

Instituição: 
Dedica esse trabalha a dais paralelos que sempre inspiram a meu melhar:

Profissiona/mente, aus pacientes - especialmente as que participaram deste trabalho - por darem sentido a tantas escalhas, desde a saúde mental, a pesquisa e a crença na possibilidade de intervençães dentro do cantexta de saúde pública para pessaas cam problemas devida abusa de álcaol. Pelas partilhas, escutas, conversas e mumentas que possive/mente nem cunseguiria culacar em palavras nessa tese, só possa agradecer e dedicar esse trabalha.

Pessaalmente, aus meus sabrinhos (Jaãa, Davi, Cecilia e Maria) que pela pureza e amor que sãa únicas e contribuem indiretamente, sempre, com tuda que sai de melhar de mim... 
Gastaria de agradecer aqui às muitas pessaas inspiradoras e solícitas que, de certa forma, ajudaram-me a finalizar essa tese ou foram especiais durante essa jornada.

Primeira, se é que possa fazê-la, agradecer à Deus, que me deu a impulsa da início e a farça para continuar a jornada.

À minha família, muito presente nos meus anseios, planos e canquistas, não tendo sida diferente nessa empreitada. Obrigada por entenderem a distância, por sonharem tanto os meus sonhos, apoiarem minhas escolhas e serem sempre meus pilares, referências de amor e carinho e, ainda, conseguirem colorir minha vida de farma tão especial. Amo VQCês!

À minha orientadara, Professara Dra. Margarita, por ter creditada a mim a responsabilidade da tese, partilhado este e outras trabalhos, estimulado aspiraçães, pelos anos de parceria, dado conselhos e ser exemplo de dedicaçãa a trabalho. Muchas gracias!

Aos todas amigos que encontrei (TANTQS!) no períado, tanto na USP quanto fora dela. Muitíssimo abrigada por alegrarem os períndos off da tese, torceram e também ouviram muitos questionamentos meus sobre essa pesquisa.

Ao Professar Jürgen Rehm por ter me recebida no CAMH - Center af Addiction and Mental Health - em Toronto e pelos ensinamentos de pesquisa! Thank you so much!

À equipe do Principles and Practice af Clinical Research da Harvard T.H. Chan School of Public Health, especialmente an site RAQ, pelos dais anos de traca de conhecimentas sabre estudas clínicas e amadurecimento de muitas conhecimentos. Thank everyane!

À equipe PAHO/WHO pela passibilidade de pensar e entender outros saberes e espaços de trabalho e pelas tracas permitidas. Gracias! Thanks! Dbrigada!

À Camila Alvares, por acompanhar todas as visitas damiciliares - as MUITAS! - e, ainda, ter se tornada uma amiga querida.

Aus colegas da Lab148, especialmente à Gilda e Suely - pela tantas ajudas e conversas.

Aus funcionários da EERP pelo suporte durante toda pós-graduação.

À Fundaçãa de Amparo à Pesquisa do Estada de São Paula (FAPESP) pelo apaio financeira, permitir dedicaçãa exclusiva e financiar algumas empreitadas que vieram junto cam essa tese. 
"It's not a silly question if you can't answer it." Jastein Gaarder, Saphie's Warld 
Este estudo foi financiado pela Fundação de Amparo à pesquisa do Estado de São Paulo (FAPESP), processo número 2013/16080-3 e recebeu ainda financiamento para período sanduíche, processo número 2015/223490 . 


\section{RESUMO}

BARBOSA, S. P. Intervenção com familiares, usuários de álcool e álcool mais outras drogas: um estudo clínico. 119 páginas. Tese (Doutorado). Escola de Enfermagem de Ribeirão Preto, Universidade de São Paulo, São Paulo, 2017.

A Atenção Primária à Saúde (APS) pode ser uma possibilidade de acesso a usuários de álcool em uso de risco ou dependência, sendo a Intervenção Breve (IB) uma possiblidade de intervenção. Este estudo clínico randomizado por cluster objetiva verificar a efetividade da IB quando comparado ao grupo controle. Os participantes do estudo (Grupo Intervenção - GI e Grupo Controle - GC) foram contatados por visita domiciliar após indicação dos serviços de Estratégia de Saúde da Família (ESF) da região Oeste de Saúde de Ribeirão Preto - SP. Os usuários inclusos foram usuários maiores de 18 anos e com escore de consumo $\geq 7$, segundo AUDIT. Os instrumentos utilizados foram AUDIT (Alcohol Use Disorders Identification Test), ASSIST (Alcohol, Smoking and Substance Involvement Screening Test), perfil sociodemográfico e Diário de consumo de álcool. Após as intervenções foram realizados follow-up de um mês e seis meses após término da última intervenção. As medidas quantitativas de desfecho foram a pontuação no instrumento AUDIT, na qual se utilizou as alterações na pontuação do instrumento como balizador para verificar a efetividade das intervenções. No grupo intervenção realizou-se ainda uma entrevista semiestruturada. A análise estatística foi feita com uso Regressão Linear Multinível para a amostra do estudo (23 participantes) e o mesmo com a amostra simulada de 30, 50 e 100 participantes hipotéticos. Os 23 participantes (12 do GI e 11 do GC) tinham média de idade em 48.2 anos, sendo 16 participantes homens (nove no GI e sete no GC). Sobre os anos de estudo, a média foi de 7.8 anos (GI a média foi de 9.5 e no GC 6.3 anos). No total, foram realizadas 323 visitas domiciliares. Referente consumo, a bebida mais escolhida foi cerveja e 15 dos 23 participantes não sabiam expressar como se sentiam antes da ingestão de bebida alcoólica. No que diz respeito ao uso de outras drogas na vida, dez participantes da amostra usavam apenas álcool (quatro do GI e seis do GC). Sete participantes usavam álcool e tabaco (quatro GI e três GC). Cinco participantes eram usuários de múltiplas drogas (3 GI e 2 GC). Entre as múltiplas drogas, as mais comuns foram a maconha e a cocaína. Sobre o comportamento de consumo abusivo de álcool episódico o consumo mais abusivo variou de 2,85 a 16, 2 doses. A média dos AUDIT durante o follow up não diferiu muito. A média de AUDIT do GI foi de 15.5 ( $\left.\mathrm{T}_{0}\right)$, $16.25\left(\mathrm{~T}_{1}\right)$ e $11.6\left(\mathrm{~T}_{2}\right)$. Para o GC a média foi de $15.36\left(\mathrm{~T}_{0}\right), 8.1\left(\mathrm{~T}_{1}\right), 16.36\left(\mathrm{~T}_{2}\right)$. Sobre os resultados da efeito multinivel misto, na amostra real deste estudo não houve diferença significativa $(p=0.80)$ entre os grupo intervenção e controle, embora tenha sido observado efeito da intervenção. Sobre os dados prevenientes da simulação com tamanho amostral de 30, 50 e 100 participantes hipotéticos, não teve significância estatística, embora o efeito seja mantido. No que se refere aos resultados qualitativos, processados em três classes pelo software Alceste, foram analisados $74 \%$ do conteúdo textual, com riqueza de palavras de $94.05 \%$, cujo conteúdo resultou em três classes: classe 1, com $33 \%$ da análise e correspondeu ao contexto geral do beber: pessoas e ocasiões que promovem ou desestimulam o beber, e os estímulos foram encontros com os amigos, os sentimentos negativos e às relações sociais; classe 2, 28\% da análise e fez alusão ao indivíduo estar dependente de drogas em geral, situou o consumo de todas as substâncias (incluído o álcool) num contexto prejudicial; classe 3, que predominou com 39\%, referiu-se ao indivíduo nos aspectos frequência, quantidade e abandono do consumo. Dados referentes ao perfil da amostra, bebida de escolha e influência cultural foram corroborados em outros estudos. Apareceu ainda que, o consumo de álcool não está vinculado apenas às preferências pessoais. O estudo revelou ser possível realizar a IB, todavia, 
há necessidade de encontrar as estratégias mais efetivas para contactar os usuários e envolver suas famílias e a equipe local dos serviços de saúde. O conhecimento de aspectos qualitativos mostrou que o consumo ligado ao hábito cotidiano pareceu se relacionar a padrão de consumo mensal alto, por isso, mais danoso. Inferiu-se ainda que nesta amostra esse padrão de consumo pode ser devido à carência de orientações e aconselhamento dos profissionais de saúde sobre o hábito de beber. As vivências sociais foram relacionadas ao consumo, prover espaços e momentos de lazer na comunidade sem o incentivo ao uso de álcool e/ou substâncias psicoativas, poderia auxiliar na diminuição do consumo ou abstinência das mesmas.

Palavras chaves: Intervenção Breve; Estudo clínico; Usuários de álcool; Atenção Primária à Saúde.

Registro do Estudo Clínico no Registro Brasileiro de Estudos Clínicos - REBC: RBR5pw27c 


\begin{abstract}
BARBOSA, S. P. Intervention with relatives, alcohol and alcohol users plus other drugs: a clinical trial. 119 pages. Thesis (Doctorate). Ribeirão Preto College of Nursing, University of São Paulo, São Paulo, 2017.
\end{abstract}

Primary Health Care (PHC) may be a possibility for access to alcohol users who use risk or dependence and Brief Intervention (IB) is a possible intervention. Thus, this clinical trial randomized by cluster aimed to verify the effectiveness of IB when compared to the control group. The participants of the study (Intervention Group - IG - and Control Group - CG) were contacted by a home visit after indicating the Family Health Strategy (ESF) services of the West Region of Health of Ribeirão Preto/São Paulo state. The included users were users older than 18 years and with consumption score $\geq 7$, according to AUDIT score. The instruments used were AUDIT (Alcohol Use Disorders Identification Test), ASSIST (Alcohol, Smoking and Substance Involvement Screening Test), sociodemographic profile and Alcohol consumption diary. After the interventions, follow-up was performed one month and six months after the last intervention. The quantitative measures of outcome were the score in the AUDIT instrument, in which the changes in the instrument score were used as a benchmark to verify the effectiveness of the interventions. In the IG, a semi-structured interview was also carried out. The statistical analysis was done using Multi Level Linear Regression for the study sample (23 participants) and the same with the simulated sample of 30, 50 and 100 hypothetical participants. The 23 participants ( 12 from IG and 11 from CG) had a mean age of 48.2 years, of which 16 were men (nine in IG and seven in CG). Over the years of study, the mean was 7.8 years (mean IG was 9.5 and in CG 6.3 years). In total, 323 home visits were carried out. Regarding consumption, the most chosen beverage was beer and 15 of the 23 participants could not express how felt before drinking alcohol. Concerning the use of other drugs in life, ten participants in the sample used only alcohol (four from IG and six from CG). Seven participants used alcohol and tobacco (four IG and three CG). Five participants were users of multiple drugs (3 IG and 2 CG). Among the multiple drugs, the most common were marijuana and cocaine. On the behavior of abusive consumption episodic, the most abusive consumption ranged from 2.85 to 16.2 doses. The average AUDIT during the follow up did not differ much. The mean AUDI of the IG was $15.5\left(\mathrm{~T}_{0}\right), 16.25\left(\mathrm{~T}_{1}\right)$ and $11.6\left(\mathrm{~T}_{2}\right)$. For CG, the mean was 15.36 $\left(\mathrm{T}_{0}\right), 8.1\left(\mathrm{~T}_{1}\right), 16.36\left(\mathrm{~T}_{2}\right)$. Concerning the results of the mixed multilevel effect, in the actual sample of this study there was no significant difference $(p=0.80)$ between the intervention and control groups, although the intervention effect was observed. Regarding the data of the simulation with sample size of 30,50 and 100 hypothetical participants, it was not statistically significant also, although the effect was maintained. Regarding the qualitative results, processed in three classes by the software Alceste, $74 \%$ of the textual content was analyzed, with a wealth of words of $94.05 \%$. Regarding Class 1, 33\% of the analysis corresponds to the general context of drinking, people and occasions that promote or discourage drinking, where the incentive can be encounters with friends, negative feelings and social relations. Class 2 accounted for $28 \%$ of the analysis and refers to the individual being dependent of drugs in general, not just alcohol, placing the consumption of all substances in the same context. As for Class 3, higher class with $39 \%$, refers to the individual regarding the frequency, quantity and abandonment of consumption. The knowledge of qualitative aspects showed us that the consumption linked to the daily habits seems to be related to patterns of high consumption monthly doses and, therefore, more harmful, even if in this sample it was observed that the consumption is high also possibly due to lack of guidance and conversations with professional about the habit of drinking. As the social experiences were related to the consumption high 
doses of alcohol, perhaps provide spaces and moments of leisure free alcohol could help in the diminution or abstinence to the alcohol.

Key words: Brief Intervention; Clinical trial; Alcohol users; Primary Health Care. 


\section{RESUMEN}

BARBOSA, S. P. Intervención con la familia, los consumidores de alcohol y alcohol, más otras drogas: un ensayo clínico. 119 páginas. Tesis (Doctorado). Escuela de Enfermería de Ribeirão Preto de la Universidad de São Paulo, Sao Paulo, 2017.

A Atención Primaría a la Salud (APS) puede ser una opción de acceso a usuarios de alcohol en uso de riesgo o dependencia, siendo a Intervención Breve (IB) una posibilidad de intervención. Así, este estudio clínico randomizado por cluster objetiva verificar una efectividad de la IB cuando comparado con el grupo de control. Los participantes del estudio (Grupo Intervención GI - e Grupo Controle - GC) fueron contactados por visita domiciliaria después de la indicación de los servicios de Estrategía de Salud de la Familia (ESF) de la Región Oeste de Salud de Ribeirão Preto - São Paulo. Los usuarios incluidos en los mayores de 18 años y en el consumo de $\geq 7$ AUDIT. Los instrumentos utilizados fueron AUDIT (Test de identificación de trastornos por consumo de alcohol), ASSIST (Prueba de detección de alcohol, tabaco y toxicomanía), perfil sociodemográfico y el consumo diario de alcohol. Tras las intervenciones se realizó un seguimiento de un mes y seis meses en el término de la última intervención. En cuanto a las medidas cuantitativas de desfecho, se ha puesto el instrumento como instrumento de comprobación de la eficacia de las intervenciones. El análisis estadístico se realizó a través de múltiples niveles de regresión lineal para la muestra del estudio (23 participantes) y lo mismo con la muestra simulada de 30, 50 y 100 participantes hipotéticos. Os 23 participantes (12 do GI y 11 do GC) tienen media edad en 48,2 años, siendo 16 participantes hombres (no hay GI y siete no GC). Sobre los años de estudio, una media de 7,8 años (GI a media fue de 9,5 y no GC 6.3 anos). En total, había 323 visitas a domicilio. Sobre el consumo de alcohol, la bebida más consumida fue cerveza y 15 de 23 participantes no sabían expresar como se sienten antes de ingestión de bebida. No obstante, los participantes de la muestra usaban apenas alcohol. Siete participantes usaban alcohol y tabaco (cuatro GI y tres GC). Cinco participantes fueron usuarios de otras drogas (3 GI y 2 GC). Entre las otras drogas, como más comunes eran una marijuana y una cocaína. Sobre el comportamiento de consumo episodio de alcohol, el consumo más abusivo varió de 2,85 a 16, 2 dosis. El promedio AUDIT durante el seguimiento no cambiado mucho. El promedio AUDIT de GI fue de 15,5 $\left(\mathrm{T}_{0}\right), 16,25\left(\mathrm{~T}_{1}\right)$ y 11,6 $\left(\mathrm{T}_{2}\right)$. En el GC el promedio fue de $15.36\left(\mathrm{~T}_{0}\right), 8.1\left(\mathrm{~T}_{1}\right), 16.36\left(\mathrm{~T}_{2}\right)$. Entre los grupos de intervención y control, se ha observado el efecto de la intervención $(\mathrm{p}=0.80)$. Sobre los datos preventivos de la simulación con el tamaño de 30, 50 y 100 participantes hipotéticos, no tenía significancia estadística. En los resultados cualitativos, fueran procesados en tres clases por software Alceste. Referente a la Clase 1,33\% de los análisis realizados en el contexto general del consumo de bebidas alcohólicas, como las personas y las ocasiones en que se promociona o desestima el consumo de bebidas alcohólicas. En la clase 2, 28\% de la evaluación y la evaluación de todo el individuo dependiente de las drogas en general, no solo alcohol, situando o consumo de todas las sustancias como num contexto. La Clase 3, la mayor parte de Clase 39\%, se refiere a la persona en la frecuencia, la cantidad y el abandono del consumo. El conocimiento de los aspectos cualitativos ha demostrado que el consumo de al hábito diario parece estar relacionado con los patrones de consumo de dosis mensuales de alta y por lo tanto más perjudicial, pero todavía esta muestra se ha observado que el consumo es alto también, posiblemente, debido a la escasez directrices y conversaciones con profesionales sobre el hábito de beber. Las experiencias sociales estaban relacionados con el abuso de alcohol, así proporcionar espacios y tiempo libre podría ayudar a disminuir o la abstinencia de alcohol. 
Palabras clave: Intervención Breve; Ensayo clínico; Consumidores de alcohol; Atención Primaria de salud. 


\section{LISTA DE FIGURAS}

Figura 1 Mapa de consumo de álcool no mundo

Figura 2 Localização geográfica dos serviços de Núcleos de Saúde da Família

Figura 3 Diagrama de randomização do estudo

Figura 4 Fluxograma de participantes do estudo

Figura 5 Fluxograma das etapas de coletas dos dados

Figura 6 Modelo de medidas principais do estudo

Figura 7 Fluxograma das etapas do programa de intervenção breve

Figura 8. Classificação hierárquica descendente (dendograma) do corpus analisado. 


\section{LISTA DE TABELAS}

Tabela 1. Características gerais da amostra.

Tabela 2. Escores mínimo e máximo do AUDIT por grupo.

Tabela 3. Efeito com amostra simulada de participantes.

Tabela 4. Efeito com amostra simulada de participantes. 


\section{LISTA DE SIGLAS}

APS

ASSIST

AUDIT

CEP

GC

GI

IB

OMS

TCC

VD
Atenção Primária à Saúde

Alcohol, Smoking and Substance Involvement Screening Test

Alcohol Use Disorders Identification Test

Comitê de Ética em Pesquisa

Grupo Controle

Grupo Intervenção

Intervenção breve

Organização Mundial da Saúde

Terapia Cognitivo Comportamental

Visita domiciliar 


\section{SUMÁRIO}

INTRODUÇÃO..................................................................................................................................................... 19

OBJETIVOS.............................................................................................................................................. 27

REFERENCIAL TEÓRICO.....................................................................................................29

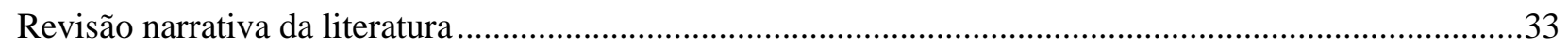

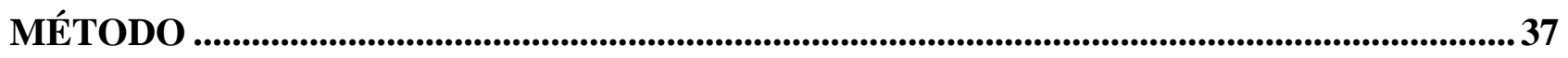

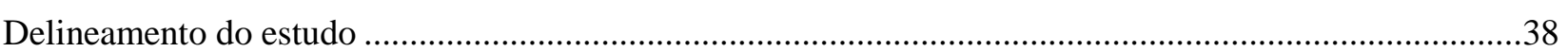

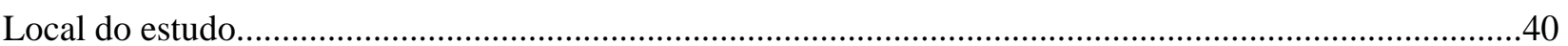

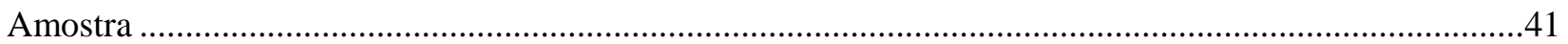

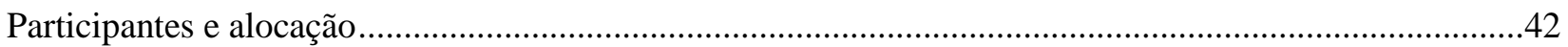

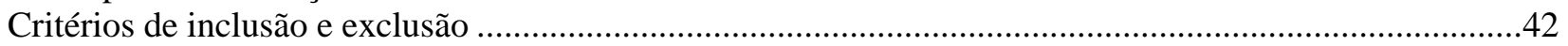

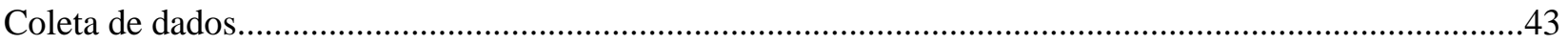

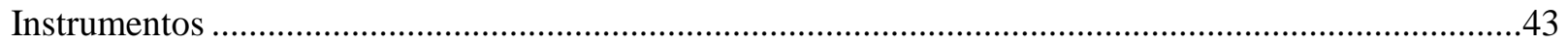

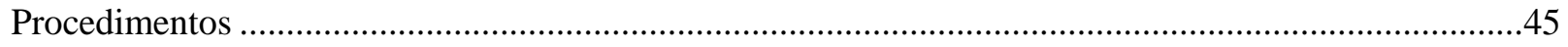

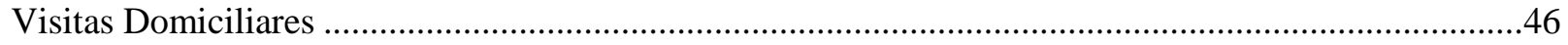

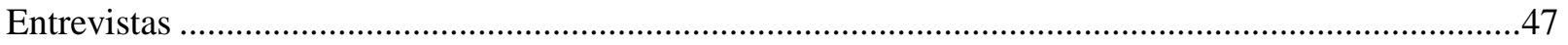

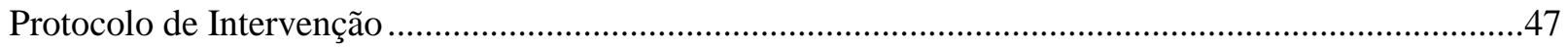

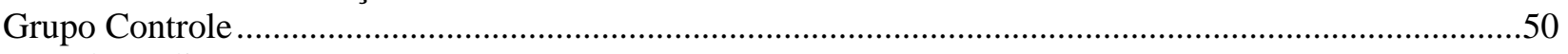

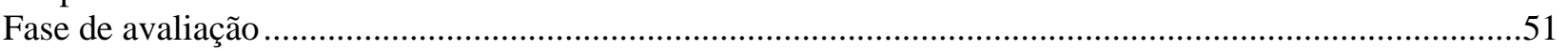

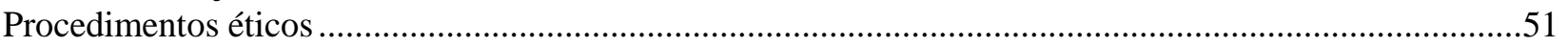

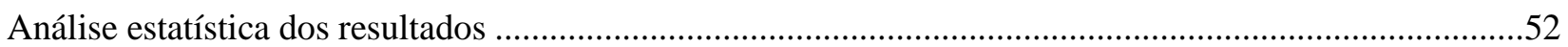

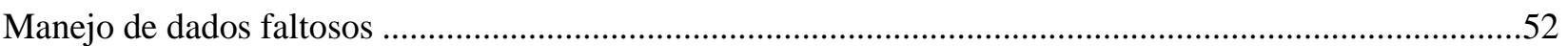

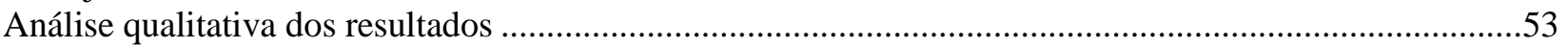

RESULTADOS ..................................................................................................................................................5

DISCUSSÃO................................................................................................................................. 73

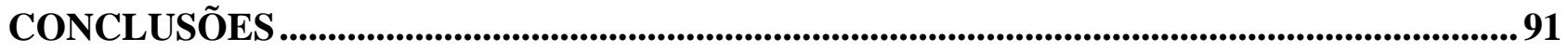

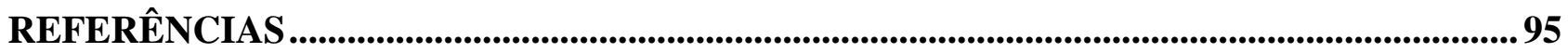

Anexos

Apêndice 


\section{Introdução}

O álcool afeta uma série de neurotransmissores cerebrais, tais como o sistema glutamatérgicos, opiáceis, gabaérgicos, dopaminérgicos e serotaninérgicos (CHASTAIN, 2010). A ativação desses sistemas provoca a tolerância e, quando em ingestão contínua, a dependência. Esses efeitos tão diversos no cérebro findam por provocar um quadro de dependência dos mais difíceis de serem tratados dentre as drogas psicoativas e desafiam os profissionais a optarem por intervenções e tratamentos que sejam, cada vez mais, de comprovada efetividade na diminuição ou na cessação do uso de álcool.

Nutt, King e Phillips (2010) apontaram o uso de álcool como um dos maiores causadores de danos, tendo-se ciência que existe uma grande variedade destes, que podem ser desde danos econômicos - o que torna os estudos sobre uso de álcool de grande interesse econômico - social e de saúde. Segundo os mesmos autores, num ranking de uso de drogas no Reino Unido, o álcool foi a droga com maior dano (para o usuário e para os outros), seguida da heroína e cocaína. Além disso, Smyth et al., (2015) concluíram após um estudo de coorte com 11.4970 participantes com idade entre 35 a 70 que o beber pesado episódico ${ }^{1}$ foi associado com aumento do risco de mortalidade e lesões.

A despeito dessas informações, o álcool é a substância psicoativa mais consumida e com maior aceitação de danos por riscos voluntários pela sociedade, como pontua Rehm, Lachenmeier e Room (2014). Além disso, os mesmos autores ratificam a contribuição do uso de álcool para aumentos de mortes involuntárias, como os acidentes de trânsito, por exemplo, não justifica tamanha aceitação social que o consumo abusivo de álcool tem.

Ante o exposto, alguns estudos têm sido executados no intuito de provar a associação do uso ou abuso de álcool, desde com direção perigosa de carros (REYNAUD et al., 2002), problemas de pressão arterial (GUAL et al., 2015), cânceres (CONNOR, 2016) e aumento do risco de suicídio (POMPILI et al., 2010), visto que tentativas de suicídios são maiores em usuários de álcool que na população em geral.

Assim, dada a heterogeneidade dos efeitos do uso (físico, psíquico e socais), sabe-se que o uso danoso é pulverizado nas diversas faixas etárias e, talvez por isso, não é difícil encontrar pessoas

\footnotetext{
${ }^{1}$ Beber episódio pesado ou binge drinking é um termo usado para definir o consumo de cinco ou mais doses para homens e 4 ou mais doses para mulheres em uma única ocasião (WECHSLER et al., 1995).
} 
que sofrem devido ao uso abusivo de álcool nos diversos serviços de saúde (unidades de emergências, hospitais e serviços de atenção primária à saúde) (REHM et al., 2010). Contudo, tais sujeitos nem sempre têm a devida atenção por parte dos profissionais no que se refere ao consumo de álcool e a prevalência do uso é ainda considerada alta o mundo, conforme se pode ver no mapa abaixo (Figura 1).

Cabe ainda pontuar que o aspecto crônico da dependência de drogas, nelas incluindo a dependência de álcool, remete a presença constante dos usuários de álcool nos serviços de saúde e o caráter inconstante nos seguimentos de intervenção ou tratamento para os usuários (McLELLAN et al., 2000).

Para Babor et al. (2010), a maioria das pessoas com problemas gerais que frequentam os serviços de saúde, são dependentes de álcool ou usuários num padrão nocivo, o que torna a abordagem sobre o consumo uma das questões de saúde pública mais prementes. A Organização Mundial da Saúde (OMS) aponta em relatório recente o álcool como fator causal de mais de 200 doenças e injúrias à saúde no mundo, existindo ainda relação considerável entre consumo de álcool e doenças infecciosas como tuberculose e HIV (WHO, 2014) o que associa o consumo abusivo ainda como uma importante variável no agravamento de doenças.

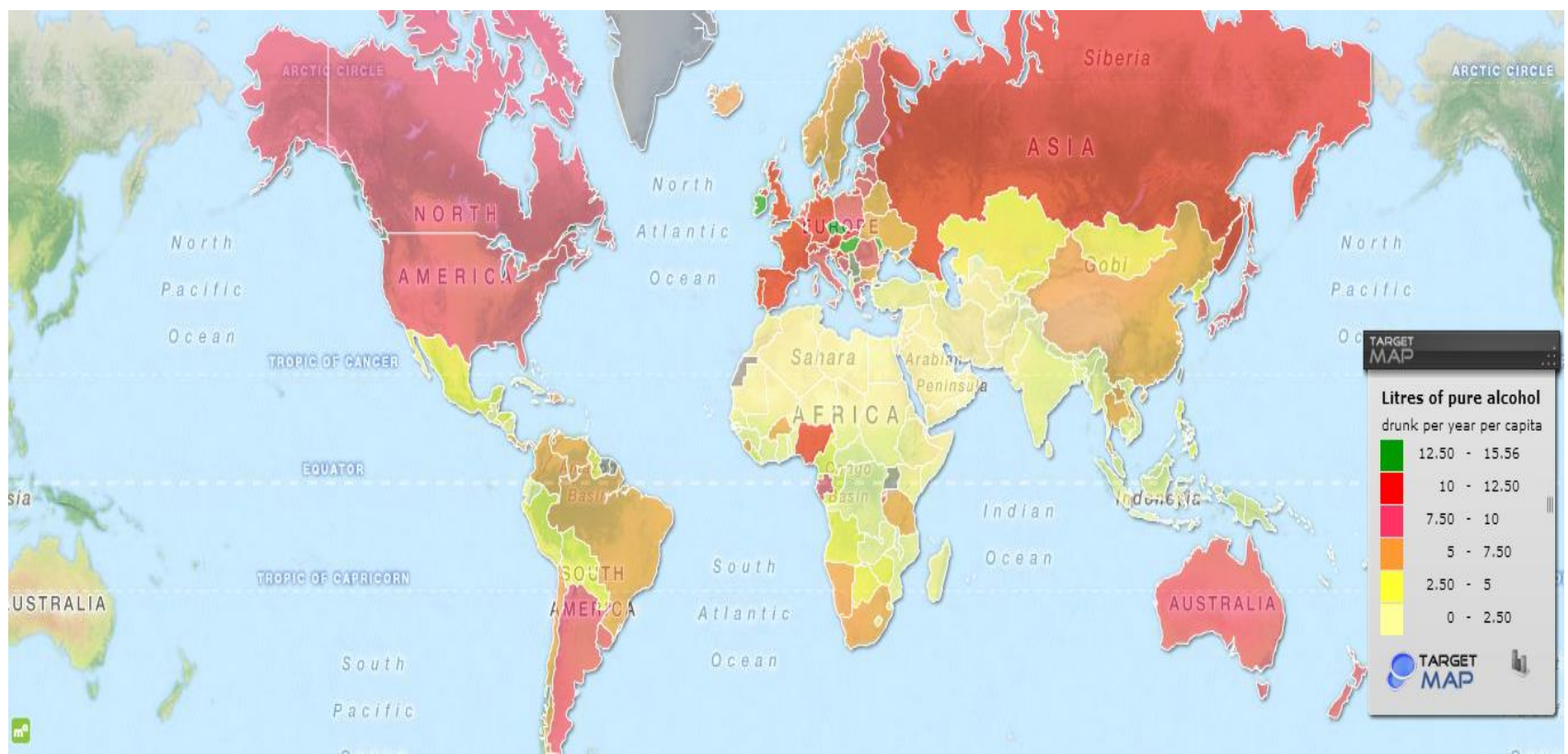

Figura 1: Mapa de consumo de álcool no mundo. Fonte: TargetMap®. Acesso Mar, 2016.

No contexto de Atenção Primária em Saúde (APS) danos ocorridos pelo uso abusivo de álcool são considerados altos e presentes num faixa populacional bem diversa, isso sendo ratificado 
por estudos com diversidades amostrais de participantes. Aponta-se ainda a associação do uso com outras doenças de grande demanda dos serviços de atenção primária, tais como a hipertensão, a insônia, os problemas de fígado, a depressão e transtornos de ansiedade (REHM et al., 2015).

Além disso, muitos pacientes com consumo problemático de drogas não têm acesso ao tratamento e prover opções que consistem em modelos de atenção integrada é totalmente condizente com a política de atenção primária (CHAN et al., 2013).

Porém, mesmo ante o impacto do uso e/ou dependência de álcool no mundo, é notório as lacunas em estratégias de atenção, intervenção ou tratamento ao uso e abuso de álcool, embora desde o ano de 2008, os países membros da OMS tenham feito melhorias nas áreas de ações recomendadas pela estratégia global para redução do uso nocivo de álcool, tais como implementação de políticas nacionais escritas com intuito de redução da prevalência do consumo, limitação da disponibilidade de álcool e implementação de restrições (WHO, 2014).

Porém, ainda que as políticas tenham resultado em avanços, tais como o desenvolvimento de instrumentos de rastreamento, grande parte dos usuários de álcool atendidos na APS continuam não sendo questionados quanto ao consumo de álcool e ainda existe uma carência na implementação dessas políticas e diversas limitações (FONTANELLA et al., 2011; KANER et al., 2013).

No que se refere à epidemiologia do uso de álcool na América Latina, sabe-se que devido às condições de saúde serem precárias quando comparadas com países da Europa e América do Norte, por exemplo, o próprio controle do uso e os estudos são ainda em número não satisfatório. Um dos estudos mais recentemente publicados sobre o contexto do uso de álcool na América Latina, revelou que, em países como Equador, El Salvador e Guatemala, o consumo desta droga foi o primeiro responsável por cerca de 67 fatores de risco em todas faixas etárias (LIM et al., 2012).

Estudos internacionais têm demonstrado que 20-30\% dos pacientes da APS são bebedores danosos (KANER et al., 2013). O beber de risco é um padrão de consumo de álcool que aumenta a vulnerabilidade do organismo para problemas físicos e psicológicos, enquanto que no padrão de consumo nocivo esses problemas já estão presentes.

Uma revisão sistemática da Cochrane de 29 estudos clínicos que utilizaram Intervenção breve e foram realizados no contexto da APS mostrou que houve uma redução no consumo de álcool de 38 gramas por semana quando comparado com procedimentos de avaliação somente clínica, tratamento padrão ou ofertas de folhetos informativos no mesmo contexto primária de atendimento (KANER et al. 2007).

A diminuição no número de doses traz benefícios para a saúde propriamente dita dos usuários além de diminuir os gastos em geral e inclusive com os problemas de saúde decorrentes do 
uso, pois é sabido que pessoas com ingestão de altas doses de álcool (mais de cinco doses para homens e quatro doses para mulheres) tem mais custos para saúde quanto comparados com pessoas abstinentes (ALDRIDGE et al., 2016).

Ainda com relação aos custos para intervenção ou tratamento, o estudo de Barbosa et al. (2016) mostrou os custos do rastreamento, intervenção breve e encaminhamento de usuários de álcool de acordo com o serviço apropriado. Na avaliação dos autores, a intervenção breve teve um custo estimado de 7,81 doláres por unidade ou em $\$ 400$ por ano, em caso de locais em que os usuários não permaneciam internados. Assim, as intervenções precoces são apontadas como as menos onerosas para atender as demandas dos usuários de álcool.

Para diminuição dos custos com tratamento, uma das alternativas seria a detecção precoce de usuários de álcool, cujo objetivo é identificar pessoas que estão em uso de risco de álcool. Tal identificação permite planejar ações antes que os problemas decorrentes do uso de álcool já tenham se instalado, além de propiciar a possibilidade de oferecimento de tratamento e cuidados devido uso de álcool (STROBBE, 2014; WHO, 2014).

Sobre a epidemiologia de uso abusivo de álcool no Brasil, que ratifica a necessidade de intervenções, um estudo com 755 usuários de serviço de atenção primária de uma cidade do interior de São Paulo mostrou que $22 \%$ faziam uso problemático de álcool, ao passo que $10 \%$ destes pontuaram no AUDIT com escore que sugeria dependência (VARGAS; BITTENCOURT; BARROSO, 2014). Em levantamento nacional sobre consumo de álcool realizado em 149 municípios, se percebeu que houve um aumento em cerca de $20 \%$ de bebedores frequentes (LARANJEIRA et al., 2013).

Conforme estudos (GONÇALVES et al., 2011; RONZANI; MOTA; SOUZA, 2009; BARROS; PILLON, 2006) e seguindo recomendações da OMS (2002), a APS pode ser um meio importante de acesso a usuários de álcool, sendo esse nível de atenção adequado para o trabalho de prevenção secundária de uso problemático de álcool e outras drogas.

Esse aspecto certamente pesa quando se pensa em estratégias de intervenção no consumo abusivo do álcool. Contudo, muito embora existam estratégias possíveis, cabe fazer a ressalva quanto à formação prática dos profissionais para o atendimento efetivo, pois estudos em populações mais distantes dos grandes centros formadores mostraram que existe a capacidade profissional para identificar pessoas com problemas de uso e abuso de álcool, porém o conhecimento sobre as ações frente a essa demanda é insuficiente (MORETTI-PIRES; CORRADI-WEBSTER; FURTADO, 2011).

Com base em estudos internacionais (FOULDS et al., 2012, NEMETH et al., 2013) e 
nacionais (TAUFICK et al., 2014; VARGAS; BITTENCOURT; BARROSO, 2014), pode-se afirmar que há pouco reconhecimento pelos profissionais e as orientações dadas aos usuários de álcool são ainda muito incipientes. No Brasil, num Município do Sudoeste do país (UberlândiaMinas Gerais), foi observado que as abordagens médicas realizadas eram raras e superficiais, sem uso de qualquer instrumento de rastreamento, o que pode acarretar em baixo reconhecimento do consumo abusivo ou mesmo de dependência (TAUFICK et al., 2014).

Para a mensuração efetiva dos problemas relacionados ao uso de álcool, profissionais, como médicos, enfermeiras, assistentes sociais ou agentes comunitários de saúde da APS necessitam dominar as estratégias de rastreamento para que possam identificá-los e, prever intervenções para as pessoas com padrão de uso de risco ou evidenciar a presença de danos à saúde (RONZANI et al, 2005).

A triagem de indivíduos em risco no momento em que estes procuram o serviço de saúde (DAVOUDI; RAWSON, 2010) pode ser uma boa estratégia. Cabe destacar, que a procura aos serviços de saúde, por vezes, não está relacionada às queixas referentes ao uso de substâncias psicoativas, tal como constado em estudo conduzido em unidades de emergências, onde dos 463 participantes, $48 \%$ apresentaram níveis de consumo de risco ou nocivo e, ainda assim, as principais queixas e sintomas na procura atendimento de emergência foram "dor de cabeça", "dores em geral" e "mal-estar", ou seja, condições não diretamente relacionadas ao consumo de álcool (LUIS et al., 2014)

Talvez por isso, os médicos tendam a identificar casos mais severos de dependência de álcool na presença de uma comorbidade clínica, principalmente hipertensão e disfunções no fígado (REHM, 2016), o que não é um dado muito animador, uma vez que prevenir esses problemas e promover a saúde dos usuários seria o mais adequado.

Assim, na atenção primária é razoável que a pessoa não busque ajuda especializada, visto que muitas vezes não associa seus sintomas ao consumo de substâncias psicoativas. Esperar que o usuário de substâncias, no caso do álcool, venha ao serviço de saúde quando se conscientizar que esse uso é um problema, pode gerar um intervalo de tempo considerável que pode conduzi-lo a dependência, surgimento ou agravamento de queixas relacionadas ao seu consumo, gerando a necessidade de intervenções mais longas e caras, propósito contrário ao da saúde pública (MONTEIRO, 2013).

Ressalta-se ainda, que a maioria dos bebedores problemáticos de álcool não procura tratamento pelo fato de não estarem cientes da necessidade que têm de fazê-lo e da realidade de que o problema ou os problemas decorrentes do uso de álcool não pode ser resolvido por eles mesmos 
(PROBST et al., 2015; SHULER et al., 2015).

Aspectos peculiares da Atenção Primária em Saúde (APS) fazem desse um lócus importante para o cuidado aos usuários de risco de álcool e detecção de usuários problemáticos. A equipe de saúde tem a possibilidade de acompanhamento longitudinal do indivíduo e sua família, agregado ao conhecimento das vulnerabilidades e apoios oferecidos pelo território em que habitam, tais como o acesso do usuário ao álcool, pelo número de bares existentes e os recursos de que dispõe (templos religiosos e espaços de convivência controlados, por exemplo) para fortalecer mudanças de comportamentos e a criação de vínculo. Também na APS é mais frequente a criação de vínculos com os serviços de saúde, dadas as estratégias de atendimento disponíveis nos serviços comunitários (como visitas domiciliares), o que permite a possibilidade de incluir familiares e a rede de apoio de serviços de saúde especializada, quando se fizer necessário.

$\mathrm{O}$ ambiente de atenção primária também foi considerado ideal para dar continuidade ao monitoramento e repetir intervenções (BABOR; HIGGINS-BIDDLE; SAUNDERS, 2001). Tal contexto de assistência já havia sido apontado como uma das melhores ocasiões para desenvolvimento de ações preventivas, pois oferece boa relação custo-efeito, possibilita o atendimento de um número maior de pessoas e dá a oportunidade de intervenção antes que o padrão de uso provoque danos à saúde do usuário.

Frente a esses dados, existe consenso quanto à necessidade de enfatizar que no campo da saúde pública se empreendam pesquisas que possibilitem o desenvolvimento de intervenções efetivas quanto ao uso de drogas psicoativas em geral, e o com o uso e abuso de álcool não é diferente. Na APS é importante implementar abordagens que permitam identificar e intervir em pacientes que apresentem padrões de risco de uso dessas substâncias. Além disso, a possibilidade de uso de drogas deve ser considerada na avaliação preliminar de uma variedade de situações clínicas que podem estar relacionadas ao uso nocivo dessas substâncias, o que minimizaria situações reais presentes no contexto atual de saúde pública (HINGSON; COMPTON, 2014).

Possivelmente, em decorrência da ênfase dada ao tratamento farmacológico nas doenças mentais em geral (inclusive nas adições a substâncias psicoativas) atrelada ao aumento do número de estudos clínicos com fármacos, houve o desestímulo ao uso das intervenções psicoterápicas sob o argumento de serem menos científicas, daí existirem questionamentos quanto ao uso de intervenção breve para a diminuição do uso de álcool, sobretudo para usuários com padrão mais danoso de uso. $\mathrm{O}$ argumento, sobre as psicoterapias não se sustenta, pois constituem intervenções ou formas de tratamento com modificações em nível cerebral semelhantes aos tratamentos biológicos ou farmacológicos, como a reorganização neuronal após sessões de psicoterapia, evidenciado em 
estudo de imagens, comprovando assim a interferência fisiológica tal qual acontece com uso de fármacos (PROSSER; HELFER; LEUCHT, 2016).

Diante do exposto, o presente estudo justifica-se na medida em que ampliará o conhecimento sobre as características dos usuários de álcool no contexto da APS, ampliará a possibilidade de aplicação de instrumentos de triagem para uso de álcool na população comunitária e permitirá identificar o contexto onde se dará a intervenção com fins de verificar a sua efetividade. 


\section{Objetivos}

\section{Geral}

- Verificar a efetividade da Intervenção breve para usuários de álcool em serviços de Atenção Primária à Saúde.

\section{Específico}

- Verificar a efetividade de quatro sessões de Intervenção Breve aplicado em usuário de álcool da Atenção Primária à Saúde (APS) com escore AUDIT (10-itens) $\geq 7$ quando comparado ao grupo controle.

\section{Questão de pesquisa}

Há diminuição no consumo de álcool após quatro sessões de intervenção breve em usuários de álcool em seguimento na atenção primária quando comparamos com usuários que receberem apenas folheto informativo?

\section{Hipótese}

$\mathrm{H}_{0}=$ Não haverá diferenças entre consumo de álcool dos participantes usuários de álcool da Atenção Primária à Saúde do Grupo Intervenção e Grupo Controle após o período de intervenção.

$\mathrm{H}_{1}=$ Usuários de álcool do Grupo Intervenção apresentarão redução maior no consumo de álcool quando comparados com o Grupo Controle. 


\section{Referencial Teórico}

Esta pesquisa tem o alicerce teórico na terapia cognitiva comportamental (TCC) tendo ainda influência da Teoria Centrada na pessoa de Carl Rogers e seu processo terapêutico. A TCC combina técnicas cognitivas e comportamentais que, por meio da pesquisa e da prática clínica, vem demonstrando há anos a efetividade na redução de sintomas e taxas de recorrência em vários transtornos psiquiátricos (KNAPP; BECK, 2008). Beck, o fundador da terapia cognitiva, aplicou os princípios teóricos e terapêuticos da TCC em uma série de transtornos, incluindo o abuso de substâncias (BECK et al., 1993; McHUGH, HEARON; OTTO, 2010). Além disso, julga-se que intervenções baseadas em pressupostos cognitivos comportamentais são efetivas para diferentes níveis de educação e renda (PERSONS, BURNS; PERLOFF, 1988), diversidade semelhante à encontrada na comunidade.

No que diz respeito a relação da TCC com a dependência às drogas, a visão cognitiva comportamental é de que o comportamento de uso, como outro comportamento aprendido, é mediado por pensamentos, emoções e ações e, por isso, passível de intervenção (MARQUES; SILVA, 2000).

De uma forma geral, os fundamentos dessa terapia, centram-se nos dez princípios norteados por Beck: 1) a base terapêutica no contínuo desenvolvimento do paciente e seus problemas cognitivos; 2) a aliança terapêutica segura; 3) a ênfase na colaboração e participação ativa do paciente; 4) a orientação na meta e foco no problema; 5) a ênfase no presente; 6) a educação, pois visa ensinar o paciente a se tornar seu próprio terapeuta e enfatiza a prevenção de recaídas; 7) o tempo de intervenção determinado; 8) as sessões estruturadas; 9) o ensino à identificação, avaliação e a resposta aos pensamentos e crenças disfuncionais; e, 10) o uso de uma variedade de técnicas (BECK, 2008 ).

Dentre as variedades de técnicas preconizadas, pode-se classificá-las em três divisões: 1) terapias de habilidades de enfrentamento; enfatizam o desenvolvimento de habilidades que objetivam fornecer instrumentos para lidar com as situações problemáticas (na qual se encaixa a IB); 2) terapia de solução de problemas; enfatiza estratégias para lidar com as várias dificuldades pessoais; e 3) terapias de reestruturação; dão ênfase a que os problemas emocionais são consequência de pensamentos mal adaptados, assim, a meta é reformular pensamentos para tornálos mais adaptativos (MAHONEY, 1995). 
No que se refere ao referencial da IB, atenta-se para os seis elementos componentes que foram primariamente descritos por Bien, Miller e Tonigan (1993), sendo eles: Devolução (Feedback), Responsabilidade (Responsability), Recomendações (Advice), Inventário (Menu de opções), Empatia (Empathy) e Autoeficácia (Self-efficacy). Esses elementos são descritos usualmente como FRAMES, que incorpora então os conceitos de feedback personalizado, responsabilidade, orientação, menu de opções, empatia e alta eficácia (Self-efficacy). Ainda dentro deste referencial, a abordagem da entrevista motivacional é delineada para cobrir os componentes, baseado no próprio escore da pessoa, dar o feedback utilizando um cartão de respostas; orientar sobre os riscos à saúde associados ao uso; colocar a responsabilidade da mudança no indivíduo; expressar preocupação sobre os escores do indivíduo; questionar sobre os pontos positivos propiciadas pelo uso; questionar sobre os pontos negativos propiciadas pelo uso; resumir a conversa sobre prós e contras do uso; expressar preocupação a respeito das coisas ruins; por fim, oferecer um material informativo para levar consigo (SPEAR et al., 2009; BIEN, MILLER; TONIGAN,1993).

Assim sendo, intervenção individual baseada na TCC para usuários de álcool, deve se concentrar no participante e nos seus desejos com relação ao consumo, seja manter-se em abstinência, seja diminuir o uso. Tal decisão baseia-se nos princípios de manter o sentido, o objetivo, a escolha e a direção do sujeito que deseja o processo de mudança (MILLER; ROLLNICK, 1991).

A IB, utilizada como diretriz para a intervenção com os usuários, tem suas bases também nos princípios da Entrevista Motivacional (EM), provenientes da psicologia social, cognitiva e comportamental e tem como pressuposto que um comportamento pode ser mudado, que a motivação deve ser avaliada e adaptada para ação e que a percepção dos indivíduos diz respeito à sua responsabilidade no processo de mudança de comportamento a ser desenvolvido (MILLER; ROLLNICK, 2001). Além disso, aconselha sobre alternativas de mudança e ajuda a traçar estratégias adequadas para alcançá-las que partem da própria pessoa, não de um terapeuta diretivo, reforçando a capacidade do indivíduo de produzir suas mudanças, o que compõe o elemento da auto eficácia (RASSOOL, 1998). A IB com essa fundamentação, se mostrou efetiva e adequada (KRISTENSON et al, 1983; MILLER; ROLLNICK, 1991).

Este modelo de intervenção vem mostrando que pessoas que receberam essa abordagem apresentaram melhoras nos padrões avaliados na maioria dos estudos quando comparados aos que não receberam nenhum tratamento e, inclusive, seus resultados têm sido iguais a tratamentos psicoterápicos extensos (MILLER; ROLLNICK, 2001). A triagem e a intervenção breve têm se mostrado eficaz tanto em uso de risco quanto em uso abusivo de álcool (BIEN, MILLER; 
TONIGAN,1993; KAHAN, WILSON, BECKER, 1995; WILK et al. 1997), muito embora a efetividade em dependentes não esteja muito clara. Há argumentos sobre a intervenção breve ser efetiva somente em bebedores de risco, da mesma forma, estudos apontam a efetividade tanto no grupo de bebedores de risco como no de dependentes, porém com a recomendação de que os dependentes de álcool também sejam acompanhados por serviço especializado de dependência para que os efeitos sejam mais satisfatórios (MILLER; ROLLNICK, 1991; SEGATTO et al., 2007).

Cabe ressaltar que o número de sessões de IB pode variar de uma a oito, podendo durar de 10 a 20 minutos cada uma (BIEN, MILLER; TONIGAN, 1993), embora não haja consenso na literatura quanto ao número de encontros e ao tempo de duração.

A Intervenção Breve (IB) vem de encontro à recomendação do usuário de álcool ser protagonista no seu tratamento ou processo de intervenção. Esta modalidade de intervenção pode ser realizada por qualquer categoria de profissional da saúde sem que isso comprometa a efetividade da intervenção, desde que os profissionais tenham disponibilidade e sejam treinados.

Ainda com relação a fatores que influenciam as IB, Babor, Higgins-Biddle e Dauser (2005) avaliaram a realização de intervenções em contextos diferentes de atenção à saúde, em um provido por médicos e em outros por serviços com profissionais de nível médio e concluíram que, independente do modelo de provisão, há outras questões que interferem no sucesso da intervenção, tais como: estabilidade organizacional dos serviços, tempo dos trabalhadores disponível para intervenção, liderança e planejamento dos profissionais para intervenção.

No Brasil, De Micheli, Fisberg e Formigoni (2004) verificaram a efetividade do uso de IB em adolescentes na assistência primária a saúde, observando uma redução na prevalência do consumo de álcool e na intensidade de problemas, bem como redução nos comportamentos de risco quando comparado com adolescentes do grupo controle.

Outra questão que influencia o resultado da IB são os estágios motivacionais, inicialmente descritos em 1983 no modelo Transteórico (DiCLEMENTE, SCHLUNDT, GEMMELL, 2004) desenvolvido por Prochaska e DiClemente. Trata-se de modelo que descreve os estágios de mudança de comportamento, nele autores afirmam que os comportamentos são guiados por quatro estágios: pré-contemplação, contemplação e preparação, ação e manutenção, embora eles não sejam estanques nem ocorram necessariamente nessa sequência; o indivíduo pode permanecer um longo tempo num deles e avançar para um estágio mais avançado ou retroceder para um estágio anterior. Este modelo é atualmente um dos mais aplicados para explicar, compreender comportamentos aditivos e trabalhar com intervenções que visem mudança e ajuda os membros da equipe de saúde a identificar o estágio de prontidão para mudança no qual a pessoa se encontra. 
Segundo o modelo, na fase de pré-contemplação não existe por parte do indivíduo a percepção de problemas relacionados a algum comportamento, tais como excesso de peso, falta de atividade física ou comportamento de uso ou abuso de álcool; na fase de contemplação existe a percepção de um comportamento problemático e ele considera a possibilidade de mudá-lo, mas ainda não há um planejamento real para mudança; na ação a mudança é iniciada, por exemplo, reduzir o consumo de álcool e na fase de manutenção o indivíduo procura manter a mudança alcançada na fase anterior (DiCLEMENTE, SCHLUNDT, GEMMELL, 2004).

A compreensão do funcionamento das escolhas dos indivíduos tem relação com significado que atribuem a seus comportamentos como sendo ou não nocivos. O conhecimento disso é relevante quando se pretendem propor intervenções ou tratamentos que visem mudança de comportamentos, dentre eles no padrão de consumo de álcool.

\section{Revisão narrativa da literatura}

Optou-se por realizar a revisão narrativa da literatura sobre estudos clínicos que utilizaram a intervenção breve como técnica de intervenção para redução do consumo de álcool no contexto da Atenção Primária em Saúde (APS).

A bases de dados selecionadas foi a Pubmed. A base de dados Pubmed foi selecionada por ser a maior base de dados na área da saúde, englobar a base de dados Medline e ter tradicionalmente um grande volume de publicação de estudos clínicos. Assim, o esquema de busca pode ser visualizado na figura abaixo.

\section{Pubmed}

Filtros: Estudos clínicos, pesquisa realizadas em humanos, artigo completos e publicados nos últimos cinco anos.

- Descritores brief intervention AND alcohol AND primary care

- 67 artigos: 12 foram incluídos. Os artigos excluídos englobavam: IB realizadas por meios eletrônicos, com população de rua, adolescentes ou mulheres grávidas; IB associadas com comorbidades (hipertensão, diabates e doenças psiquiátricas graves) ou com múltiplas drogas; IB realizadas em salas de emergências; uso da IB para mudança do estilo de vida, revisão sistemática e dois não eram estudos clínicos.

A pergunta utilizada nessa busca foi: Quais são os resultados da intervenção breve em 
estudos clínicos com usuários de álcool adultos realizados nos serviços de atenção primária à saúde publicados nos últimos cinco anos na base de dados Pubmed?

A revisão foi realizada até agosto de 2016 e foi realizada após aplicação de filtros próprios da base de dados e leitura dos resumos, a priori. Os artigos selecionados foram lidos por inteiro a fim de se responder à questão proposta na revisão.

Os benefícios da intervenção breve têm sido exaustivamente assinalados para o uso no contexto da atenção primária. Contudo, ressalta-se que ainda falta similaridade nos protocolos de intervenção, pois não se evidenciam quais questões especificamente foram tratadas durante as sessões de intervenção, o que dificulta as comparações de taxa de sucesso ou fracasso dos estudos. Embora em uso há mais de 25 anos e tenha ocorrido um aumento do número de estudos clínicos publicados no contexto da atenção primária com uso de intervenção breve para usuários de álcool, ainda há lacunas quanto ao conteúdo e aos protocolos das intervenções em si, o que provoca implicações sérias quanto a generalizações quando se trata de interpretação a respeito da eficácia ou efetividade (McCAMBRIDGE; CUNNINGHAM, 2014; McCAMBRIDGE, 2013).

Acresce-se a isso a excessiva validade interna da maioria dos estudos, ou seja, estudos com homogeneidade da amostra e controle das intervenções, sendo muitos estudos focados em homens em idade adulta média e com os demais grupos de bebedores de álcool sub representados, tornando esses estudo longe do padrão de estudos clínicos pragmáticos ${ }^{2}$, mais representativos e capazes de informar a prática clínica no contexto desejado (BOBOR; HIGGINS-BIDDLE; DAUSER; BURLESON; ZARKIN; BRAY, 2006, EDWARDS; ROLLNICK, 1997, KANER et al., 2007).

No estudo de Kaner et al. (2013) com 2991 participantes de serviços de atenção primária foram divididos em três categorias: os grupos "pacientes com folheto informativo", "pacientes que receberam cinco minutos de aconselhamento ${ }^{3}$ breve" e outro de "20 sessões de intervenção breve", não mostraram diferença estatisticamente significante. Inclusive, os autores sugeriram como procedimento a realização do rastreamento, seguido pelo simples feedback e uma informação escrita, como forma mais apropriada para reduzir o consumo de álcool em usuários da atenção primária. O mesmo resultado ocorreu no estudo de Allen et al. (2011) numa amostra de 441 homens participantes após IB e três meses de avaliação.

Quantos aos resultados de Mertens et al. (2015), um cluster randomizado, realizado dentro

\footnotetext{
${ }^{2}$ Estudo clínico pragmático são aqueles que se dedicam, assim como os demais estudos clínicos, a verificar o efeito de uma intervenção. Contudo, em estudos pragmáticos, as intervenções mimetizam o mais próximo possível do que é realizado na prática clínica, o que faz desse tipo de estudo um importante balizador e indicador de práticas clínicas mais efetivas.

3 Aconselhamento ou counseling é aconselhamento comportamental breve ( $<10$ minutos) (MILLER; ROLLNICK, 1991).
} 
de um sistema privado de saúde com semelhanças com a atenção primária pública, os autores destacaram a necessidade de mais de 12 meses para a implementação rastreio, IB e tratamento. Para os mesmos, a triagem realizada por médicos, com intervenção e encaminhamento para outros médicos, é o modelo mais adequado para melhorar a saúde preventiva. Cabe ressaltar que esse estudo traz dados sobre o contexto de atenção privada, que é muito pouco explorado em pesquisas, sobretudo pesquisas relacionadas ao consumo de álcool. Além disso, o baixo custo pode ser um atrativo para a implementação dessas intervenções também no contexto privado (HUMENIUK; DENNINGTON; ALI, 2008) e o fato de terem se mostrado superiores sobre outros tipos de ações ou tratamentos (PURSHOUSE et al., 2013).

Kuerbis et al. (2015), após um estudo piloto, randomizado, para determinar a eficácia inicial de um rastreio enviado e intervenção para pessoas com idades maiores de 50 anos mostrou, após três meses, uma redução maior no grupo experimental.

No estudo de Watson et al. (2013), com seguimento de 12 meses, a IB de no mínimo cinco minutos foram superiores às intervenções escalonadas para reduzir o consumo de álcool oferecidas em 12 meses.

Com base em evidências consistentes da redução de uso de álcool através da IB, Dhital et al. (2013), criaram um protocolo para testar a intervenção quando realizada por farmacêuticos em suas farmácias. Outro protocolo sobre o uso da IB por dentistas foi construído (NTOUVA et al., 2015), e embora esses profissionais tenham bastante contato com pacientes usuários de álcool, pois o uso acarreta problemas dentários, o seu envolvimento na tentativa de diminuir o consumo é muito incipiente.

No protocolo publicado por Kouimtsidis et al. (2015), a população do estudo são pessoas com deficiência intelectual. Assim, a possibilidade de uso das IBs no contexto de saúde primária também com esse grupo parece animador, sobretudo se estamos aplicando esse tipo de intervenção num ambiente comunitário e onde usualmente, não é feita a avaliação cognitiva dos usuários de álcool.

Embora alguns estudos tenham apontado ressalvas no uso da IB, a maioria realmente confirma o sucesso na redução no consumo após essa intervenção. Destaca-se as iniciativas da construção de protocolos de pesquisa do uso de álcool destinados a populações da APS um pouco diversas das usuais, iniciativas essas que apontam os caminhos que profissionais da atenção em saúde vem tomando, dado o uso excessivo nos diversos grupos.

Outro fato a ser ressaltado são as divergências quanto às medidas avaliativas de sucesso nos diversos estudos, tais como medidas de dias de consumo, gramas de álcool consumidas por ocasião 
e números de doses. Essa questão dificulta a realização de comparações e, somado a isso há o fato dos estudos terem sido realizados em locais culturalmente diferentes, com participantes de diferentes níveis educacionais e predominantemente do sexo masculino. 


\section{Método}

\section{Delineamento do estudo}

Trata-se de Estudo Clínico Pragmático ${ }^{4}$, randomizado-controlado, paralelo, aberto, conduzido na comunidade e com o objetivo de atender necessidades da população adstrita a um espaço determinado (Registro REBEC RBR-5pw27c).

No que se refere ao tipo de estudo clínico, Coutinho, Huf e Bloch (2003) ressaltam a diferenças de dois tipos de estudos clínicos, o estudo clínico explanatório e estudo clínico pragmático. Ensaios clínicos pragmáticos descrevem os resultados mimetizando a prática clínica para avaliar a efetividade. Além disso, têm as condições para execução menos rígidas e os objetivos científicos são diretamente voltados para prática clínica nesse contexto comunitário.

Acredita-se que as características locais podem influenciar os efeitos das intervenções e pesquisas dessa natureza possuem a capacidade de alargar as generalizações de seus resultados e detectar diferenças regionais (HULLEY et al., 2001). Neste estudo cabe ressaltar que, devido a peculiaridade do local de recrutamento e disposição dos potenciais participantes, a forma de randomização dos sujeitos se deu por cluster. Essa opção se deve porque as características populacionais dos serviços eram semelhantes e não se conhecia previamente os usuários de álcool dos serviços contatados para participar do estudo. Além disso, esse tipo de randomização evitou o problema potencial de contaminação entre os braços do estudo, já que os participantes foram aleatorizados por serviços e não individualmente (PORTNEY; WATKINS, 2009).

A vantagem científica demonstrada nesses estudos, que se dedicam a aplicar uma intervenção ou tratamento e avaliam seu desfecho, é a capacidade de demonstrar causalidade, ou seja, avaliar até que ponto as mudanças observadas são relacionadas à intervenção executada. Além disso, esses estudos têm comprovado poder no apontamento de quais intervenções são as mais adequadas para os mais diversos problemas em saúde, o que não se mostra diferente na dependência de álcool.

Alguns aspectos devem ser respeitados neste método, tais como a alocação aleatória e cegamento, que é o desconhecimento de qual braço de alocação os participantes se encontram na

\footnotetext{
${ }^{4}$ Cabe ressaltar que durante o processo de registro deste estudo clínico houve divergências quanto à nomenclatura a ser dada ao mesmo. Segundo parecerista da REBEC este estudo deveria ser nomeado como estudo clínico de prevenção - como está no registro. Porém, dado que as intervenções foram realizadas em usuários sabidamente abusadores de álcool entendemos que este é um estudo pragmático, como tentamos realizar junto à REBEC.
} 
pesquisa durante o período de coleta e/ou após essa fase (HULLEY et al., 2001; BUEHLER et al., 2009).

Embora se considere que o cegamento seja um aspecto importante em estudo clínicos, nesse estudo isso foi impossibilitado para os participantes, dada a natureza da intervenção. Contudo, aplicou-se esse procedimento no indivíduo que fez as aplicações do AUDIT no período de avaliação, visto que não lhe foi comunicado em qual braço se encontrava o participante.

O estudo avaliou o desfecho das intervenções nos usuários de álcool que receberam IB e no grupo controle, composto pelos usuários de álcool que receberam apenas a triagem com aplicação dos instrumentos (ASSIST e AUDIT - 10 itens) com a oferta subsequente de um folheto informativo.

Assim, o estudo teve três fases: fase de rastreamento, fase de intervenção/controle e fase pós-intervenção para avaliação com follow up de seis meses, realizado em dois momentos: um mês e seis meses após a primeira intervenção. Tal tempo de avaliação está em conformidade com os estudos de De Micheli, Fisberg e Formigoni (2004), Cunningham et al. (2012).

Como o propósito centrou-se em avaliar a efetividade, julgou-se oportuno definir os termos efetividade, eficácia e eficiência para justificar a opção pelo primeiro termo. Eficácia se refere ao efeito produzido por determinada intervenção, porém sendo a intervenção realizada em condições experimentais ou ideais. A eficiência relaciona-se a mensuração dos resultados e os custos destes, já a efetividade, medida verificada neste estudo, diz respeito ao impacto real de alguma intervenção em condições reais e não ideais (DONABEDIAN; WHEELER; WYSZEWLANSKI, 1982; SILVA; FORMIGLI, 1982).

O cenário do atual estudo foi na comunidade, sendo este o local mais adequado para se fazer intervenções e avaliá-las quanto à efetividade, uma vez que na comunidade não se pode controlar certos fatores, o que torna esse modelo mais próximo do real.

Além disso, o desenho desse estudo sobressai-se aos estudos de eficácia para os objetivos propostos por propiciar reflexão ou resposta para questões de acesso de cuidado ou intervenção (INSTITUTE OF MEDICINE, 2001).

A opção por incluir usuários que fazem uso de álcool mais outras drogas deve-se por julgar que a intervenção poderá reduzir o uso do álcool de usuários da comunidade local, pois conforme evidenciam as referências bibliográficas apresentadas, o consumo de álcool contribui para a origem de muitos problemas de saúde (WORDEN; McCRADY, 2013). A finalidade da pesquisa é contribuir para a implementação das mesmas ações em outros serviços semelhantes. 


\section{Local do estudo}

A pesquisa foi desenvolvida na área adstrita a seis serviços de Atenção Primária que oferecem atendimento às famílias da região Oeste do município de Ribeirão Preto, interior do estado de São Paulo. A região oeste deste município conta com uma população estimada em cerca de 141.000 habitantes e a Área Básica de Atenção à Saúde desta região inclui atualmente seis serviços comunitários com foco na família, denominados Núcleos de Saúde da Família - NSF (Figura 2), denominação específica dada a esse tipo de serviço na Região do estudo, haja vista que em outros serviços do Município em que há atendimento semelhante, este recebe a denominação comum do Ministério da Saúde, Estratégia de Saúde da Família (ESF).

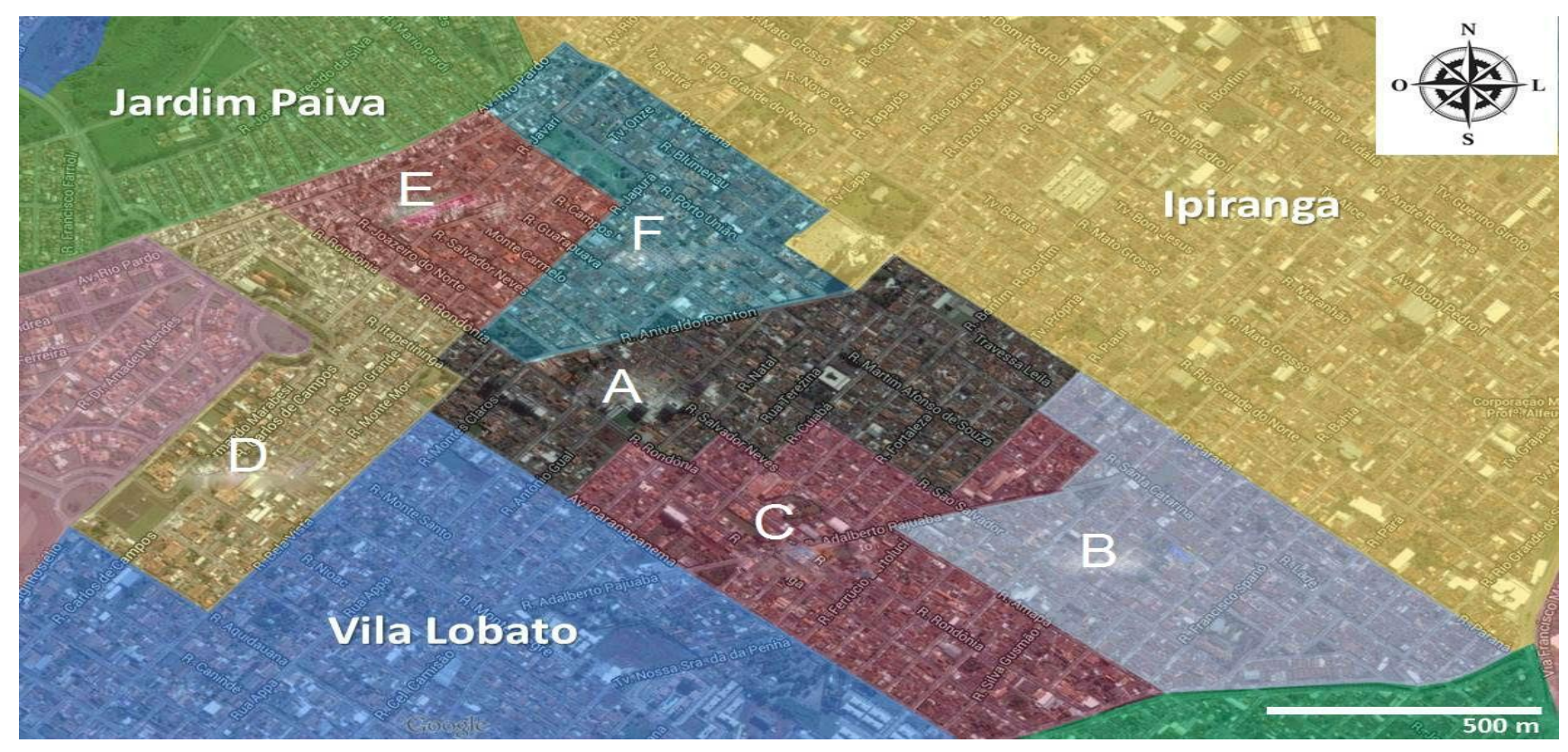

Figura 2. Localização geográfica dos serviços de Núcleos de Saúde da Família da Região Oeste. Fonte: Google maps. Imagem pesquisada e cedida pelo Professor Edson Martinez da Faculdade de Medicina da Universidade de Sao Paulo.

A zona Oeste de Saúde da cidade é ainda caracterizada como uma das mais dependentes do Sistema Único de Saúde (SUS) em decorrência do poder aquisitivo dos moradores com renda per capita de $\mathrm{R} \$ 291$ a $\mathrm{R} \$ 1.019$ (BRASIL, 2013). Cabe destacar que um estudo recente realizado na capital do estado de São Paulo demonstrou que pessoas que vivem em áreas com baixo poder aquisitivo e, por isso, em desvantagem social, têm maiores chances de apresentarem perturbações relacionadas ao uso de álcool (SILVEIRA et al., 2014), por isso as expectativas quanto aos impactos 
das intervenções do atual estudo eram positivas.

Os locais onde se encontram os NSF são majoritariamente formados por residências, com poucos recursos comunitários (escolas, templos e espaços de convivência). Há ainda o destaque para a quantidade de bares - legais ou não - existentes e a presença do tráfico de drogas ilícitas, o que confere a esse território certa periculosidade e uma maior vulnerabilidade social.

Cada NSF possui um número de famílias registradas pertencentes à sua área territorial de abrangência (a qual é dividida em micro áreas), o que facilita o acesso a visitas domiciliares e o acompanhamento da saúde dos usuários destes serviços.

\section{Amostra}

Para o cálculo do tamanho da amostra optou-se por delimitar um valor para o efeito detectável (ou tamanho do efeito) através do uso da classificação de Cohen (1988). Essa classificação estabelece como efeito médio (ou efeito detectável ou ainda tamanho do efeito) de 0.25. Com relação ao nível de significância (alfa) foi utilizado o valor de 0.05 e para o poder do teste (beta) um valor de 0.90. Considerou-se o valor da correlação entre as amostras pertencentes ao mesmo grupo (correlação intra-grupo) que se quer detectar, aqui estabelecido em 0.60 e para prevenir perdas de amostras no decorrer do estudo, foi considerada uma taxa de abandono de $30 \%$ (0.3) e para a taxa de sucesso da Intervenção Breve considerou-se valor já obtido em outro estudo de cerca de 10\% (HEATHER, 2012). O tamanho da amostra proposto neste ensaio clínico inicialmente, incluindo-se grupos de intervenção e controle, seria composto de 10 sujeitos em cada grupo, totalizando 20 participantes distribuídos de acordo com o NSF ao qual estavam vinculados.

Neste estudo, optou-se pela randomização (Figura 3) por serviços ou cluster, assim, os grupos inicialmente planejados para este estudo (intervenção em usuários, em familiares e grupo controle) foram determinados segundo o NSF aos quais os participantes estavam vinculados. O NSF A não foi incluído no estudo devido a opção do mesmo em não colaborar com a indicação de potenciais participantes do estudo.

Ressalta-se que dada a impossibilidade de execução do grupo com familiares, a qual previa-se o uso de intervenção por meio da técnica de Resolução de Problemas, o grupo de familiares foi excluído da pesquisa. 


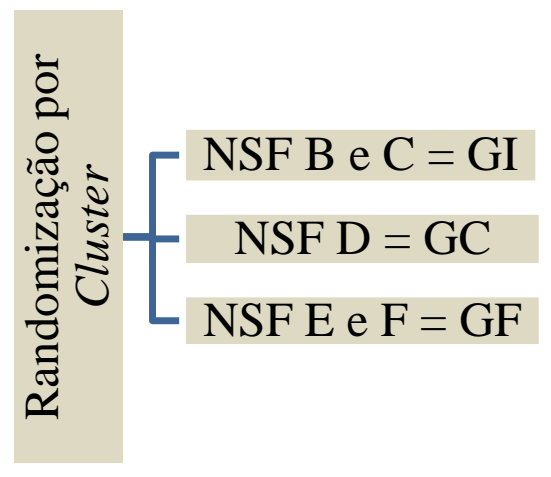

Figura 3 - Diagrama da Randomização do Estudo. Ribeirão Preto. 2015.

\section{Participantes e alocação}

Participantes vinculados ao serviço do Núcleos de Saúde da Família (NSF) B e C foram alocados no grupo de intervenção (GI); participantes vinculados ao NSF D foram alocados no grupo controle (GC). Participantes do NSF E e F inicialmente haviam sido alocados para um grupo de intervenção com familiares (embora não tenham entrado na análise deste estudo). Cabe ratificar que antes da randomização não se tinha conhecimento de quais participantes tinham vínculos com os serviços e que essa opção de randomização foi escolhida devido a semelhança entre os serviços no que se refere ao perfil dos usuários em seguimento, fato que endossa e legitima esse tipo de randomização. Além disso, o não conhecimento do perfil dos participantes antes da alocação segue o princípio de inviolabilidade da randomização, uma vez que os participantes não puderam migrar para outro grupo de estudo.

\section{Critérios de inclusão e exclusão}

Foram participantes elegíveis para este estudo usuários de álcool não internados, com AUDIT (10 itens) com escore $\geq 7$, maiores de 18 anos, moradores dos territórios abrangidos pelos serviços e serem cadastrados nos mesmos. Os critérios de exclusão dos participantes foram: ter internação hospitalar durante o período de coleta de dados, condição visível de intoxicação por uso de drogas ou apresentar-se ativamente psicótico. Não se excluíram usuários de outras drogas (cocaína, tabaco, ou crack, por exemplo), o que poderia ser apontado no instrumento ASSIST, pois a sua inclusão aproximou a amostra dos casos comumente vistos nessa comunidade, onde é relatado com frequência o uso de outras drogas em associação com o álcool. A não exclusão de usuários de outras drogas baseou-se nos argumentos presentes no estudo de Roy-Byrne et al. (2014). 


\section{Coleta de dados}

Neste estudo utilizaram-se procedimentos e técnicas de coleta de dados utilizados nas abordagens quantitativa e qualitativa, as quais são detalhadas no relato a seguir.

\section{Instrumentos}

O ASSIST é um instrumento concebido por pesquisadores de vários países sob a coordenação da OMS para detecção do uso de álcool, tabaco e outras substâncias psicotrópicas e encontra-se traduzido para diversas línguas, inclusive já é validado em estudo no Brasil (HENRIQUE et al, 2004), no qual as propriedades psicométricas mostraram-se satisfatórias (confiabilidade do instrumento foi boa - alfa de Cronbach de 0,80 para álcool, 0,79 para maconha e 0,81 para cocaína), boa sensibilidade (variando de 84 a 91\%), especificidade (variando de 79 a 98\%). Foi um dos instrumentos escolhidos neste estudo, devido à sua boa sensibilidade, ser de rápida aplicação (cerca de 5 a 10 minutos), poder ser utilizado para rastrear o consumo de diversas substâncias psicoativas, ser de fácil interpretação e ser adequado para uso em serviços não especializados. Também foi escolhido no intuito de obter padronização referente às respostas ao uso de drogas; para essas, o instrumento pontua o uso em baixo, moderado e de alto risco (HENRIQUE et al., 2004; SPEAR et al., 2009). Este instrumento foi concebido por pesquisadores de vários países

Sobre o AUDIT (Alcohol Use Disorders Identification Test), este foi desenvolvido para detectar precocemente pessoas com padrões de uso excessivo de álcool. O mesmo foi desenvolvido por um grupo internacional de pesquisadores incentivados pela OMS. Ressalta-se que o AUDIT visa avaliar o padrão de consumo e as consequências do consumo de álcool nos últimos 12 meses por meio de itens sobre o uso de álcool, sobre dependência e sobre problemas decorrentes do uso em uma pontuação que definem zonas de riscos.

Quanto as zonas referentes ao nível de risco do AUDIT, existem quatro: Zona I, onde o escore AUDIT vai de 0-7 e a abordagem adequada seria promoção de educação para o álcool; Zona II, escore de 8-15 e momento ideal para se fazer aconselhamento simples; Zona III, escore vai 1619, onde se recomenda aconselhamento simples, psicoterapia breve e acompanhamento; Zona IV, escore de 20-40 pontos e recomendação de encaminhamento para avaliação diagnóstica e tratamento, há aqui sugestão de dependência de álcool (BABOR; HIGGINS-BIDDLE, 2001). A utilização nesta pesquisa visou averiguar o grau de dependência e os problemas devidos ao uso de álcool em seus usuários. Também houve interesse em aplicá-lo por ser um instrumento com potencial para incentivar a redução do consumo de álcool, uma vez que possibilita a identificação 
precoce do uso nocivo e permite o feedback imediato ao participante quanto ao padrão de uso, no mesmo ato da aplicação.

No que diz respeito à confiabilidade, a maioria dos estudos que utilizaram o AUDIT (10 itens) tem demonstrado alfa de Cronbach maior ou igual a 0,80 (MENESES-GAYA et al., 2009) o que explica seu uso em diversas pesquisas sobre o consumo de álcool com populações diversas (estudantes, usuários de serviços de emergência, na atenção primária e no contexto hospitalar). Além disso, os resultados deste instrumento foram comparados com as alterações dos marcadores biológicos do consumo de álcool, tais como gama-glutamil e apresentou uma especificidade de 97.9\% (DOLMAN; HAWKES, 2005).

O AUDIT é composto por 10 itens com questões sobre quantidade, frequência e problemas relacionados ao consumo de álcool (SHEVLIN; SMITH, 2007). Os resultados podem variar de 0 a 40, sendo sete o ponto de corte para ingestão de risco (MENESES-GAYA et al., 2009).

Sabe-se que já existe uma versão mais curta do AUDIT (10 itens), o AUDIT C, contudo este tem demonstrado ser mais adequado para homens, talvez porque se espelha diretamente nas questões que se relacionam mais ao beber de risco e, mesmo com bom desempenho para triar e identificar padrões de uso de risco, existe certa indicação do uso de diferentes pontos de cortes para homens e mulheres a fim de manter sua sensibilidade e especifidade (DAWSON et al., 2005). Tal fato reforçou a opção de uso pelo AUDIT (10 itens).

No atual estudo foi considerada, para fins de resultados estatísticos, a pontuação obtida pelo participante caracterizando-o como consumidor de álcool no padrão nocivo, independente da zona de risco. Nos dados quantitativos, na análise dos resultados, se considerou a mudança na pontuação do instrumento AUDIT (10 itens), e não a mudança na zona de risco, por ser mais apropriado em pesquisas clínicas a análise de resultados como dados contínuos, já que a análise categórica dos resultados, embora seja de mais fácil compreensão clínica, de certa forma empobrece a pluralidade de respostas (NAGGARA et al., 2011).

Para título de avaliação só foram considerados resultados positivos à intervenção, a diminuição nos padrões de uso de álcool apontados no instrumento AUDIT e eventual manutenção da pontuação por considerar-se que isso pode ser um indicador de certo controle no ato de beber.

AS entrevistas foram do tipo semi-estruturadas, realizadas no último dia de contato com os participantes e só do grupo intervenção. Para May (2004) essa natureza de entrevista pressupõe um "caráter aberto", onde o participante entrevistado dentro de suas concepções, mas não tão livremente, já que o pesquisador atua para que o mesmo não perca o foco da questão. 


\section{Procedimento}

O projeto de pesquisa foi apresentado previamente nos NSF do estudo e apenas um serviço se recusou a participar. Os serviços colaboraram indicando potenciais participantes para o estudo e divulgando entre a equipe de saúde, o que permitiu uma maior devolutiva de informações sobre os usuários de álcool entre os pesquisadores e os serviços. As informações do levantamento da situação de uso e abuso de álcool na área adstrita à zona Oeste foram obtidas por meio do contato com as equipes de Saúde da Família (ESF) dos núcleos, a saber: Agentes Comunitários de Saúde (ACS), médico/a e enfermeiro/a e foram confirmadas por meio de visitas domiciliares.

Após essa etapa, foram realizadas as primeiras visitas domiciliares (VDs). Nessa primeira visita, todas as informações sobre a pesquisa e as intervenções foram repassadas aos potenciais participantes e, em caso de aceite, foi agendado dia, local e horário para assinatura do Termo de Consentimento Livre e Esclarecido (TCLE) e para aplicação dos instrumentos (ASSIST e AUDIT). Aqueles participantes do estudo que tiveram um escore $\geq 7$ no AUDIT (10 itens) foram convidados a participar da pesquisa e inseridos no grupo de IB (se usuário do NSF B e C) e no grupo controle (se usuário do NSF D).

Segundo fluxograma do estudo (Figura 4) os participantes em potenciais (no total 104), foram àqueles indicados pelas equipes e contatados por meio de visita domiciliar, para participar no estudo e na sequência, aplicar os instrumentos de triagem: AUDIT (10 itens) e ASSIST.

Dada a randomização por cluster, dos 104 potenciais participantes, 47 eram do GI, 37 do GC. Cabe destacar, que 20 potenciais participantes foram excluídos devido a não se enquadrarem nos critérios.

Houve perdas de participantes, pois dos 47 participantes do grupo de intervenção, foi possível finalizar a intervenção apenas em 12, sendo que em 35 excluídos (14 não foram mais encontrados, 15 mudaram de área, 5 apresentaram AUDIT $\leq 7$ e 1 recusou participar). No grupo controle foram indicados 37 potenciais participantes e foram excluídos 26 pelos seguintes motivos: 19 por não serem encontrados nas residências, cinco recusaram e dois relataram terem parado de beber.

No que se refere a taxa de referência, a sensivitividade da indicação de problemas de uso de álcool, sobretudo nesse estudo onde nem todos os profissionais utilizavam o AUDIT ou outro instrumento de rastreamento, é corrorado por Mitchell et al. (2012) que verificou que no que se refere ao álcool, os problemas só foram registrados adequadamente em 27,3\%. 


\section{Visitas domiciliares}

Todos os contatos com participantes do estudo foram realizados por meio das visitas domiciliares (VD). Ludman e Curry (2015) reforçaram a VD como uma chave para fornecer aos participantes de um estudo clínico semelhante, o conhecimento, as atitudes e confiança e, assim, facilitar as intervençõe sentre os usuários de substâncias psicoativas.

Para minimizar a composição pequena do número final de participantes, excluídos pelo critério de "não encontrado" foram realizados, pelo menos, três visitas, em dias da semana e em horários diferentes, e também foi usado o contato telefônico, sempre que possível e registrado na pesquisa como tentativa de contato ou convite.

Foram realizadas um total de 323 visitas domiciliares no período de outubro de 2014 a janeiro de 2016. Antes e após cada visita reportava-se o que ia ser feito e os resultados ( se continuava sendo morador no local, horário em que não estava em casa) ao serviço de atenção primária no qual o participante estava vinculado, em atenção aos interesses dos núcleos de saúde da família e, por se julgar adequado dar feedback das visitas realizadas para atualizar os profissionais.

Nesse sentido, foram agendadas reuniões com as equipes dos serviços para retorno de informações coletadas durante as visitas, a exemplo de um idoso usuário de álcool que sofria violência no lar cujo serviço responsável ainda não tinha conhecimento do fato.

Foram realizadas ainda, 99 ligações telefônicas. No entanto, essa estratégia se mostrou ineficaz nessa amostra, pois os participantes, maioria de baixa renda e morando em situação de comunidade, trocavam muito de número telefônico ou não atendiam o celular, sendo esse meio de comunicação não eficiente para a proposta de diminuir as perdas de participantes.

Ainda com relação às visitas, calculou-se a taxa de sucesso baseada no número de visitas que os participantes estavam em domicílio dividido pelo número total de visitas, sendo a taxa de sucesso $63 \%$. Embora a taxa de sucesso tenha sido satisfatória, nem sempre o participante que estava em casa no dia da visita aceitava a aplicação de instrumento ou a intervenção nesse dia.

Dada a periculosidade do território de saúde onde residiam a maioria do parcipantes, todas as visitas foram realizadas pela pesquisadora principal acompanhada de uma aluna da gradução em fase de treinamento em iniciação científica. Ainda que a coleta de dados fosse realizada por visita domiciliar, procurou-se sempre respeitar o participante no sentido de deixá-lo à vontade para recusar ou solicitar que a visita fosse realizada em outro horário, dado que marcar as visitas via telefone, como já relatado, foi quase sempre impossível. 


\section{Entrevistas}

As entrevistas realizadas ao final, no último dia de contato com os participantes do grupo intervenção, foram todas gravadas, com sua autorização e consentimento e, posteriormente, transcritas, juntamente com as sessões de intervenção, excluindo-se as falas da pesquisadora.

As questões, realizadas concomitantes às sessões de intervenção também, visaram identificar o que os participantes pensavam a respeito da intervenção, a existência de acompanhamento aos problemas relativos ao uso de álcool no serviço de APS ao qual estavam vinculados e como estavam inseridas as relações de consumo de álcool na sua vida.

No grupo controle, não houve entrevista por se entender que se realizadas a qualquer tempo do contato com os participantes, poderia configurar-se como uma sugestão ou intenção de modificação do comportamento com relação ao uso de álcool, o que colocaria o grupo controle em situação de "falha.

\section{Protocolo de Intervenção Breve (IB)}

Para a aplicação da Técnica de IB, elaborou-se um protocolo para nortear a intervenção que foi conduzida de forma individualizada na residência do participante.

Foram realizados quatro encontros baseados nos princípios "FRAMES" da IB e tiveram, em média, 30 minutos. A cada encontro foram programadas questões a serem levantadas sendo todas voltadas para o hábito de consumo de bebidas alcoólicas (Apêndice II). Segundo a teoria, de maneira geral, os objetivos foram delimitados pelo próprio participante e sempre foram considerados os pontos fortes e fracos do consumo durante as intervenções. Houve a utilização de dois folhetos ilustrativos sobre os efeitos do uso do álcool no corpo e os recursos disponíveis na rede de saúde local que podiam auxiliar no enfrentamento dos problemas de álcool. Dado o perfil dos clientes da atenção primária em saúde na região (pessoas com baixa renda e escolaridade), os folhetos ilustrativos (Apêndice VIII) pareceram ser adequados para o entendimento das questões de saúde implicadas no consumo abusivo de álcool, embora essa medida tenha sido empírica. Assim, segue a descrição de cada encontro no Quadro 1. 
Quadro 1. Descrição das sessões de Intervenção Breve.

\begin{tabular}{|c|c|c|c|}
\hline Sessão & Objetivos & Tarefas mediadoras da intervenção & $\begin{array}{c}\text { Tarefas para } \\
\text { casa }\end{array}$ \\
\hline 1 & $\begin{array}{l}\text { Conhecer e } \\
\text { discutir a rotina } \\
\text { de consumo de } \\
\text { álcool }\end{array}$ & $\begin{array}{l}\text { Identificação da rotina de consumo através da } \\
\text { discussão do Diário de consumo de álcool; } \\
\text { Identificação e discussão dos sentimentos relatados } \\
\text { antes o consumo (exemplo: tristeza, raiva, } \\
\text { ansiedade...). Caso o participante não consiga } \\
\text { identificar os sentimentos, estimulá-lo a "se } \\
\text { perceber" antes de iniciar o consumo de álcool. }\end{array}$ & $\begin{array}{l}\text { Diário } \\
\text { consumo } \\
\text { álcool }\end{array}$ \\
\hline 2 & $\begin{array}{l}\text { Discutir prós e } \\
\text { contras do } \\
\text { consumo }\end{array}$ & $\begin{array}{l}\text { Leitura do Diário de Consumo de álcool e exploração } \\
\text { dos prós e contras do consumo de álcool, segundo a } \\
\text { percepção do usuário e as situações ligadas ao uso } \\
\text { (festas, encontros com amigos, trabalho). }\end{array}$ & $\begin{array}{l}\text { Diário } \\
\text { consumo } \\
\text { álcool }\end{array}$ \\
\hline 3 & $\begin{array}{l}\text { Discutir e dar } \\
\text { feedback sobre } \\
\text { a capacidade } \\
\text { para mudança }\end{array}$ & $\begin{array}{l}\text { Leitura do Diário de Consumo de álcool e discussão } \\
\text { sobre a capacidade do participante para efetuar } \\
\text { mudanças e questionamento sobre planejamento de } \\
\text { metas para mudança para a próxima semana. }\end{array}$ & $\begin{array}{l}\text { Diário } \\
\text { consumo } \\
\text { álcool }\end{array}$ \\
\hline 4 & $\begin{array}{l}\text { Feedback geral } \\
\text { e discussão de } \\
\text { planos para } \\
\text { mudanças }\end{array}$ & $\begin{array}{l}\text { Leitura do Diário de Consumo de álcool das últimas } \\
\text { semanas e incentivo à reflexão sobre a capacidade de } \\
\text { mudança. Realizado ainda o feedback da } \\
\text { pesquisadora ao participante. Nesse encontro o } \\
\text { feedback e a reflexão quanto à mudança são } \\
\text { realizados no sentido de trazer o problema de beber } \\
\text { no nível de outros problemas e na condição de hábito } \\
\text { de saúde controlável e sai da seara da moralidade. }\end{array}$ & $\begin{array}{l}\text { Diário } \\
\text { consumo } \\
\text { álcool }\end{array}$ \\
\hline
\end{tabular}


Figura 4 - Fluxograma de participantes do estudo.

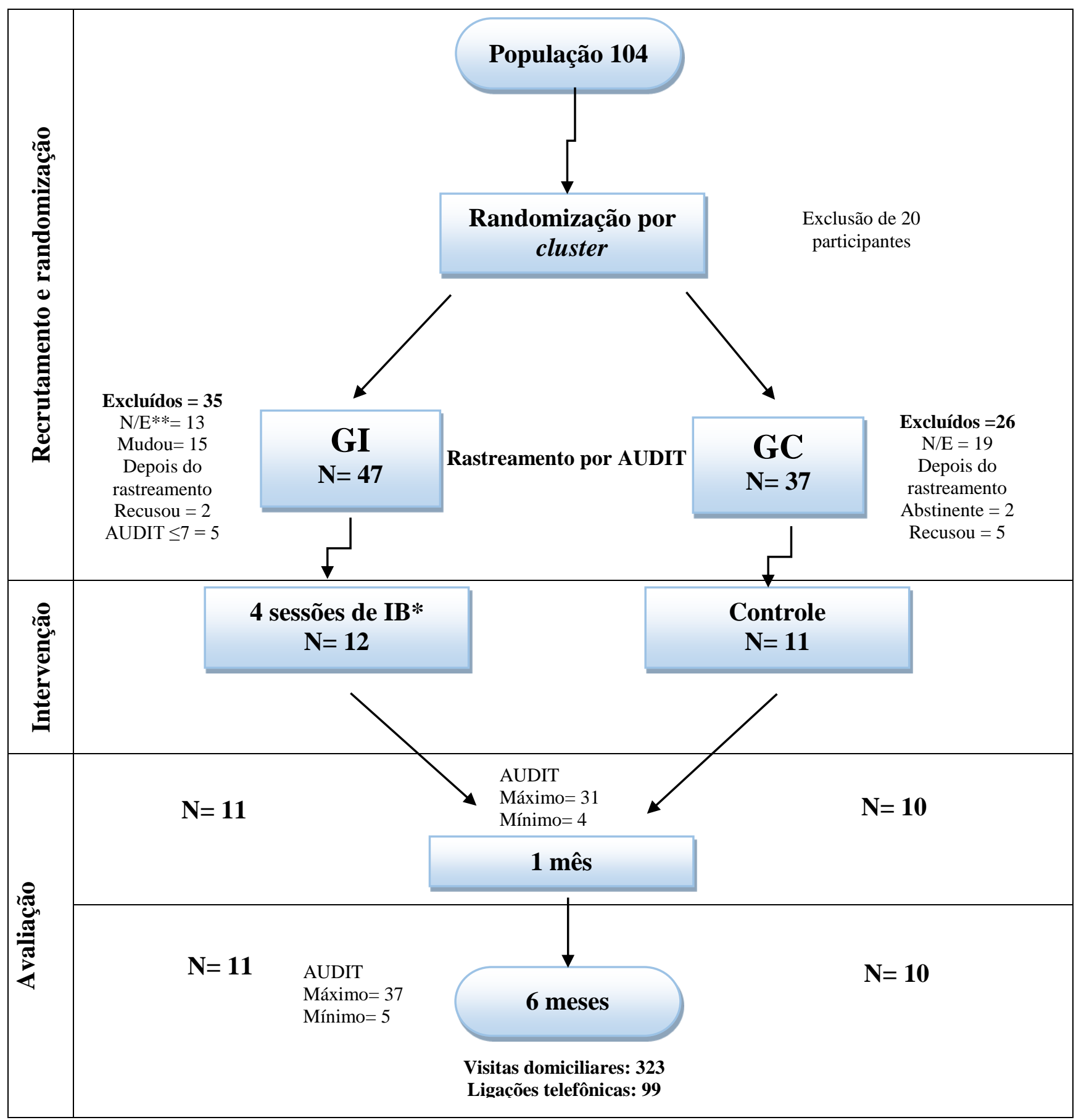

IB: Intervenção breve. ** Potenciais participantes classificados como não encontradoa (N/E) só foram assim julgados após a realização de três visitas domiciliares em dias e horários diferentes.

Durante as quatro intervenções foi utilizado o Diário de consumo de álcool (Apêndice I), instrumento elaborado num projeto de extensão (PROCURA) vinculado à Escola de Enfermagem de Ribeirão Preto - Universidade de São Paulo para acompanhamento de pacientes usuários de drogas 
psicoativas e adaptado para esse estudo. Ele consiste num relato sobre o consumo de álcool e os sentimentos que acompanham este uso. Esse instrumento teve o propósito de incentivar o indivíduo a perceber e a refletir sobre seu próprio uso de álcool, pois cada um podia construir seu próprio "diário" de consumo semanal, e com isso visualizar a quantidade de substância ingerida.

O diário fundamenta-se nos pressupostos da TCC, que recomenda direcionar "tarefas" para que os pacientes, no caso de terapias, possam refletir sobre suas ações fora do ambiente e horário da terapia ou intervenção com um profissional. O diário se fundamenta em princípios de educação e aprendizado ao orientar o indivíduo para a identificação, avaliação e resposta aos pensamentos e crenças disfuncionais (BECK, 2008), uma vez que no instrumento é solicitado ao participante que relembre os sentimentos vividos antes do consumo, com vistas a ajudá-lo a estimular sua autopercepção. Essa iniciativa está em conformidade com a TCC, pois permite ao participante conectar seu comportamento com os sentimentos e proporciona uma percepção de si que pode auxiliar na mudança de padrões já estabelecidos de ações. No caso deste estudo, tais procedimentos possibilitaram e enriqueceram a discussão com o profissional-pesquisador.

Há de se ressaltar ainda, que o diário facilitou a introdução dos diálogos sobre a semana anterior e permitiu o questionamento quanto aos planos da semana seguinte. Cada participante (do grupo controle e do grupo intervenção) preencheu 4 mapas de consumo semanal, ou seja, fez-se um mês de acompanhamento diário do consumo de álcool.

Além disso, toda a intervenção individual se concentrou no participante e nos seus desejos com relação ao consumo de álcool: manter-se em abstinência ou diminuir o uso. As intervenções foram realizadas em domicílio, em horário agendado conforme disponibilidade do usuário, fato que também permitiu um vínculo de confiança para as intervenções subsequentes.

As visitas domiciliares se mostraram a opção mais adequada para realizar as IB neste estudo. Primeiro, por facilitar a participação do sujeito, que de outro modo precisaria se locomover até o serviço ou até a pesquisadora e ainda pôde-se estabelecer uma agenda de encontros pactuada entre todos e em horários acessíveis ao usuário. Segundo, as visitas domiciliares, embora tenham se mostrado mais demoradas e trabalhosas que o planejado, favoreceu o vínculo terapêutico com o usuário de álcool, o que pode ter contribuído para obter medidas de uso de álcool auto referidas pelos usuários, mais fidedignas.

\section{Grupo controle}

Devido tratar-se de um estudo clínico randomizado foi constituído um grupo controle que 
era formado por usuários de álcool que apresentaram as mesmas características elegíveis do grupo intervenção. Neste grupo, após aplicação do ASSIST e AUDIT, foi entregue um folheto informativo (Apêndice VIII), em consonância com o aspecto ético quanto à necessidade de informar os sujeitos sobre a sua situação de beber potencialmente nociva à saúde.

Na elaboração do material informativo foi considerado o possível nível de compreensão dos usuários de álcool e no, contudo elaborou-se um resumo com informações referentes ao manejo do desejo de beber com vistas a possibilitar que o usuário seja agente disseminador na divulgação do risco de beber entre pessoas do seu convívio. Para avaliar a compreensão desse conteúdo, o material foi submetido a um teste piloto com usuários em geral dos serviços de saúde, os quais não manifestaram dificuldades de entendimento ou sugestões para mudança. Não houve qualquer contato da pesquisadora com os sujeitos do grupo controle após entrega deste material e somente na fase de avaliação (um mês e seis meses) os participantes foram contatados para aplicação do AUDIT e do Diário de consumo de álcool.

\section{Fase de avaliação}

As avaliações dos participantes do estudo (usuários de álcool), foram realizadas um mês $\left(\mathrm{T}_{1}\right)$ e seis meses $\left(\mathrm{T}_{2}\right)$ após a última intervenção para verificar o impacto da intervenção na redução do escore do AUDIT. A fim de se evitar interferências nesta etapa do estudo, a reaplicação do AUDIT não foi realizada pela pesquisadora que efetuou as intervenções, mas, por um membro externo convidado para tal após treinamento e explicação sobre os aspectos éticos da pesquisa envolvendo seres humanos, baseados na Resolução 466/2012. Contudo, ressalta-se que as entrevistas no grupo intervenção foram realizadas pela pesquisadora após reaplicação do AUDIT.

\section{Procedimentos éticos}

Este projeto de pesquisa insere-se em um projeto maior denominado "Identificação das necessidades e proposta de intervenção nos problemas de saúde mental e uso de drogas psicoativas em população usuária de Programa Saúde da Família (PSF) do Município de Ribeirão Preto/SP” desenvolvido em toda área de atenção primária à saúde da Região Oeste e foi submetido e aprovado no Comitê de Ética da Escola de Enfermagem de Ribeirão Preto da Universidade de São Paulo (Anexo I). O mesmo projeto recebeu financiamento pela Fundação de Amparo à Pesquisa do Estado de São Paulo (FAPESP) através do edital CNPq- PPSUS. 


\section{Análise estatística dos resultados}

Os dados foram digitalizados em planilha Excel. Feito isso, utilizou-se o pacote estatístico STATA, versão 13.1 para estatística descritiva e inferencial.

Para análise inferencial, procedeu-se à análise estatística por modelagem mista para os resultados e, após, dada a amostra do estudo, realizou-se ainda uma simulação estatística para verificação de comportamento dos dados com amostra hipotética de 30, 50 e 100 participantes. A simulação levou em conta que o comportamento dos dados simulados seria semelhante aos dados primários, ou seja, tivessem média e desvio padrão iguais aos da amostra primária de 23 participantes para os diferentes tempos de medida, $\mathrm{T}_{0}, \mathrm{~T}_{1}$ e $\mathrm{T}_{2}$, conforme podemos ver no Quadro 2.

\begin{tabular}{|c|c|c|c|c|c|}
\hline Grupo & $\begin{array}{c}\text { Média } \\
\text { AUDIT }\end{array}$ & $\begin{array}{c}\text { Desvio } \\
\text { padrão }\end{array}$ & Grupo & Média AUDIT & $\begin{array}{c}\text { Desvio } \\
\text { padrão }\end{array}$ \\
\hline Intervenção $\mathrm{T}_{0}$ & 15.1 & 7.25 & Controle $\mathrm{T}_{0}$ & 15.36 & 4.80 \\
\hline Intervenção $\mathrm{T}_{1}$ & 16.25 & 8.13 & ${\text { Controle } \mathrm{T}_{1}}$ & 11.81 & 5.13 \\
\hline Intervenção $\mathrm{T}_{2}$ & 11.66 & 5.97 & Controle $\mathrm{T}_{2}$ & 16.36 & 8.60 \\
\hline
\end{tabular}

Quadro 2. Relação tempo, média e desvio padrão do escore de AUDIT por grupo de alocação.

Assim, a estatística inferencial foi realizada com uso de efeitos mistos de regressão linear multinível. Cabe ressaltar aqui o pressuposto estatístico teórico para execução desse tipo de modelagem, tomando ciência da limitação de generalizações com uso desse tipo de procedimento.

Para gerar os dados da amostra simulada usando o STATA, procedeu-se primeiro a rodar a estatística para métodos mistos na amostra real de 23 participantes do estudo. Dado isto, com a média e o desvio padrão da variável resposta AUDIT para cada tempo e cada grupo (intervenção e controle) fez-se códigos para geração da amostra e, posteriormente, submeteu-se novamente os dados para regressão linear para cada amostra simulada.

\section{Manejo de dados faltosos}

Devido caso particular da população deste estudo, onde esperava-se um número considerável de dados faltosos, optou-se por manipular os dados através do método mais conservativo a fim de evitar viéses. A opção também justifica-se devido o conhecimento de que muitos estudos com essa mesma população assumem que dados faltosos são iguais a um padrão de consumo pior ao medido anteriomente, o que fortemente indica a necessidade de manipulação e não ignorância dessa possibilidade (HALLGREN; WITKIEWITZ, 2013). 
Assim, embora ao fim do estudo os dados faltosos tenham sido considerados pequenos (apenas duas perdas em cada fase de avaliação - duas no primeiro e duas no sexto mês), o método de manipulação foi repetir a última observacao realizada ou Last observation carried forward $(L O C F)$, termo e sigla em inglês. Essa escolha é considerada a mais conservativa, inclusive recomendada pela Food and Drug Administration (FDA) dos Estados Unidos por apresentar menores chances de acrescer viés ao resultados.

\section{Análise qualitativa dos resultados}

Quanto às análises qualitativas deste estudo clínico, as mesmas foram realizadas através do uso do Software Alceste. As entrevistas com o grupo intervenção foram transcritas e preparadas para leitura no software. Foi excluído em toda a transcrição as falas da pesquisadora.

O Alceste trabalha por etapas, sendo elas a leitura do corpus, o cálculo das matrizes de dados e classificação das Unidades de Contextos Elementares (UCE), a descrição das classes e UCE, cálculo complementar e cálculo dos dicionários fazendo reconhecimento das Unidades de Conteúdo Inicial (UCI). As UCEs que são segmentos textuais com respeito a ordem e agrupamento das palavras com base nas raízes das mesmas, tais quais "beb" para as palavras beber, bebendo, bêbado, por exemplo. (MOREIRA et al., 2005; REINERT, 1990).

O uso de técnicas qualitativas em estudos clínicos não é recente, embora seja ainda pouco frequente. Craig et al. (2008) recomendaram o uso de técnicas qualitativas em estudos clínicos para um maior entendimento de intervenções mais complexas e para prover insights no processo de mudança de comportamento, bem como para entender de forma mais complexa os resultados quantitativos dos ensaios clínicos. Dada a complexidade do comportamento humano e do manejo deste para que ocorram mudanças, um estudo, em que a mudança de comportamento em relação ao uso de álcool é a principal meta, justifica aprofundar-se no entendimento de aspectos mais subjetivos do problema. Além disso, esses resultados podem agregar conhecimento aos achados de outras pesquisas.

A análise qualitativa objetivou integrar componentes não mensuráveis pelo instrumento quantitativo ou não passíveis de mensuração com uso do AUDIT. Além de contribuir com elementos para ampliar a discussão de motivos do consumo e os aspectos positivos sobre a intervenção. 


\section{RESULTADOS}




\section{Resultados}

A análise quantitativa e qualitativa dos dados somou conhecimento sobre as intervenções e deu margem a levantar mais hipóteses para compreensão dos dados. Enquanto a primeira quantificou as informações através do uso de instrumentos reconhecidos, a segunda dedicou-se a esmiuçar através dos registros de gravações dos encontros de intervenção e dos Diários de Consumo de Álcool, os aspectos subjetivos.

No que se refere aos dados quantitativos, as análises centraram-se sobretudo nos escores do AUDIT, doses consumidas (semanais e mensais) e o comportamento dessas variáveis nos dois grupos.

Conforme Tabela 1, observa-se que os grupos eram semelhantes ou equilibrados quanto às variáveis de idade, gênero, parceiro sexual e mesmo quanto à procedência. A variável, anos de estudo foi a que se mostrou ligeiramente diferente, mas, considerando o desvio padrão nos dois grupos as médias se aproximam. Quanto ao número de doses, houve diferenças entre os grupos, sendo observado no grupo controle maior consumo semanal e, consequentemente, mensal que o observado no grupo intervenção.

Tabela 1. Características gerais da amostra.

\begin{tabular}{|c|c|c|c|}
\hline Variável & Grupo Intervenção & Grupo controle & Amostra \\
\hline Idade $(x)$ & 49.3 & 47.09091 & 48.2 \\
\hline \multicolumn{4}{|l|}{ Gênero (n) } \\
\hline Masculino & 9 & 7 & 16 \\
\hline Feminino & 3 & 4 & 7 \\
\hline Anos de estudo $(x)$ & 9,5 (DP 2,3) & 6,3 (DP 3) & $7,8$ (IC $6.5-9.1)$ \\
\hline Visitas domiciliares $(x)$ & 11,5 & 16,8 & 14 \\
\hline \multicolumn{4}{|l|}{ Parceiro sexual (n) } \\
\hline Sim & 6 & 8 & 14 \\
\hline Não & 6 & 3 & 9 \\
\hline Doses semanais $(x)$ & 29,5 & 47,1 & 37,9 \\
\hline Doses mensais $(x)$ & 118 & 188,4 & 151,6 \\
\hline \multicolumn{4}{|l|}{ Procedência (n) } \\
\hline Estado de São Paulo & 11 & 9 & 20 \\
\hline Ceará & 0 & 1 & 1 \\
\hline Pará & 0 & 1 & 1 \\
\hline Minas Gerais & 1 & 0 & 1 \\
\hline
\end{tabular}

Coleta de dados. Ribeirão Preto, 2016. (x): média; IC = Intervalo de Confiança.

Com relação aos 23 participantes que finalizaram o estudo, a média de idade foi de 48.2 anos (desvio padrão de 15.7; mínima 21 anos e máxima de 72 anos). Quanto ao gênero, no presente 
estudo, 16 participantes eram homens (nove no GI e sete no GC) e sete eram mulheres (três GI e quatro GC).

Sobre os anos de estudo, optou-se pela descrição de quantos anos o participante esteve matriculado em escola formal; na amostra, a média foi de 7.8 anos (IC 6.5 - 9.1 anos de estudo). No grupo intervenção a média de anos de estudo foi de 9.5 e no grupo controle foi de 6.3 .

No que se refere ao número de visitas domiciliares, no grupo intervenção a média foi de 11,5 e no grupo controle 16,8 . No total, foram realizadas 323 visitas domiciliares. O número maior de visitas domiciliares no grupo controle justifica-se pela ausência de contato e vínculo com a equipe de pesquisa, uma vez que o contato se restringiu a aplicação de instrumentos, assim, com mais frequência os participantes não foram encontrados no domicílio e quando estavam, solicitavam o adiamento por alguns dias, da aplicação dos instrumentos. Como resultado, houve o aumento do período de coleta de dados e do número de visitas domiciliares. Quanto ao número de visitas domiciliares para cada participante, observa-se no Quadro 3 que em 17 participantes foram realizadas mais de 10 visitas domiciliares, sendo que o número de visitas programadas seria de seis para participantes do grupo intervenção e três para os que estavam alocados no grupo controle. Isso demonstra que mesmo com aqueles que concordaram em colaborar com o estudo houve dificuldades em estabelecer contato, esse dado revelou que essa não é uma população de fácil acesso para pesquisa e, possivelmente, tampouco para tratamento no serviço ao qual se vinculam.

Com relação aos parceiros, 14 participantes têm parceiros sexuais (seis GI e oito no GC). Quando questionados sobre a prática sexual após ingestão de bebida alcoólica, oito participantes afirmaram que sim (cinco GI e três GC), costumavam ter relações sexuais após beber.

Quanto à procedência, 19 participantes nasceram no Estado de São Paulo (doze nascidos na própria cidade de Ribeirão Preto), e três em outros Estados brasileiros, sendo um da Região CentroOeste (Minas Gerais), um da Região Nordeste (Ceará) e outro da Região Norte (Pará).

Quando questionados com quem moravam, apenas três participantes referiram viver sozinhos (sendo duas mulheres do GC e um homem do GI). A média de pessoas residindo na mesma casa do participante foi de 2, 5 (mínimo de um e máximo de cinco pessoas).

Em relação às atividades remuneradas, onze pessoas realizavam alguma atividade remunerada (seis participantes do GI e cinco do GC). Quanto ao tipo de atividade remunerada (trabalho formal ou aposentadoria), dez participantes realizavam, sendo seis do GI e quatro do GC. $\mathrm{Na}$ amostra quatro pessoas relataram serem aposentados (dois no GC e dois no GI), sendo um deles aposentado e com outra atividade de complementação de renda. 
A análise dos dados obtidos através do Diário de Consumo de álcool forneceu as doses ingeridas e as bebidas alcoólicas consumidas por semana, horário de consumo, dias de consumo, bebida de preferência, sentimentos associados ao beber, episódio mais abusivo e, por último, as visitas domiciliares, tais informações estão apresentadas no Quadro 3. Nesse quadro também se incluiu o perfil ASSIST para as outras drogas, em caso de uso, dada a riqueza dessas informações, considerou-se oportuno fazer esclarecimentos adicionais no intuito de facilitar a compreensão do seu conteúdo. 


\begin{tabular}{|c|c|c|c|c|c|c|c|c|c|c|}
\hline Grupo & Gênero & $\begin{array}{c}\text { Doses } \\
\text { mensais }^{5}\end{array}$ & $\begin{array}{c}\text { Doses } \\
\text { semanais }^{6}\end{array}$ & $\begin{array}{l}\text { Horário de } \\
\text { consumo }\end{array}$ & $\begin{array}{c}\text { Dias de } \\
\text { maior } \\
\text { consumo }\end{array}$ & $\begin{array}{l}\text { Bebida mais } \\
\text { consumida }\end{array}$ & $\begin{array}{l}\text { Sentimentos } \\
\text { percebidos }\end{array}$ & Outras drogas na vida & ASSIST $^{7}$ & VDs \\
\hline GI & Mas & 88 & 22 & S/preferência & $\mathrm{NE} * * *$ & Pinga & Felicidade & Tabaco & 31 & 10 \\
\hline GI & Fem & 132 & 33 & S/preferência & $\mathrm{NE}$ & Cerveja & Tristeza, irritação & $\begin{array}{c}\text { Cocaína, tabaco, maconha, } \\
\text { anfetamina, inalante e alucinógeno }\end{array}$ & $\begin{array}{c}24,23,6 \\
3,3,3\end{array}$ & 13 \\
\hline GI & Mas & 129 & 32 & Meio-dia e à noite & $\mathrm{NE}$ & Pinga e cerveja & Ignora & Tabaco & 21 & 7 \\
\hline GI & Fem & 52 & 13 & S/preferência & Dom* & Cerveja & Preocupação & - & - & 9 \\
\hline GI & Mas & 60 & 15 & S/preferência & $\mathrm{NE}$ & Cerveja & Ignora & Tabaco & 30 & 16 \\
\hline GI & Mas & 40 & 10 & Meio dia & $\mathrm{NE}$ & Cerveja & Ignora & Tabaco & 24 & 16 \\
\hline GI & Mas & 72 & 18 & Manhã & $\mathrm{NE}$ & Cerveja & Tristeza & - & - & 12 \\
\hline GI & Fem & 16 & 4 & S/preferência & $\mathrm{NE}$ & Cerveja & Solidão & - & - & 20 \\
\hline GI & Mas & 372 & 93 & Noite & $\mathrm{NE}$ & Cerveja & Ignora & Cocaína, maconha & 15,19 & 8 \\
\hline GI & Mas & 168 & 42 & Noite & $\mathrm{NE}$ & Cerveja & Ignora & Maconha, cocaína, tabaco & $23,15,19$ & 9 \\
\hline GI & Mas & 220 & 55 & S/preferência & $\mathrm{NE}$ & Cerveja & Ignora & - & - & 8 \\
\hline GI & Masc & 67 & 17 & S/preferência & $\mathrm{NE}$ & Cerveja & Ignora & Tabaco & 24 & 10 \\
\hline GC & Fem & 67 & 17 & Meio dia & $\mathrm{NE}$ & Cerveja & Ignora & - & - & 10 \\
\hline $\mathrm{GC}$ & Mas & 48 & 12 & Meio dia & $\mathrm{NE}$ & Cerveja & Ignora & - & - & 14 \\
\hline GC & Mas & 47,4 & 11,8 & Manhã e noite & Dom e quar* & Cerveja e pinga & Ignora & Tabaco & 21 & 10 \\
\hline $\mathrm{GC}$ & Mas & 48 & 12 & S/preferência & $\mathrm{NE}$ & Cerveja & Ignora & - & - & 17 \\
\hline $\mathrm{GC}^{8}$ & Mas & 174,8 & 43,7 & Manhã & $\mathrm{NE}$ & Pinga & Deprimido & Tabaco & 24 & 14 \\
\hline GC & Mas & 48 & 12 & S/preferência & $\mathrm{NE}$ & Pinga & Ignora & Tabaco & 15 & 21 \\
\hline GC & Fem & 56 & 14 & Noite & $\mathrm{NE}$ & Cerveja & Ansiedade & Maconha, cocaína, tabaco & $28,9,15$ & 15 \\
\hline $\mathrm{GC}$ & Mas & 80 & 20 & S/preferência & $\mathrm{NE}$ & Cerveja & Ignora & - & - & 17 \\
\hline $\mathrm{GC}$ & Fem & 40 & 10 & S/preferência & $\mathrm{NE}$ & Cerveja & Ignora & - & - & 20 \\
\hline $\mathrm{GC}$ & Fem & 40 & 10 & S/preferência & $\mathrm{NE}$ & Cerveja & Ignora & - & - & 25 \\
\hline $\mathrm{GC}$ & Mas & 132 & 33 & S/preferência & $\mathrm{NE}$ & Cerveja & Ignora & Maconha, tabaco & 6 & 23 \\
\hline
\end{tabular}

Quadro 1. Caracterização quanto ao Diário de Consumo de álcool e perfil ASSIST.

\footnotetext{
${ }^{5}$ As doses semanais foram obtidas através do Diário de consumo de álcool fazendo uma média semanal dos diários obtidos durante a coleta.

${ }^{6}$ As doses mensais foram obtidas atrás do cálculo estimado do consumo mensal de álcool através do Diário de consumo de álcool.

${ }^{7}$ Escore do ASSIST para drogas de consumo, exceto álcool.

${ }^{8}$ Participante foi diagnosticado com câncer de mama
} 
Em relação ao Quadro 1, sobre o dia preferencial de consumo de álcool, obtido a partir do Diário de consumo de álcool e através de entrevista, a resposta de 20, dos 22 participantes, foi de que não há um dia de preferência de consumo de álcool ou ocasião específica para tal. Assim, beber nessa amostra parece estar mais relacionada ao hábito cotidiano ou um comportamento já estabelecido, não relacionados a eventos ou oportunidades específicas que aumentam as chances de consumo. Tal fato remete-nos a uma certa gravidade, pois o beber "ocasional" parece ser comum, cotidiano, inclusive com alguns relatos de consumo no período da manhã.

Sobre a bebida mais escolhida para consumo (Quadro 1), a cerveja foi a primeira. A escolha da pinga está provavelmente ligada ao poder aquisitivo de compra e à disponibilidade, sendo ela e a cerveja as bebidas mais acessíveis em termos de preço e, por isso, com maior possibilidade de consumo e em maior quantidade também. Sendo que existem três participantes usuários de pinga, um deles com o consumo também de cerveja. Enquanto no GI há dois sujeitos que consomem pinga, um desses consumindo cerveja também.

Relativo aos sentimentos percebidos (Quadro 1), em 15 dos 23 participantes os mesmos não sabiam expressar como se sentiam antes da ingestão de bebida alcoólica. A autorreflexão ou percepção de si sobre fatores ligados ao consumo de álcool, onde não há compreensão de que sentimentos podem ser os propiciadores do início do consumo ou quais são os fatores que interferem nos comportamentos, sobretudo comportamentos de adição, é outro fato que parece demonstrar um padrão com tendência mais abusivo de consumo. Destaca-se que a percepção das mulheres sobre os sentimentos vivenciados antes do consumo de álcool foi maior do que nos homens (quatro de sete participantes mulheres em comparação a três dos quinze participantes homens). Dos participantes que relataram a percepção de sentimentos antes do consumo, a maioria foi de espectro negativo (tristeza, irritação, ansiedade, solidão, preocupação), apenas um homem relatou vivenciar sentimento positivo antes do consumo (felicidade).

Quanto ao uso de outras drogas na vida, dez participantes da amostra usavam apenas álcool (quatro do GI e seis do GC). Sete participantes usavam álcool e tabaco (quatro GI e três GC). Cinco participantes eram usuários de múltiplas drogas (3 GI e 2 GC), as mais comuns foram a maconha e a cocaína. 


\begin{tabular}{|c|c|c|c|c|c|c|}
\hline Grupo & Gênero & $\begin{array}{c}\text { Estágio de mudança no } \\
\text { primeiro encontro } 9\end{array}$ & $\begin{array}{c}\text { Estágio de mudança no último } \\
\text { encontro }\end{array}$ & Consumo episódico mais abusivo & Doses consumidas & Unidades de álcool \\
\hline GI & Masc & Contemplação & Ação & 1 dose de pinga $+600 \mathrm{ml}$ de cerveja & 3 & 4,9 \\
\hline GI & Fem & Pré-contemplação & Pré-contemplação & 5 litros de cerveja & 14,2 & 24,2 \\
\hline GI & Masc & Pré-contemplação & Pré-contemplação & 3 doses de pinga $+600 \mathrm{ml}$ de cerveja & 5 & 8,9 \\
\hline GI & Fem & Pré-contemplação & Pré-contemplação & 1 litro de cerveja & 2,85 & 4,8 \\
\hline GI & Masc & Contemplação & Contemplação & 10 chopes & 10 & 17 \\
\hline GI & Masc & Pré-contemplação & Pré-contemplação & 1,200 L de cerveja & 3,4 & 5,8 \\
\hline GI & Masc & Pré-contemplação & Contemplação & 3 garrafas & 5,1 & 8,7 \\
\hline GI & Fem & Contemplação & Ação & 4 latas & 4 & 6,8 \\
\hline GI & Masc & Contemplação & Contemplação & 8 cervejas +3 copos de vinho & 16,2 & 26,6 \\
\hline GI & Masc & Contemplação & Contemplação & 6 cervejas & 10,2 & 17,4 \\
\hline GI & Masc & Contemplação & Contemplação & Cinco latas & 5 & 8,5 \\
\hline GI & Masc & Contemplação & Pré-contemplação & 3 garrafas de cerveja & 5,1 & 8,7 \\
\hline $\mathrm{GC}$ & Fem & Pré-contemplação & Ação & 2 litros & 5,7 & 9,7 \\
\hline GC & Masc & Contemplação & Ação & 12 latas de cervejas & 12 & 20,4 \\
\hline GC & Masc & Pré-contemplação & Pré-contemplação & 2 doses de pinga +2 cervejas & 6 & 9,8 \\
\hline $\mathrm{GC}$ & Masc & Pré-contemplação & Pré-contemplação & 2 litros & 5,7 & 9,7 \\
\hline $\mathrm{GC}$ & Masc & Pré-contemplação & Pré-contemplação & $250 \mathrm{ml} \mathrm{de}$ pinga & 5 & 14,2 \\
\hline $\mathrm{GC}$ & Masc & Contemplação & Contemplação & 3 doses de pinga + cerveja & 5 & 8,9 \\
\hline $\mathrm{GC}$ & Fem & Pré-contemplação & Contemplação & 2 litros & 5 & 9,7 \\
\hline $\mathrm{GC}$ & Masc & Contemplação & Contemplação & 2 litros & 5,7 & 9,7 \\
\hline $\mathrm{GC}$ & Fem & Pré-contemplação & Contemplação & 1 litro & 2,85 & 4,8 \\
\hline $\mathrm{GC}$ & Fem & Pré-contemplação & Contemplação & 2,5 litros & 7,1 & 12,1 \\
\hline GC & Masc & Pré-contemplação & Pré-contemplação & 2 litros & 5,7 & 9,7 \\
\hline
\end{tabular}

Quadro 2. Estágio de mudança no primeiro, último encontro, consumo episódico, doses e unidades de álcool.

\footnotetext{
${ }^{9}$ Segundo Prochaska e DiClemente
} 
No que se refere à prontidão para mudança, eles foram classificados a partir do primeiro e do último contato, conforme os estágios motivacionais de mudança de Prochaska e Di Clemente (Quadro 2); no primeiro contato, seis participantes do GI foram classificados no estágio motivacional de contemplação, pois sinalizavam a percepção clara do uso de álcool como um problema na sua vida, seja por motivos familiares, sociais ou de saúde. No GC três participantes foram classificados no estágio de contemplação, totalizando nove participantes do estudo nesse estágio. Treze participantes (cinco do GI e oito do GC) foram classificados como na fase de pré-contemplação e embora tenham aceitado espontaneamente participar de um estudo que, sabidamente abordaria o consumo de álcool e proporia modificações na diminuição do padrão de consumo, expressavam abertamente a percepção de que o uso de álcool não constituía um fator problemático para qualquer área de sua vida, social, familiar, financeira ou de saúde.

No último encontro, foram identificados no estágio de pré-contemplação cinco participantes do grupo intervenção (três homens e duas mulheres) e quatro homens do grupo controle. Cinco participantes em cada grupo estavam no estágio de contemplação, sendo três mulheres no grupo controle e os cinco do grupo intervenção eram todos do gênero masculino. Foram identificados na fase de ação para mudança quatro participantes, sendo uma mulher e um homem em cada grupo. Nessa fase de estágio, evidenciou-se que esses participantes estavam de fato em processo de diminuição do uso de álcool, com planos em execução e inclusive relatos de mudança de hábitos de vida para reforçar e facilitar o período de transição, a exemplo de uma dessas participantes que relatou estar evitando a ida em confraternizações com os amigos que consumiam bebidas alcoólicas.

Para identificar o consumo abusivo de álcool episódico (Quadro 2), foi solicitado aos participantes que cada um relatasse o episódio de maior consumo de álcool e constatou-se que o consumo mais abusivo variou de 2,85 a 16, 2 doses (média de 6,57 doses da amostra, aproximadamente 10 unidades de álcool; mediana 5,4; moda 5 doses e 5,7; Desvio padrão 2,5) e a bebida mais usada nessas ocasiões foi a cerveja, em sua maioria. O tamanho amostral de mulheres não permitiu comparações e nem foi este o objetivo da pesquisa, mas as sete participantes mulheres consumiam somente cerveja e em doses que variavam de 2,85 a 14,2. 


\begin{tabular}{|c|c|c|c|c|c|c|c|c|}
\hline Gupo & Gênero & Assist Álcool & AUDIT 1 & Zona de risco & AUDIT 2 & Zona de risco & AUDIT 3 & Zona de risco \\
\hline GI & Mas & 18 & 12 & 2 & 31 & 4 & 20 & 4 \\
\hline GI & Fem & 31 & 20 & 4 & 26 & 4 & 26 & 4 \\
\hline GI & Mas & 15 & 11 & 2 & 24 & 4 & 10 & 2 \\
\hline GI & Fem & 24 & 11 & 2 & 18 & 3 & 8 & 2 \\
\hline GI & Mas & 20 & 13 & 2 & 12 & 2 & 16 & 3 \\
\hline GI & Mas & 15 & 9 & 2 & 9 & 2 & 8 & 2 \\
\hline GI & Mas & 18 & 12 & 2 & 11 & 2 & 8 & 2 \\
\hline GI & Fem & 22 & 12 & 2 & 8 & 2 & 8 & 2 \\
\hline GI & Mas & 18 & 25 & 4 & 10 & 2 & 9 & 2 \\
\hline GI & Mas & 33 & 33 & 4 & 15 & 2 & 10 & 2 \\
\hline GI & Mas & 39 & 18 & 3 & 24 & 4 & 11 & 2 \\
\hline GI & Masc & 13 & 10 & 2 & 7 & 1 & 6 & 1 \\
\hline GC & Fem & 25 & 21 & 4 & 10 & 2 & 17 & 3 \\
\hline $\mathrm{GC}$ & Mas & 32 & 19 & 3 & 11 & 2 & 11 & 2 \\
\hline GC & Mas & 19 & 14 & 2 & 4 & 1 & 5 & 1 \\
\hline GC & Mas & 13 & 8 & 2 & 8 & 2 & 8 & 2 \\
\hline GC & Mas & 30 & 19 & 3 & 19 & 3 & 19 & 3 \\
\hline GC & Mas & 13 & 10 & 2 & 8 & 2 & 14 & 2 \\
\hline GC & Fem & 27 & 13 & 2 & 14 & 2 & 20 & 4 \\
\hline GC & Mas & 20 & 13 & 2 & 9 & 2 & 37 & 4 \\
\hline GC & Fem & 18 & 22 & 4 & 21 & 4 & 22 & 4 \\
\hline GC & Fem & 18 & 19 & 3 & 16 & 3 & 16 & 2 \\
\hline GC & Mas & 28 & 11 & 2 & 10 & 2 & 11 & 2 \\
\hline \multicolumn{2}{|c|}{$\overline{\mathrm{X}}$ e IC } & $\begin{array}{c}\text { Alfa } \\
0.68 *\end{array}$ & \multicolumn{2}{|c|}{$\begin{array}{c}15.4 \\
12.8-18.0\end{array}$} & \multicolumn{3}{|c|}{$\begin{array}{c}14.1 \\
11-17.1\end{array}$} & $\begin{array}{c}13.9 \\
10.6-17.1\end{array}$ \\
\hline
\end{tabular}

Quadro 3. Escores de AUDIT e Zona de uso por participante.

*Alfa de Cronbach entre ASSIST e medida do escore de AUDIT 1. 
Sobre o consumo semanal (Quadro 4), a divisão do mesmo em dois intervalos principais, observou-se que predominou no GC o consumo de 10 a 22 doses, com 9 participantes, enquanto que no GI cinco participantes se enquadraram nesse padrão. No intervalo entre 32 e 93 doses há o predomínio do GI (cinco participantes). Verifica-se, portanto, que o GI apresenta usuários num consumo semelhante ao $\mathrm{GC}$ e outros num mesmo número, com um consumo mais elevado. Destaca-se os dois participantes, um do GI cujo consumo se situa próximo ao considerado pela OMS10 como consumo de baixo risco, quando comparado aos demais e outro do GC bem acima dos demais participantes.

\begin{tabular}{|c|c|c|}
\hline Doses semanais/participantes & Grupo Intervenção (GI) & Grupo Controle (GC) \\
\hline $10-22$ & 5 & 9 \\
\hline $32-93$ & 5 & 0 \\
\hline 4 doses & 1 & 7 \\
\hline Doses mensais/participantes & Grupo Intervenção (GI) & Grupo Controle (GC) \\
\hline $40-60$ & 2 & 4 \\
\hline$\geq 60$ a 220 & 7 & 1 \\
\hline$\geq 372$ doses & 1 & 0 \\
\hline 16 & 1 & 5 \\
\hline
\end{tabular}

Quadro 4. Relação de doses semanais e mensais por grupo do estudo.

Ao avaliar a ingestão de unidades de álcool observou-se que apenas cinco participantes ingerem uma quantidade dentro do preconizado pelos índices da OMS, desses todos são homens. Cabe ressaltar que segundo recomendação de consumo semanal pela Organização Mundial de Saúde (OMS), para homens não se indica mais que 14 doses por semana e 7 doses para mulheres. Esse dado reforça o caráter abusivo de consumo de álcool na amostra deste estudo e no provável comprometimento da saúde, na persistência desse padrão abusivo de consumo de álcool.

Em relação à quantidade de doses consumidas por mês (dados presumidos com base no consumo semanal ${ }^{11}$ ) observa-se um uso variado, porém com certa predominância em algumas quantidades de forma a ser possível agrupar os nove que consomem num intervalo de 40 a 60 doses/mês, dois no grupo GI e sete no GC. O intervalo entre 60 doses até 220 doses está

\section{${ }^{10} \mathrm{OMS}$}

${ }^{11} \mathrm{O}$ consumo semanal foi baseado também no estudo de Salonsalmi et al. (2012) que avaliou também a media do consumo semanal de sua amostra. No estudo de Rahhali et al. (2015), o consumo de álcool foi medido por dia e descrito em gramas por consumo. 
presente em onze participantes, sete do GI e quatro do GC. Observa-se ainda o intervalo dos consumidores acima de 300 doses, sendo um em cada grupo, com destaque para um sujeito do GC que consome até 362 doses. Como outra particularidade há a presença de um cliente no GI com média de consumo mensal de 16 doses.

No presente estudo, o consumo situado no espectro dos 40 a 60 doses, chamou a atenção, pois como predominou entre o GC, fez refletir sobre se esse seria o padrão considerado "normal" ou dentro do perfil de seus pares, caberia então investigar quanto isso estaria influenciando nesse padrão de consumo. Como o padrão de consumo mensal foi calculado com base no consumo semanal, julga-se que constitui uma aproximação da realidade.

Sobre a variável resposta do estudo, o Quadro 3 e Tabela 2, fornecem o detalhamento quanto ao escores, por participante, do AUDIT. Ressalta-se que as médias e os intervalos de confiança (IC) das médias são referentes ao período da medida (T0, T1 e T2) e não aos grupos separados (intervenção e controle). Para analisar a consistência interna do ASSIST para álcool nesse estudo, foi feito o teste alfa de Cronbach, com o primeiro escore obtido no AUDIT, o qual o resultado foi 0.68 , o que indica uma confiabilidade aceitável. Na Figura 6, vemos o AUDIT por tempo de medida, escores mínimo e máximo e o detalhamento por grupo.

Tabela 2. Escores mínimo e máximo do AUDIT por grupo

\begin{tabular}{cccc} 
AUDIT por tempo & Mínima & Máxima & Mínima e máxima por grupo \\
\hline $\mathrm{T}_{0}$ & 8 & 33 & $9 \mathrm{IG}$ 8 GC / 33 GI 22 GC \\
$\mathrm{T}_{1}$ & 4 & 31 & $7 \mathrm{GI} 4 \mathrm{GC} / 31 \mathrm{GI} 21 \mathrm{CG}$ \\
$\mathrm{T}_{2}$ & 5 & 37 & $6 \mathrm{GI} 5 \mathrm{GC} / 26 \mathrm{GI} 37 \mathrm{GC}$ \\
\hline
\end{tabular}


Como podemos ver na Figura 6, a média dos AUDIT durante o follow up não diferiu muito. A média de AUDIT do GI foi de $15.5\left(\mathrm{~T}_{0}\right), 16.25\left(\mathrm{~T}_{1}\right)$ e $11.6\left(\mathrm{~T}_{2}\right)$. Para o GC a media foi de 15.36 $\left(\mathrm{T}_{0}\right), 8.1\left(\mathrm{~T}_{1}\right), 16.36\left(\mathrm{~T}_{2}\right)$. Além disso, no primeiro e na terceira avaliação observa-se a presença de outliers, ou seja, medidas muito discrepantes ao restante da amostra.

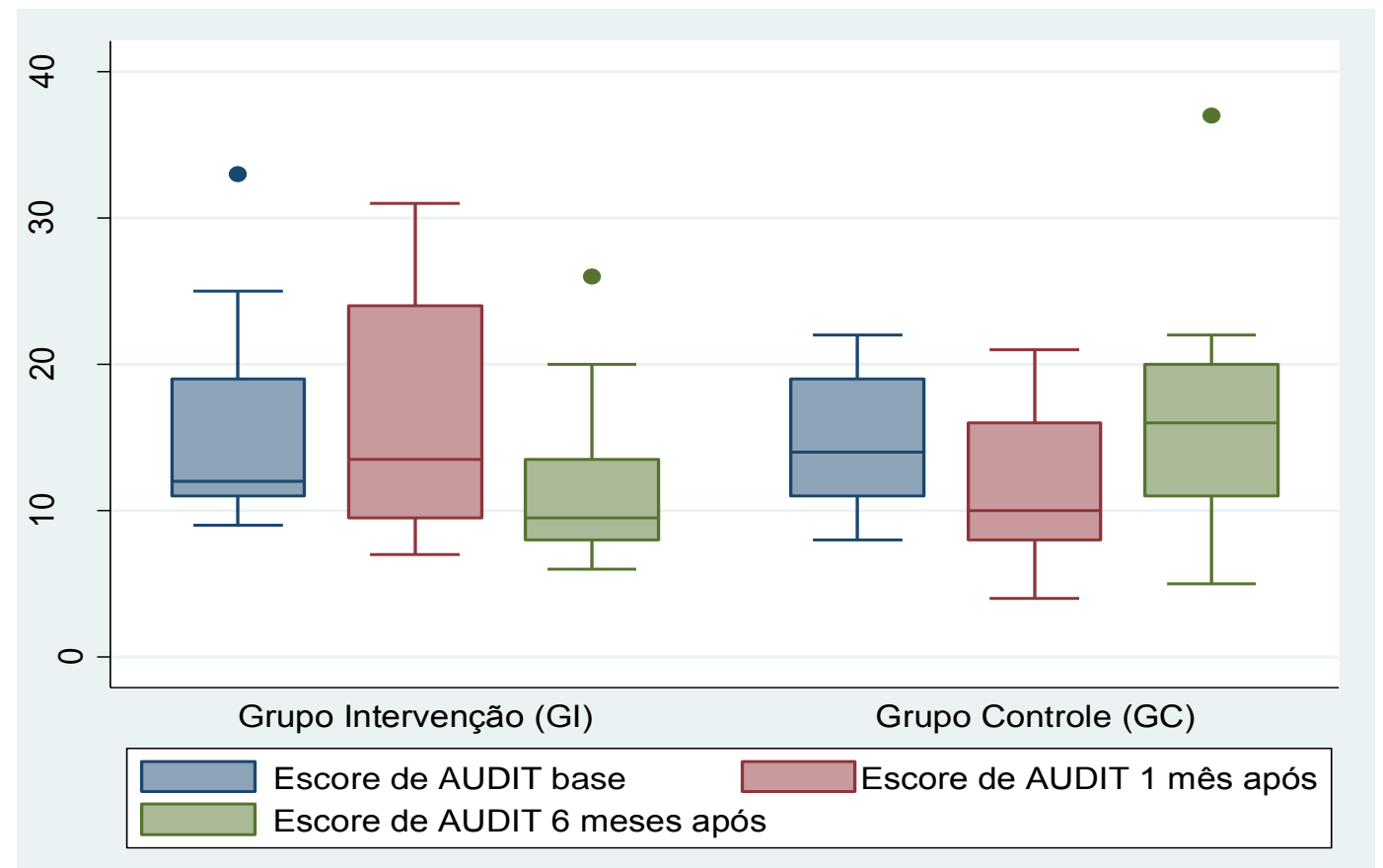

Figura 6. Box plot das médias de escores de AUDIT conforme medida de tempo.

No GI a média aumentou na primeira medida $\left(\mathrm{T}_{1}\right)$ e, depois de seis meses diminuiu. $\mathrm{O}$ oposto podemos ver no GC, quando a medida do escores de AUDIT diminui do $\mathrm{T}_{0}$ para o $\mathrm{T}_{1} \mathrm{e}$ depois aumenta no sexto mês $\left(\mathrm{T}_{2}\right)$. Talvez isso aconteça nessa amostra porque os participantes do grupo controle podem ter tido consciência que estavam participando de um estudo e tiveram maior atenção no padrão de consumo no início, dada a dificuldade de se manter uma mudança de comportamento sem um vínculo com intervenção contínua, onde os usuários podem ter se desistimulado e voltado ao consumo no mesmo padrão.

Com relação aos dados discrepantes (outliers), o escore do dado discrepante no $\left(\mathrm{T}_{0}\right)$ foi de 33 (sendo a média de consumo de doses desse sujieto de 42 doses) e no $\mathrm{T}_{2}$ o dado discrepante apresentou escore de 26 (consumo de doses semanal 33), ambas do grupo intervenção. O dado discrepante do grupo controle apresentou escore de 37 (20 doses/semana). Cabe ressaltar que o 
consumo de doses semanais parecer dissoar do escore AUDIT por ser autoreferido e, ainda, feito pelo recordatório do Diário de Consumo.

Sobre os resultados do efeito multinivel misto, como se observa na Tabela 3, na amostra real deste estudo (23 participantes - 12 grupo intervenção e 11 grupo controle) não houve diferença significativa $(\mathrm{p}=0.80)$. Embora tenha sido observado efeito da intervenção.

Tabela 3. Efeitos mistos para amostra real de participantes.

\begin{tabular}{cccccc}
\hline AUDIT & Coef. & Robust Std. Err. & $\mathbf{Z}$ & $\mathbf{P}>|\mathbf{z}|$ & 95\% Conf. Interval \\
\hline $\begin{array}{c}\text { Grupo de } \\
\text { alocação }\end{array}$ & -1363636 & 2.48 & 0.05 & 0.956 & -4.745 .01 \\
Tempo & & & & & \\
$\mathbf{T}_{\mathbf{1}}$ & .75 & 2.97 & 0.25 & 0.80 & -5.086 .58 \\
$\mathbf{T}_{\mathbf{2}}$ & -3.83 & 2.44 & 1.57 & 0.11 & -8.630 .96 \\
$\begin{array}{c}\text { Efeito de } \\
\text { interação grupo }\end{array}$ & & & & \\
tempo & & & & & \\
& & & & & \\
$\mathbf{1} \mathbf{2}$ & 4.29 & 3.22 & 1.33 & 0.18 & -2.0210 .61 \\
$\mathbf{1}$ & -4.83 & 3.59 & -1.35 & 0.17 & -11.872 .20 \\
& & & & & \\
\hline
\end{tabular}

Fonte: Coleta de Dados. Ribeirão Preto, 2016.

Sobre os dados prevenientes da simulação (Tabela 4), considerando a mesma variabilidade dos escores de AUDIT nos diferentes tempos de medida $\left(\mathrm{T}_{0}, \mathrm{~T}_{1}\right.$ e $\left.\mathrm{T}_{2}\right)$ com tamanho amostral de 30, 50 e 100 participantes, não houve significância estatística, embora o efeito seja mantido. Assim, para o tamanho da amostra 30 o efeito foi $-1,91$, para o tamanho da amostra 50 o efeito foi $-3,45$ e para 100 participantes o efeito esperado seria $-2,51$.

Tabela 4. Efeito com amostra simulada de participantes.

\begin{tabular}{ccc}
\hline Número de participantes & Coef & Valor de p \\
\hline $\mathbf{3 0}$ & $-1,91$ & 0.6 \\
$\mathbf{5 0}$ & $-3,45$ & 0.1 \\
$\mathbf{1 0 0}$ & $-2,51$ & 0.2 \\
\hline
\end{tabular}

Fonte: Coleta de Dados. Ribeirão Preto, 2016. 
Esses dados estatísticos apontam que, embora a intervenção breve tenha efeito na diminuição do consumo do álcool, a entrega de folheto informativo também pode induzir mudanças de comportamentos relativos ao consumo, basta abservar a diminuição no escore após o primeiro mês no grupo controle. Ainda que essa diminuição não tenha sido sustentada por seis meses, é cabível refletir sobre o contexto comunitário onde acontece a vida cotidiana dessas pessoas e, o consumo de álcool é um hábito comum e onde todas orientações dadas aos participantes durante as ações para diminuir o consumo (IB e entrega de folheto), com o tempo, podem ter sido relegadas a um segundo plano por sentirem não serem mais participantes da pesquisa e a leitura do folheto deixar de ser novidade. Para os participantes do grupo intervenção, embora não haja evidência de diferença significativa, o processo de mudança foi mais demorado, e creditamos isso a intervenção, uma vez que a diminuição no escore do AUDIT depois de seis meses ainda foi observada, como mostrado na Figura 6.

Sobre a interação entre os grupos e o tempo na amostra simulada, a amostra de 30 e 100 participantes mostrou significância, quando com 30 participantes $(\mathrm{p}=0.019)$ interação grupo $\mathrm{T}_{0}$ e na segunda medida $\left(\mathrm{T}_{1}\right)$ com os 100 hipotéticos participantes a interação $\mathrm{T}_{0}$ e $\mathrm{T}_{1}$ teve $\left.\mathrm{p}=0.000\right)$.

\section{Resultados qualitativos}

Os dados provenientes do áudio das intervenções e das entrevistas finais realizadas com os participantes do grupo intervenção compuseram o material qualitativo. O corpus neste estudo é composto por 12 unidades de contextos iniciais (UCI), constituídas pelas falas dos 12 participantes do grupo intervenção. Esses dados foram processados em três classes pelo software Alceste: classe 1, 2 e 3. Conforme podemos ver na figura 7. Na análise do corpus pelo Alceste, foram analisados $74 \%$, com riqueza de palavras de $94.05 \%$. 


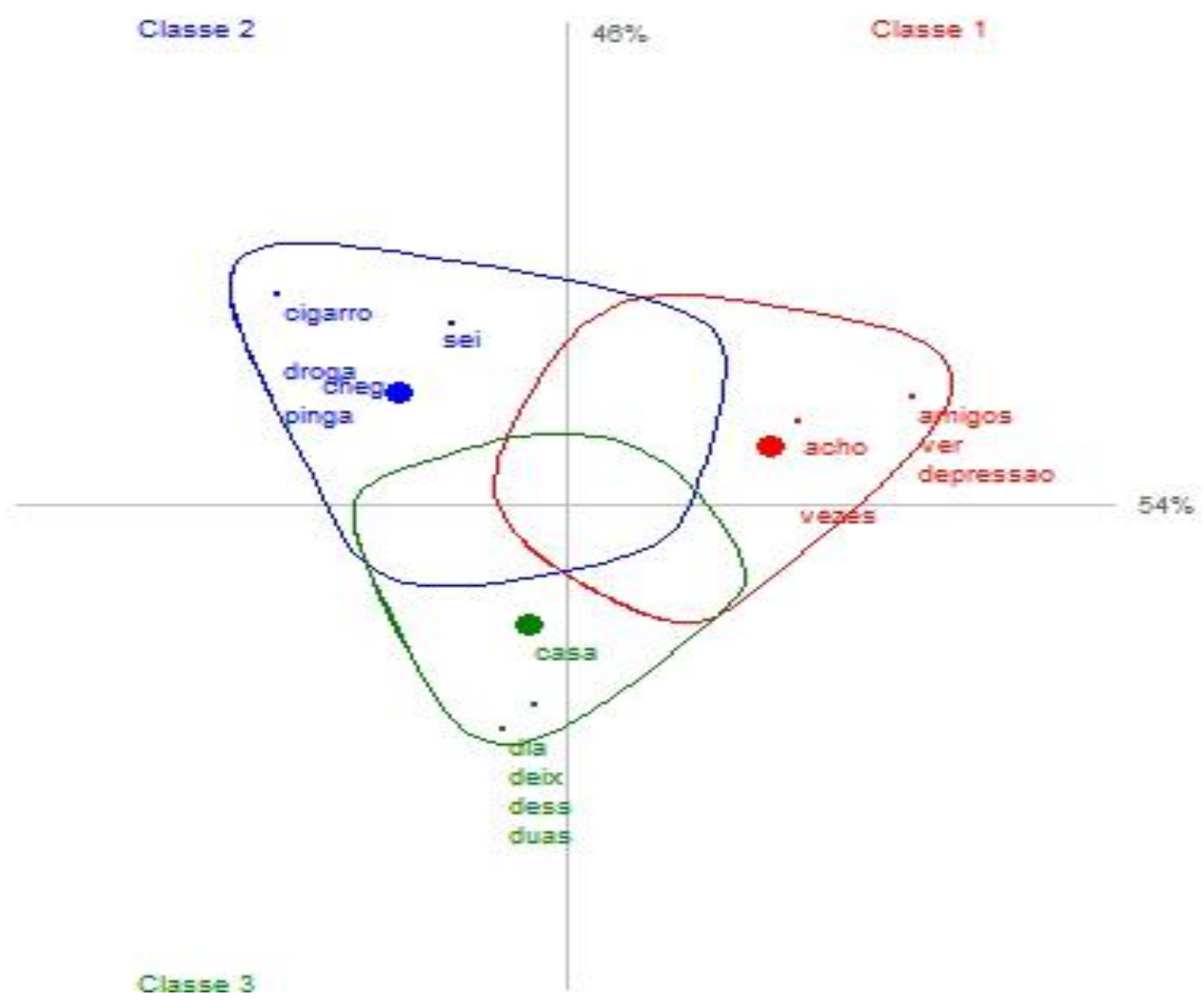

Figura 7. Análise de correspondência coordenada (AFC) apresentada pelo Alceste.

Na figura acima, o programa Alceste evidencia a classificação das três classes, bem como possibilidades de confluência de pontos de palavras comuns às classes, que nesse caso não foi observado. A classificação hierárquica descendente, ou o dendograma, como se observa na figura 8 , refere-se às características (palavras agrupadas) das classes e o teste Chi-quadrado. 


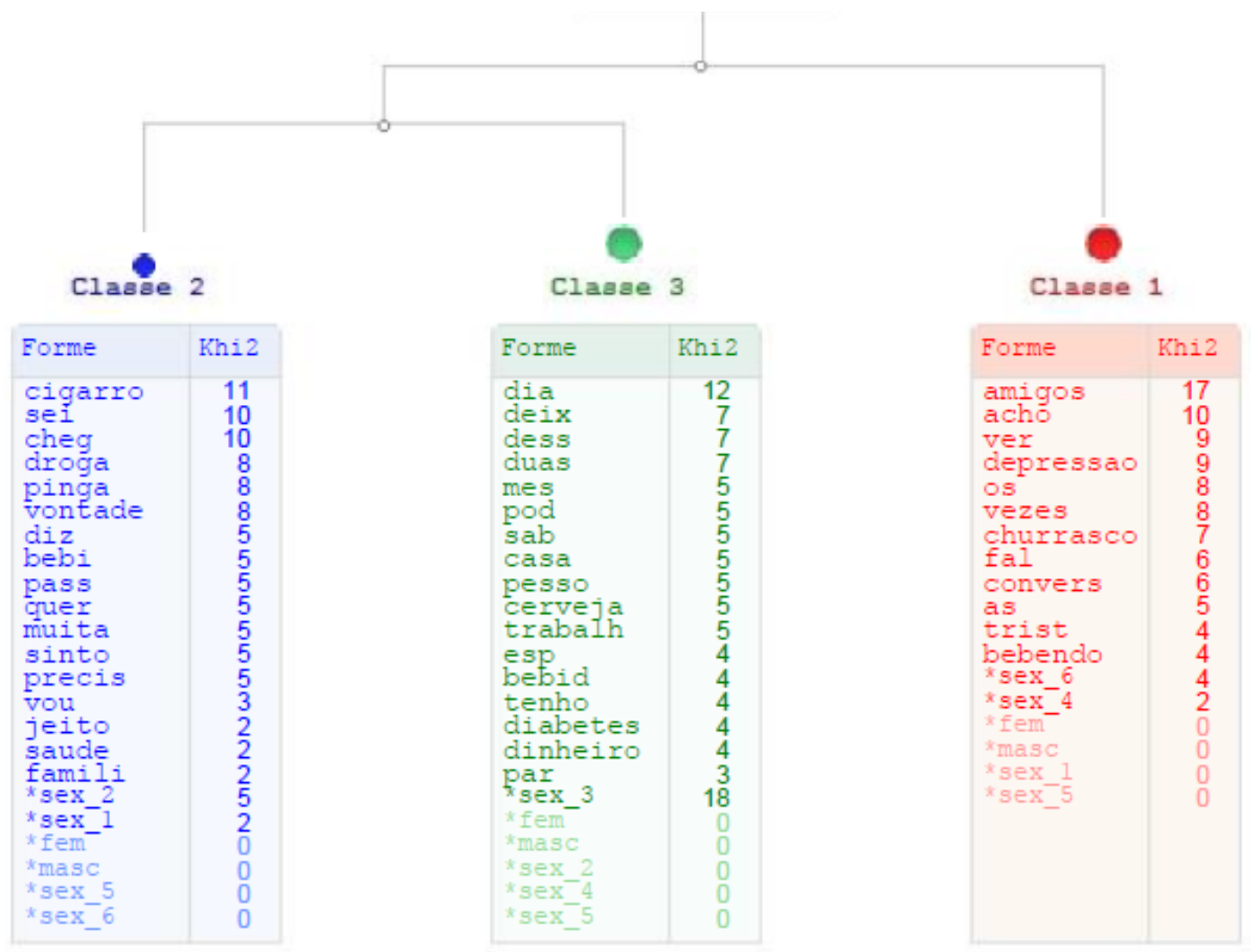

Figura 8. Classificação hierárquica descendente (dendograma) do corpus analisado.

Na classe 1,33\% da análise, referiu-se ao "contexto geral do beber, as pessoas e ocasiões que promovem ou desestimulam o beber", onde os estímulos podem ser encontros com os amigos, os sentimentos negativos (tristeza, depressão principalmente) vivenciados antes consumo de álcool e as relações sociais, onde o beber álcool está sempre presente. Conteúdo derivado das falas em que o teste qui-quadrado $\left(\mathrm{Chi}^{2}\right)$ apontou maior associação com as seguintes palavras: amigos $\left(\mathrm{Chi}^{2}=17\right)$, acho $\left(\mathrm{Chi}^{2}=10\right)$, ver $\left(\mathrm{Chi}^{2}=9\right)$, depressão $\left(\mathrm{Chi}^{2}=9\right)$, churrasco $\left(\mathrm{Chi}^{2}=7\right)$, triste $\left(\mathrm{Chi}^{2}=4\right)$, bebendo $\left(\mathrm{Chi}^{2}=4\right)$.

As falas envolvem ocasiões que promovem encontros e socialização como reuniões com amigos em que as conversas levam ao estímulo de beber (no bar, em churrascos), predominam os sentimentos negativos que estimulam o beber (tristeza, depressão). Para esse grupo, usar drogas foi um dispositivo para aplacar sentimentos negativos e gerar sentimentos positivos, tais como alegria ou felicidade, ainda que passageiros.

Às vezes, beber estar também associado à disponibilidade de bebida ou à "pressão" de amigos e a estratégia encontrada pode ser evitar os espaços sociais onde o álcool está presente ou o encontro com os amigos. O relato de conversas que podem auxiliar na reflexão sobre o consumo e o 
propósito deste também foi lembrado. "Às vezes", foi um termo utilizado pelos participantes para referir-se às situações de frequência de consumo de bebidas alcoólicas e ocasiões em que “extrapolavam" no consumo devido à influência da ocasião ou dos amigos.

Às vezes eu bebo por causa da tristeza, para esquecer... Fim de semana, às vezes, você extrapola, no meio dos amigos, no churrasco, bebendo com os amigos... uma coisa leva à outra. Uma pessoa fala "toma mais um, toma mais um...

O “às vezes" também pode estar associado à condição de não consumo quando isso se vincula à presença de sintoma de doença.

Às vezes, minha pressão aumenta ou por causa do diabetes, porque eu tomo remédio para diabetes... aí eu não bebo

À classe 2 correspondeu $28 \%$ da análise e fez alusão ao indivíduo "estar dependente de drogas em geral", não somente de álcool, situando o consumo de todas as substâncias num mesmo contexto prejudicial. Inclusive, entre o cigarro e o álcool os participantes se posicionaram considerando o cigarro como mais prejudicial, talvez para justificar ou amenizar o seu consumo de álcool. Parece que o disparador para o consumo se relaciona com os sentimentos negativos (ira, raiva e tristeza). Também parece haver consciência de que o uso pode gerar problemas de saúde ("estar se matando"). A dificuldade em lidar com a vontade de beber ("chego e bebo"), de buscar ajuda ("preciso"), ter controle, de lidar com a abstinência e não conseguir sair do lugar relacionouse a "ter opinião", e ser responsável por si mesmo nessa relação com as drogas. Reconheceram a necessidade de acompanhamento, de parar a ponto de um indivíduo relatar como alternativa mudar de casa para não ir ao bar.

As palavras que descreveram essa classe foram cigarro $\left(\mathrm{Chi}^{2}=11\right)$, sei que " $\mathrm{faz}$ mau" $\left(\mathrm{Chi}^{2}=10\right)$, “chegar e beber" $\left(\mathrm{Chi}^{2}=10\right)$, droga $\left(\mathrm{Chi}^{2}=8\right)$, pinga $\left(\mathrm{Chi}^{2}=8\right)$, vontade $\left(\mathrm{Chi}^{2}=8\right), \mathrm{diz}$ $\left(\mathrm{Chi}^{2}=5\right)$, bebi $\left(\mathrm{Chi}^{2}=5\right)$, querer ajudar $\left(\mathrm{Chi}^{2}=5\right)$.

Apareceu o consumo de drogas no geral, principalmente o álcool e o tabaco, a vontade de consumir e fica ainda explícito, o desejo e a necessidade que os participantes têm de outras pessoas aprovarem ou os orientarem quanto ao consumo. 
Por volta das 11:30 da manhã que me dá vontade de beber, depois que passou esse horário, acabou [a vontade]

A mesma coisa o cigarro, eu sei que está me fazendo mau, eu preciso parar, eu posso ter um controle, eu consigo ficar sem beber, mas como faço para estabelecer esse limite?

Você [pergunta para pesquisadora] não acha que eu estou bebendo menos?

Quanto à classe 3, maior classe com 39\%, referiu-se ao indivíduo no tocante à "frequência, quantidade e abandono do consumo". As palavras com mais forte associação, mostrado pelo Chi ${ }^{2}$ foram dia $\left(\mathrm{Chi}^{2}=12\right)$, deixar $\left(\mathrm{Chi}^{2}=7\right)$, associado à questão de deixar de beber ou deixar a bebida, desse $\left(\mathrm{Chi}^{2}=7\right)$, duas $\left(\mathrm{Chi}^{2}=7\right)$, mês $\left(\mathrm{Chi}^{2}=5\right)$, pode $\left(\mathrm{Chi}^{2}=5\right)$, sábado $\left(\mathrm{Chi}^{2}=5\right)$, casa $\left(\mathrm{Chi}^{2}=5\right)$, pessoas $\left(\mathrm{Chi}^{2}=5\right)$, cervejas $\left(\mathrm{Chi}^{2}=5\right)$, trabalho $\left(\mathrm{Chi}^{2}=5\right)$.

Nessa classe as justificativas para não deixar de beber ou parar foram colocadas em comparação com a quantidade de beber dos outros, o beber foi visto como forma de lazer possível por limitação do dinheiro ("beber em casa" ou em local de menor custo) ou limitação física (não pode sair de casa), beber também foi percebido como o lazer possível. As falas remetem ainda a uma "auto negociação" para parar o consumo "um dia vou parar...", ao gasto de recursos que envolvem o consumo e à situação financeira dos participantes que, sem possibilidades para outras formas de lazer, encontram no álcool uma opção. Outro aspecto presente nessa classe relaciona-se às doenças ou sintomas que os participantes mencionaram ter, estão relacionadas ou pioram com o consumo [O médico do serviço sempre joga na minha cara que eu bebo e tenho diabetes], isso levou alguns a refletir sobre a necessidade de parar ou diminuir o consumo. A comparação com pares, na maioria das vezes feita para justificar um relato de consumo dito moderado de álcool também foi incluída nessa classe.

Na quarta não bebi porque não tinha dinheiro. Se tivesse bebia duas, três latas... Eu tenho diabetes e sempre o pessoal do serviço de saúde diz para eu diminuir o consumo [de álcool]

Então, não temos dinheiro para sair, para fazer outras coisas

Quanto à comparação com os pares, isso muitas vezes pareceu estar relacionado a um beber num padrão supostamente "normal”, já que era praticado pelas pessoas com quem se relacionavam e foi compreendido como um padrão que não havia causado problemas à saúde ou família, fato que muitas vezes observavam nos seus pares. Inclusive houve registros de falas em que os participantes 
afirmaram que seu padrão de beber era "abaixo da média" de seus companheiros. Durante as intervenções esses participantes foram orientados que o dano devido ao uso de álcool não é percebido rápido e nem está tão diretamente ligado ao consumo. 
DISCUSST̃̃ 


\section{Discussão}

A demanda de usuários de álcool no contexto primário é frequente, porém esses usuários são comumente relatados pelos profissionais como difíceis de serem acompanhados, por apresentarem maior mobilidade territorial, o que dificulta o planejar e realizar intervenções específicas. Talvez por essas questões, os usuários de álcool são pouco assíduos aos serviços de saúde e também, possivelmente, devido ao caráter crônico e oscilante dos problemas apresentados em decorrência do uso e abuso de álcool. McLellan et al. (2000) destacaram esse caráter crônico como motivo para as dificuldades de seguimento, tratamento e manutenção dos resultados, pontuaram ainda que, desta forma, as intervenções precisam ser mais estruturadas e contínuas para que se possa obter resultados mais satisfatórios.

\section{Caracterização}

Quanto à média de idade do estudo, 48,2 anos, foi semelhante à faixa etária onde o consumo de álcool foi considerado maior em inquéritos sobre o consumo na APS. No inquérito domiciliar de Jomar et al. (2015), realizado na cidade do Rio de Janeiro, a faixa etária de usuários de álcool foi semelhante ao da pesquisa atual, porém com diferença quanto a predominância de gênero, algo que pode ser justificado pela forma de recrutamento (visita domiciliar) pois, nesse espaço territorial vigora a constituição ainda patriarcal da maior parte das famílias, o que justifica serem as mulheres as mais encontradas em domicílio em expedientes de trabalho. Neste estudo, embora o contato primário com os participantes fosse por visita domiciliar, a indicação inicial dos domicílios partiu do serviço de saúde.

A perda de participantes na amostra inicial (foram indicados inicialmente 104 potenciais participantes pelos serviços, referidos como usuários problemáticos de álcool) dificulta predizer que o perfil da amostra é semelhante a da população usuária de álcool da área geográfica dos serviços de saúde contactados.

Os aspectos como gênero, poucos anos de estudo e o alto padrão de consumo foram confirmado em outra pesquisa no Brasil (JOMAR et al., 2015). No que se refere aos anos de escolaridade, parece que o dado do atual estudo é ligeiramente maior ao da condição da população geral do Brasil, em que a maioria das pessoas possui poucos anos de estudo, segundo o Relatório do Desenvolvimento Humano do Programa das Nações Unidas (2015) uma média de 7,7 anos de estudo (PNUD, 2015). 
A baixa escolaridade foi inclusive associada fortemente com o consumo nocivo, acrescidos dessa variável com o gênero masculino (ABREU et al., 2011). Entretanto, a incapacidade intelectual, presumida a partir dos poucos anos de estudo foi apontada por Kouimtsidis et al. (2015) como um indicativo para uso de IB na redução do consumo de álcool.

A idade é um fator que deve ser considerado em estudos sobre álcool, sobretudo porque faixas etárias extremas como crianças, adolescentes e pessoas em idosas são mais vulneráveis aos danos decorrentes do uso abusivo, embora não seja a faixa de maiores consumidores (WHO, 2014). No atual estudo existe um grupo de participantes que se situa na faixa etária de idosos (sete participantes com idade maior ou igual a 60 anos) e, portanto, é um dado que merece atenção.

Quanto ao número de mulheres (apenas sete), isso pode ser justificado também pela associação do uso de álcool ao gênero masculino e pelo fato dos serviços não perguntarem como rotina se as mulheres fazem uso de álcool. Além disso, ser do gênero masculino ainda está fortemente implicado com situações de lazer onde o álcool é parte central e componente da manifestação cultural de masculinidade e aceitação social nesse gênero (MENDOZA, 2004). Cabe ressaltar que o consumo crescente de álcool dentro da população do gênero feminino deve chamar atenção dos serviços para rastreio e acompanhamento também entre mulheres.

No que se refere à bebida de escolha, a cerveja predominou, como evidenciado nos relatos e nos resultados do Diário de consumo de álcool. Isso é corroborado pelos resultados do estudo nacional sobre o consumo de álcool (LARANJEIRA et al., 2012), que apontam também a cerveja como a bebida alcoólica mais consumida. Este é um importante dado porque algumas associações de danos à saúde são mais fortes dependendo da escolha de bebida para o consumo. Por exemplo, no estudo de coorte de Smyth et al. (2015) o consumo de bebidas destiladas apresentou riscos mais elevados de mortalidade, acidente vascular cerebral, câncer e admissões hospitalares quanto comparados com pessoas que bebiam vinho ou cerveja, caso mais frequente da amostra deste estudo.

Além disso, destaca-se que o consumo de álcool não está ligado apenas às preferências pessoais, mas, às tradições culturais também, como enfatizou Koski-Jännes, Pennoen e SimmatDurand (2016) ao explicar as opções de bebidas alcoólicas mais consumidas entre Finlândia e França. Ainda sobre a bebida de escolha para consumo, Shield et al. (2015) já evidenciou que a bebida mais popular na Américas é a cerveja (55, 2\% de todo o consumo registrado), seguido por destilados $(31 \%)$ e vinho $(13,4 \%)$. Fato corroborado no atual estudo, tanto nos resultados obtidos mediante a análise quantitativa como na qualitativa, conforme evidencia a fala abaixo. 
Bebo muita cerveja... nem sei o quanto bebi...

Especialmente quanto ao consumo de vinho é interessante frisar que, embora haja estudos em que os bebedores de vinho tenham apresentado risco menor para doenças cardiovasculares (infarto, por exemplo) se comparados com os não bebedores, há pesquisadores que recomendam cautela, haja visto que na maior parte das vezes esse efeito é ocasionado em regiões onde o consumo é moderado e sem ocasiões que propiciem o consumo pesado, sendo esse benefício restrito a pessoas mais velhas, caso contrário o efeito produzido pelo consumo tende a ser prejudicial, dada a carga positiva sobre a pressão sanguínea e, como consequência, ao acidente vascular hemorrágico (REHM el al., 2009, KNOTT el al., 2015).

Além disso, a relação de consumo de álcool e câncer leva à cautela quanto às recomendações de uso para qualquer bebida alcoólica, pois medidas de saúde pública para diminuir o consumo do álcool podem prevenir câncer, dado que 5,5\% dos cânceres e 5,8\% de todas as mortes por câncer no mundo, no ano de 2012, foram atribuídos ao álcool (PRAUD et al., 2015).

Quanto às doses consumidas, esse dado é importante porque, ainda que se saiba que o álcool foi o terceiro fator causador de incapacidades no ano de 2010 (WHO, 2014), a velocidade do desenvolvimento de doença ou incapacidade pode estar diretamente relacionada ao padrão de uso do álcool (VAN DE WIEL; DE LANGEW, 2008; BRITTON; McKEE, 2000). Assim, a variabilidade quanto à quantidade de doses ingeridas por semanas $(\mathrm{GI}=29,5 ; \mathrm{GC}=47,1) \mathrm{e}$, consequentemente, mensais $(\mathrm{GI}=118 ; \mathrm{GC}=188,4)$ nos dois grupos deste estudo, leva a pensar no fácil acesso e disponibilidade do álcool para esses participantes, o que remete à própria composição territorial da comunidade na qual os participantes estavam inseridos com a presença considerável de venda de bebidas alcoólicas, carência de espaços públicos para lazer ( praças com dispositivos para recreação ou centros comunitários), e de apoio comunitário (grupos de convívio, oficinas de saúde). A falta de espaços protegidos pode estimular formas de lazer como festas realizadas por grupos, cujo interesse não seja a saúde da população, ou participar de encontros com amigos usuários abusivos de álcool.

A sequência de menções dos participantes, mostra um consumo em que os mesmos perdem a noção do quanto ingerem de álcool, esse dado mais os relatos sobre o contexto geral onde ocorria o beber (classe 1) confirmam as colocações feitas anteriormente, através da ocorrência frequente das palavras que reportaram a esse contexto (“amigos", "acho", "ver", "churrasco"):

Fim de semana às vezes você extrapola, no meio dos amigos, no churrasco, bebendo com os amigos uma coisa leva à outra. 
$\mathrm{Na}$ amostra, preocupou o alto consumo semanal e, consequentemente, mensal, o que leva a pensar que nos próximos anos os serviços participantes do estudo terão pacientes em seguimento com possível incapacidade e comorbidade associadas ao abuso de álcool. Altas doses certamente contribuirão para o aparecimento de doenças como câncer, sobretudo de fígado e pâncreas, diabetes, doenças neuropsiquiátricas, doenças cardiovasculares, infecções, injúrias intencionais e não intencionais (REHM, 2011). No presente estudo, um dos participantes do gênero masculino cujo consumo era um dos mais elevados, estava em tratamento para câncer de mama o que, ainda que de forma isolada, corrobora os dados de estudos epidemiológicos.

É importante incluir no rastreamento, o hábito do consumo porque as consequências diferem quanto a esse aspecto, a exemplo do padrão binge de consumo que pode ser danoso para saúde, conforme demonstrou o estudo de coorte de Laatikainen et al. (2003) ao evidenciar que o consumo de seis ou mais doses na mesma ocasião aumentou a mortalidade por todas as causas, como doenças isquêmicas cardíacas e causas externas, quando comparado com bebedores pesados sem ocasiões de binge. Afshar et al. (2015) relataram em seus achados, que um episódio abusivo de álcool foi suficiente para modificar o sistema imunológico provocando, a priori, um estado de processo inflamatório e, em seguida, um processo anti-inflamatório. Do ponto de vista social, altas doses de álcool consumidas podem ainda contribuir com as aposentadorias por invalidez entre adultos de meia-idade (SALONSALMI et al. (2012), certamente os problemas de saúde mencionados devem estar na origem dessa condição.

Alguns hábitos e fatores presentes no estilo de vida e passíveis de modificação, como obesidade, nutrição inadequada, sedentarismo, fumo e excesso de consumo de álcool são as causas de maior morbi mortalidade no mundo (LOPEZ et al., 2006, REHM et al., 2009), embora sejam difíceis de serem modificados. Porém, devido à sua forte contribuição para o conjunto das doenças crônicas, esses fatores deveriam ter uma ênfase maior da atenção primária à saúde, uma vez que a não intervenção prévia nessa população ocasiona o seu retorno posteriormente com maior gravidade para o contex to de cuidado primário e/ou secundário.

O material proveniente da análise qualitativa mostrou que para a amostra deste estudo, a afirmação sobre as doenças crônicas se aplica dado que usuários relatam estar cientes de possuir tais problemas de saúde e isso endossa a necessidade dos serviços de APS, reforçarem a iniciativa e procedimentos (consultas e exames clínicos, por exemplo) para identificação precoce. 
Além do usuário que apresentou câncer, as palavras retiradas das falas e pontuadas como relativas ao abandono do consumo ("dia", "deixar", "duas") inserem-se no contexto das justificativas para diminuir (ou não) ou parar.

O médico joga na minha cara que eu bebo e tenho diabetes.

No dia que eu morrer eu deixo.

Eu tenho problema de cirrose, mas não tenho diabetes, todo mundo fala para eu deixar.

Em relação ao lazer, evidenciado na classe 2, as palavras também estavam associadas às razões para não interromper o uso e mostram o consumo como uma forma de lazer, presente nas falas abaixo.

Eu e meu esposo bebemos juntos, não temos lazer, não temos parentes, não temos nada

Toda vida tinha outras coisas para fazer, agora nossa vida está reduzida a ficar em casa, cuidando da minha esposa

Ressalta-se que mesmo ante relatos de lazer associados ao uso, faz-se necessário incentivar a compreensão dos usuários sobre outras opções de entretenimento, além disso, cabe aos serviços de saúde a inclusão de procedimentos como rastreamento como uma das formas possíveis de fomentar essa discussão com os usuários de álcool e ampliar os vínculos com eles no intuito de desenvolver o suporte social através de estratégias de apoio, como maior número de visitas ou promoção de grupos de auto ajuda. Enfim, mostrar para a população usuária de substâncias psicoativas a importância do serviço de saúde.

Dado o relato da falta de prática de lazer ou outras atividades prazerosas e o uso disto como uma justificativa para o consumo, parece oportuno lembrar que o potencial para uso de substâncias e problemas relatados são maiores quando os valores individuais de recompensas são maiores, ou seja, quando o beber está associado a uma prática prazerosa, o que quer dizer que usuários com poucas disponibilidades e espaços de convivência livres de consumo de álcool serão mais atingidos pelo danos do consumo e, mais que isso, terão mais resistência a ações de intervenção (MURPHY et al., 2015). 
Outra questão a se ressaltar é a localização geográfica onde as famílias dos participantes estão inseridos, a qual é de população de baixa renda e embora os dados quanto à renda não tenham sido coletados, presume-se o baixo rendimento financeiro mensal. Esse dado tem o potencial para aumentar o impacto social e na saúde quanto à relação com uso de álcool. No nível de saúde mental esse dado é mais preocupante ainda porque torna esses usuários mais dependentes de cuidados de saúde pública, aumentando os custos de saúde para a referida região. Além disso, esse perfil sociodemográfico preocupa sobretudo porque, pobreza social, contexto social violento, caracterizado por excassez de opções de lazer e de apoio social, acompanhada por baixo desenvolvimento econômico, aumenta as taxas de morbi mortalidade atribuídas ao consumo de álcool (WHO, 2011). E ainda, sabe-se que o consumo regular alto é mais frequente em áreas com característicias sociais em desvatagem (SILVEIRA et al., 2014), tal qual a área de APS em questão.

A mobilidade de moradia dos participantes deste estudo não encontrados em domicílio em razão de mudança de residência (19 do GC e 14 GI), pode ser explicada devido à dificuldade de manutenção de emprego e renda, daí a necessidade de deslocamento para adequar a moradia à seus rendimentos. A dificuldade de emprego por usuários de álcool foi apontada em revisão de literatura por Sutton et al. (2004) devido, principalmente, a seis motivos: baixo nível educacional ou de habilidades, problemas físicos ou mentais, barreiras pessoais e interpessoais, lacunas em serviços de apoio e diversas formas de privação (como o próprio desemprego, a pobreza, degradação de habitação e crime).

Resultado de estudo (MANGIONE, et al., 1999), mostrou que a falta de lazer decorrente de problemas financeiros, esteva associada à redução da habilidade ao trabalho. Além disso, Hansen et al. (2015), argumentam que a população usuária de álcool é, sabidamente, difícil de se colocar no mercado de trabalho e manter o emprego. Os mesmos autores destacam que na Dinamarca um programa de emprego voltado para usuários de álcool não levou em consideração que as razões do consumo eram mais profundas e considerou o uso apenas como um problema individual, sendo esse fato um obstáculo para a recolocação do sujeito no mercado de trabalho.

A questão do trabalho propriamente dita na amostra de usuários, não apareceu na análise qualitativa como um ponto relevante, mas surgiu na classe "frequência, quantidade de bebida consumida" (classe 3), mais relacionada ao fato do consumo ser facilitado pelo usuário não ter compromisso com o trabalho (aposentado).

Não tem um compromisso com o trabalho... não tem aquela hora marcada eu vou beber ao meio dia, às vezes às 11 horas... quando eu quiser... 
Também apareceu a questão custos do consumo como um fator que os usuários percebem e se preocupam.

Não bebi porque não tinha dinheiro, senão bebia duas, três latas...

Você gasta muito dinheiro... compro minha bebida num depósito de bebida, fica mais

barato

Neste grupo, alguns poderiam se beneficiar, caso estivessem desempenhando um trabalho, já outros, se tivessem mais posses, aparentemente aumentariam seu consumo, inclusive buscavam estratégias para manter o seu padrão de consumo, mesmo com menos recursos financeiros.

O padrão binge de consumo já foi reportado em vários levantamentos e, no Brasil, foi verificado que entre os bebedores de álcool, 29\% relataram beber 5 ou mais bebidas por ocasião (LARANJEIRA et al., 2010). Na amostra do atual estudo também foi observado padrão binge de consumo (relatado na classe 3 dos resultados qualitativos), evidenciado nas palavras "sábado", “casa", "cerveja", "trabalho”, presentes em falas de usuários que revelavam sua forma de beber.

No sábado você bebe mais, no domingo bebe menos para poder ir trabalhar na segunda

Com relação ao número de pessoas com quem moravam, nesse estudo supõe-se que os participantes possuíam relativo apoio, pois dos 23 participantes, apenas três moravam sozinhos. No estudo de Litt, Kadden, Tennen (2005) o suporte de rede foi avaliado com uma estratégia para ajudar os usuários de álcool a interromper o consumo. No que se refere às diferenças de gênero nesse aspecto, os mesmos autores destacam que a mulheres tiveram maior tendência a preservar redes sociais mal adaptadas e, por isso, tinham baixa eficácia para redução do consumo. No estudo de MOVANDADI et al. (2015), uma análise secundária com participantes de estudo clínico usuários de álcool, mostrou que participantes com alto suporte social diminuíram o número de dias de beber pesado ao longo do tempo. Ressalta-se que problemas de relacionamento, que dificultam o estabelecer vínculos para apoio social, são esperados nessa população, principalmente porque usuários ativos de álcool por si só já se encontram em condições ativamente estressantes (DOBKIN et al., 2002).

No presente estudo os usuários aparentemente, tinham suporte social, ao menos a maioria relatou convívio (e consumo) com familiares. Entretanto a análise qualitativa de dados possibilitou 
identificar detalhes desse suporte, na classe "frequência e quantidade do consumo" (classe 3) e “estar dependente de droga" (classe 2), presentes nas falas em que justificavam o parar:

Eu estou me matando por causa disso (do consumo de álcool) e minha família está pensando em mudar para um apartamento, eu vou ter que chegar de outro jeito e não vou poder ir para o bar, é mais longe, vou ter que chegar em casa de outro jeito, é outro estilo de vida.

Não pode esquecer a responsabilidade de casa e do trabalho. Tem pessoa que bebe, maltrata a família e os filhos, se torna agressiva, eu não.

Nas duas menções dos usuários é revelada uma aparente preocupação com os familiares, mostrada através da consciência da necessidade de mudar (inclusive de espaço físico) sua vida (a primeira), da necessidade de ter parâmetros de controle para não esquecer suas obrigações e para não extrapolar comportamentos (a segunda).

\section{Intervenção}

No processo de intervenção utilizou-se a aplicação do diário de consumo, em todos os encontros previstos na aplicação da IB. O material obtido a partir dele possibilitou caracterizar o modo de beber dos usuários, dado que mostrava a frequência, quantidade, as ocasiões e os sentimentos que o usuário experimentava no beber.

No tocante aos resultados do diário de consumo de álcool, verificou-se que na sua maioria, o consumo era um hábito, associado ao modo de viver o dia-a-dia, pois no geral, não havia um padrão abusivo por ocasião ou dia específico de maior consumo. Sobre os possíveis sentimentos que eram disparadores para a procura do álcool, verificou-se um predomínio do "beber automático". A esse respeito, Lac e Donaldson (2016) apontaram os motivos relacionados ao coping emotivo, o beber para manejar sentimentos negativos, esquecer problemas ou evitar aborrecimentos e esses, como mais conectados ao hábito de beber pesado. Quanto ao beber moderado, os autores relatam estar mais associado ao conformity motives ou beber com os pares, pois existe nesse contexto a sensação de ser controlado por pessoas ou contexto externo. Para Cox et al. (2014) beber ou usar outras drogas em excesso vem acompanhado de um objetivo, ainda que muitas vezes não consciente. 
De certa forma, como já apareceu em algumas falas, os participantes da pesquisa revelaram um beber similar, pressão para que bebam em ocasiões festivas e locais que frequentam porque os amigos bebem, assim, o beber ocorre na sua presença.

As informações obtidas no presente estudo, em relação aos sentimentos parecem corroborar com os resultados obtidos pelos dois estudos citados anteriormente (LAC; DONALDSON, 2016; COX et al., 2014).

Também o conhecer os sentimentos, como se propôs no estudo atual, revelou os motivos do uso da bebida associados aos sentimentos negativos, como tristeza, depressão ou ainda o uso para estimular aspectos positivos, bem menos frequentes, daí as seguintes menções que forneceram as palavras "depressão", "triste" que orientaram a classe "ocasiões que promovem ou desestimulam o beber" (classe 1) e que incluem os motivos.

Estava triste e bebi para ficar mais alegre.

Ás vezes bebo por causa da tristeza, para esquecer... Acho que é depressão, não tristeza (o motivo que leva a beber).

Contrapõe-se à afirmação do estudo de Lac e Donaldson (2016) sobre o controle exercido pelos pares, dado originado pela análise qualitativa que revela a capacidade de superação do usuário. $\mathrm{Na}$ classe "ocasiões que promovem ou desestimulam o beber", através de palavras "amigos", "churrasco" presentes nas falas que se reportam às mesmas ocasiões promotoras do beber, apareceu como os usuários desenvolveram estratégias de driblar os amigos, pois perceberam que nesses momentos ocorre o consumo excessivo.

Você precisa passar do seu limite.

Eu tenho evitado sair, ir para churrasco para não beber...

Eles (os amigos) me ligam, me chamam para ir e eu falo uma desculpa, digo que vou ficar em casa.

Pelo exposto, na tentativa de reduzir fatores de risco comportamentais, uma ampla gama de intervenções faz-se necessária, sejam essas intervenções políticas, ambientais ou dos próprios 
serviços de saúde locais. Nesse sentido, os serviços de cuidados primários são adequados na atuação da diminuição de riscos comportamentais (CHAN, 2013).

Dentre os procedimentos utilizados neste estudo para realizar a intervenção, destaca-se o AUDIT como instrumento de avaliação inicial e final do consumo de álcool dos usuários. Um fator a considerar seriamente, e que já é debatido há longo tempo em pesquisas sobre consumo de álcool (Babor et al., 1987) diz respeito à variável resposta de muitos estudos por serem auto relatadas, como na atual pesquisa, visto que as perguntas sobre o AUDIT foram totalmente dirigidas ao usuário e, portanto, dependentes da sua memória e capacidade de evocar o quanto consumiram. Babor et al. (2000) argumentaram que as medidas auto referidas em estudos sobre álcool podem ser tão acuradas quanto testes biológicos, embora seja prudente associar variadas medidas como forma de certificar os resultados de estudos clínicos.

No estudo de Nirenberg et al. (2013), cujo objetivo foi justamente avaliar as diferenças de escores em um grupo que recebeu como técnica terapêutica a entrevista motivacional e outro que recebeu atendimento de rotina em serviço comunitário, e submeteram ambos a teste e reteste para verificar o escore do AUDIT, o grupo que recebeu entrevista motivacional obteve escores mais altos de AUDIT, possivelmente devido a própria experiência de tratamento, onde o vínculo e aliança terapêutica possibilitaram ao usuário responder com honestidade quanto ao relato do consumo de álcool.

No atual estudo esse dado pode ser amplificado, visto que nos seguimentos as médias do AUDIT $\left(T_{0}, T_{1}\right.$ e $\left.T_{2}\right)$ foram maiores que os do grupo controle, onde o contato foi mínimo e a medida final foi realizada por um membro diferente para evitar viés. Sobre as doses por semana registradas no Diário de consumo de álcool, os participantes do grupo de controle reportaram mais doses consumidas que o grupo intervenção. Esse fato parece ser também justificado pela questão do vínculo criado com esse grupo de participantes que, se por um lado a ausência da pesquisadora melhora a fidedignidade da aplicação de instrumentos, no caso AUDIT, por outro pode levá-los a não relatarem as reais doses consumidas durante a semana por sentirem necessidade de aprovação da pesquisadora ou para cumprirem a suposta expectativa da mesma de redução de consumo.

Sobre a variação na média de escores de AUDIT, comparando grupo controle e grupo intervenção, possivelmente ela se deve a dificuldade de manter o padrão comportamental de mudança, sobretudo porque no comportamento de uso de drogas lapsos e recaídas são esperados. Assim, diminuir o consumo é algo possível, mas a manutenção da mudança é uma tarefa difícil, como fica claro nos resultados obtidos da análise qualitativa na classe "estar dependente de droga" 
(classe 2), onde os participantes evidenciaram a dificuldade de ter controle, de lidar com a ausência do consumo e a necessidade de "ter opinião" para manter ou começar a mudança.

Tem que ter muita força de vontade, senão não consegue.

Está no tempo de diminuir, ainda dá tempo... já tentei uma época, cheguei a ir a palestras, mas você não sai do lugar... conversa, conversa e chega na esquina e vai parar no bar...

Mas tem a abstinência, você sabe, se você ficar sem, não tem jeito, você vai atrás...

Depende do meu propósito, da minha vontade de falar que não vou beber e eu não beber... Acho que consigo estabelecer uma meta na semana para diminuir o consumo

Os relatos evidenciaram o peso que os usuários atribuem a si mesmos na responsabilidade por diminuir ou interromper o consumo, como se o uso da bebida fosse uma opção unicamente da sua vontade, aparentemente não considerando outros fatores. Isso transforma a ação de mudar em um empreendimento extremamente difícil, por ser solitária e carregada de culpa.

Embora a IB tenha demonstrado efetividade na redução do consumo de álcool, uma revisão qualitativa de estudos clínicos mostrou que, tanto a triagem com uso de instrumento de rastreio, como a intervenção para uso abusivo de álcool são efetivos (JOHNSON, et al., 2010).

Para Kaner et al. (2013), apesar de vários estudos sobre intervenção breve mostrarem efetividade, a intensidade e o conteúdo ideal da intervenção breve não está clara. Foram encontrados poucos estudos (KANER et al., 2013; ROY-BYRNE et al., 2014), que assumiram que a IB nem sempre acarretou em resultados positivos, pelo menos significativos estatisticamente, e sugerem cautela na adoação generalizada desse tipo de intervenção para usuários de drogas do contexto primário.

Importante ressaltar neste estudo, que a ausência de significância estatística não representou que a IB não tenha tido efeito sobre a redução no consumo de álcool, a prova disso é a redução no AUDIT no GI após os seis meses e o fato do efeito da intervenção ter sido demostrado no modelo estatístico escolhido no atual estudo. Além disso, como mencionado por Altman e Bland (1995) a ausência de evidência não significa evidência de ausência, pois a resposta para ausência de evidência pode estar, por exemplo,nas características da amostra do estudo e não só no apontado no valor de $\mathrm{p}$. 
O estudo de Rose et al. (2015) também sugere maiores investigações sobre a capacidade do usuário iniciar os questionamentos sobre o consumo e se investigar mais a efetividade de cartazes, brochuras, ou outras ferramentas possíveis. Segundo esses autores, fatores como um único contato de intervenção diminuem a eficácia da mesma.

Para Roy-Byrne et al. (2014) também a pessoa responsável pela IB é importante pois, csideram que o simples contato de intervenção ou sua execução por outro profissional, que não o médico habituado a fazer o seguimento com o paciente na atenção primária, pode diminuir a efetividade. Nyamathi et al., (2010) ressaltam que evidências mais positivas na redução do consumo de álcool são observadas quando quem faz a intervenção são profissionais que fazem parte da APS e houve estudo (KANER et al., 2013) que teve dificuldade de mostrar diferença estatística significante entre intervenção breve e grupo folheto.

Entende-se que as diferenças encontradas nos estudos sejam decorrentes da necessidade da existência de vínculo com os usuários dos serviços e estende-se essa observação para todos os profissionais da atenção primária. Aplicar a intervenção breve junto à usuários de álcool e trabalhar a relação interpessoal no relacionamento terapêutico parece ser eficiente, por isso buscou-se no atual estudo ferramentas que mimetizazem e facilitassem nas intervenções o vínculo com os usuários. Principalmente porque atender usuários de álcool deve englobar as habilidades de aconselhamento, consciência da capacidade de resposta do usuário, necessidade de re-avaliar a qualidade do relacionamento, ainda que este seja breve, e incorporar o feedback (RITTER et al., 2002). Além disso, relações terapêuticas positivas podem ser importante quando os usuários de álcool encontramse em níveis de baixa motivação para mudança (ILGEN et al., 2006), comuns em usuários de altas doses como os usuários do atual estudo.

Além disso, a consciência dos profissionais daquilo que foi postulado por Prochaska e DiClemente nos anos 80 a respeito da mudança de comportamento, demanda entender que o processo de mudança é um trabalho pessoal e dinâmico (usuários podem estar num momento mais motivados que em outro para realizar as mudanças de comportamento relacionados ao consumo), essa compreensão potencializa a ação dos profissionais, os torna mais conscientes para acompanhar e intervir no abuso de álcool. Além disso, realizar intervenção breve com esse entendimento, diminue as frustações dos profissionais da atenção primária, que no presente caso reportaram à pesquisadora muitas vezes, as frustantes tentativas de acompanhar ou intervir na população usuária de álcool.

Sobre a prontidão para mudança, como se pretendeu na pesquisa em pauta, Rose et al. (2015) também apontam a evidência de redução de consumo de bebidas semanais após seis meses 
entre aqueles que iniciaram a discussão sobre o assunto com o profissional. No grupo onde a discussão foi iniciativa pelo usuário, a redução semanal foi de 4,4 doses (18,8\%) em comparação com 3,3 doses por semana entre aqueles em que a discussão foi iniciada pelo profissional $(13,5 \%)$. Esse dado demonstrou que quando o usuário inicia a discussão, ou seja, esta em um estágio apto a mudar, ele diminui mais o consumo. Porém, o estudo também mostrou que, a diminuição no número de doses ingeridas por dia, não teve relação com quem iniciou a discussão sobre a necessidade de redução (profissional ou o próprio usuário). Isso mostra que ainda há um longo caminho a desvendar sobre os motivos que levam as pessoas a diminuir o seu consumo e mantê-lo em padrões considerados razoáveis, em termos de saúde.

Em outro estudo, os sujeitos que receberam a devolutiva da intervenção mostraram reduções consideráveis no número de dias de consumo, em seguimento por 30 dias pós-intervenção (WORDEN; McCRADY, 2013), daí as autoras considerarem que a IB demonstrou ser bemsucedida.

A respeito do número de intervenções, como já citado, os estudos não têm um consenso quanto a quantidade de intervenções e nem tampouco ao tempo de avaliação, haja visto que foram encontrados estudos com avaliações de um mês, três meses, seis meses e mesmo por períodos maiores, como no estudo de Fleming, Mundt, French (2002), realizado também no contexto de APS, onde os resultados positivos foram mantidos por um período de quatro anos após a intervenção. Contrariando esses autores, Beich et al. (2002), Babor et al. (2005), Nilsen et al. (2006) e Rose et al. (2008) mostraram nas suas pesquisas que o efeito foi modesto e de curta duração. Com relação a isso, o presente estudo não trouxe acréscimos, dado que a medida de efeito foi até seis meses.

Sobre o uso de álcool concomitante com outras drogas, uma revisão de literatura (BIEN; MILLER; TONIGAN, 1993) analisou vários ensaios clínicos comparando IB com intervenções mais alongadas para usuários de múltiplas drogas e apontou que os resultados de 11 dos 13 ensaios revisados, sugeriram que usuários submetidos a IB mostraram tanto ou mais redução no beber do que os participantes de intervenções mais extensas, além de evidenciar que a IB se mostrou mais efetiva. No mesmo estudo, conclui-se que as melhorias dos sintomas eram duradouras nesses usuários. Tal fato corrobora a adequação do estudo atual de incluir na amostra usuários de álcool e múltiplas drogas, pois a efetividade da IB parece não ter sido afetada pelo fato de alguns participantes serem usuários de outras drogas.

No que se refere ao uso de multíplas drogas, a análise qualitativa na classe "estar dependente de drogas" (classe 2), mostrou que a amostra de usuários considerou com a mesmo valor as drogas como um todo através de palavras "cigarro", "droga", "pinga" registradas nas suas falas e 
atribuiram principalmente ao tabaco, grande dificuldade em diminuir o consumo, como fica claro nestas falas:

A mesma coisa o cigarro, eu sei que está me fazendo mau, eu preciso parar.

A pinga é uma droga assim como a maconha e a cocaína... A pinga, o cigarro, se você ficar sem não tem jeito, vai atrás...

Isso pode estar associado à influencia que o uso concomitante álcool e tabaco exercem entre a população, sobretudo de jovens e idosos, tanto homens quanto mulheres pois, segundo Nacional Household Survey on Drug Abuse (NHSDA) há de fato a capacidade do uso de ambas substâncias, tabaco e álcool, se influenciarem. Outro estudo mostrou que entre jovens adultos a prevalência de uso de álcool e tabaco chegou de 35 a 45\% (ANTHONY; ECHEAGARAYWAGNER, 2000).

Pelo exposto, a abordagem da IB mostrou-se uma estratégia que pode reverter em benefício, seja na redução do consumo (ainda que em usuários de múltiplas drogas), seja como disparador da reflexão entre os usuários de álcool, na comunidade e trazer outros benefícios adicionais.

O nível de bem-estar, mensurado por Berman, Wennberg e Sinadinovic (2015) em estudo clínico, mostrou que a redução do consumo esteve associada ao aumento da sensação de bem-estar, referido pelos participantes.

Ledermann, em 1956, revelou o fenômeno percebido entre usuários que diminuiram o consumo e que denominou de "bola de neve", definindo-o como a capacidade de diminuição de consumo que um usuário de álcool pode provocar também na diminuição do consumo em familiares e amigos. Para Heather (2012) isso fica no campo da especulação como um possível aspecto positivo da intervenção breve, já que não são encontrados estudos que comparam a diminuição do consumo de álcool do sujeito com a das pessoas que compõem a sua rede de apoio. Já em direção contrária, existe estudo que relaciona o suporte social do próprio usuário com a diminuição do consumo após a IB (MAVANDADI et al., 2015).

Sobre quem deve conduzir a IB nos serviços de APS, o presente estudo mostrou que a mesma pode ser conduzido por enfermeiros, formação acadêmica da pesquisadora, mediante um programa estruturado, a exemplo do que existe na Inglaterra, pois economiza recursos financeiros (PURSHOUSE et al., 2013), e também considera-se que otimizar a capacidade potencial que esse 
profissional possui, dada sua formação, além de aproveitar o vínculo que habitualmente ele já estabelece com a população usuária dos serviços.

Assim, o desempenho não-médico deve ser considerado como uma abordagem viável com os usuários de álcool (MERTENS et al., 2015), sobretudo em países da América Latina onde o número de médicos é considerado ainda incipiente (MINISTERIO DE SALUD DE LA NACIÓN, 2015). Outra questão a se pensar remete ao fato da intervenção breve não ser necessariamente um processo exclusivamente iniciado por profissional de saúde, dado que o usuário pode incluir o próprio consumo como tema, numa discussão com os profissionais no contexto da assistência como já mencionado (ROSE et al., 2015). Embora isso seja possível, constitui ainda um desafio sensibilizar os usuários de álcool o suficiente para que eles próprios iniciem uma discussão com médico ou outros profissionais da APS sobre a redução do seu consumo. No Brasil, o maior debate é a necessidade de que os profissionais iniciem essa discussão nos serviços de APS, seja qual for a necessidade ou tipos de consulta que esses usuários requeiram.

Embora a análise qualitativa deste estudo não tenha indicado a relevância desse fato, na classe "ocasiões que promovem ou desestimulam o beber" (classe 1), evidenciou-se através das palavras "conversa", "falar", "acho" a expectativa dos usuários de serem abordados sobre o tema.

Ninguém nunca sugeriu para eu diminuir ou parar de beber, ninguém.

O fato das equipes de saúde não conversarem a respeito do uso de álcool não é uma prerrogativa apenas dos usuários de álcool que utilizam os serviços de APS no Brasil. Field et al. (2013), evidenciaram em estudo que, poucos pacientes reportaram uma rotina de rastreamento ao uso abusivo de álcool e pouca pro-atividade no manejo dos problemas do uso por parte dos profissionais da atenção primária.

Diante do exposto, é evidente a importância de se pensar formas de promover a sensibilização para que o usuário se expresse e questione o próprio uso de álcool durante uma consulta ou visita à algum serviço de APS. Essa estratégia pode, dessa forma, ser uma via de acesso a esse grupo para diminuir os danos sociais do uso de álcool que, segundo Lochenmeier e Rehm (2015) são os maiores quando comparados às outras drogas de abuso e, embora o estudo tenha mostrado que sensibilizar os usuários e fazê-los pensar sobre como se sentem ou percebem seu consumo seja uma tarefa árdua, também mostrou que os ganhos podem recompensar o esforço.

No aspecto da interrupção do uso a análise qualitativa sugeriu haver relevância, através da frequência de frases que continham as palavras "paro... parar.." relativas às falas dos participantes. 
A esse respeito, no estudo de Field et al. (2013) os participantes explicaram o quanto os profissionais da APS fornecerem um aviso sobre os efeitos negativos do uso de álcool e a necessidade de diminuição do consumo, isso foi relatado como positivo e efetivo para discutirem o consumo e pararem ou diminuirem o consumo de álcool. Ainda no mesmo estudo, os usuários de álcool citaram a discussão com profissional como uma experiência positiva porque o faziam com alguém tecnicamente capaz.

Os resultados qualitativos mostraram ainda a ênfase do falar através das palavras "falo, falei, falar"

É interessante conversar porque tudo que é falado, por mais que você não ligue, vai ter uma hora que você vai lembrar daquilo, fica na cabeça, se você falou que faz mal.

$\mathrm{Na}$ análise qualitativa, na classe "estar dependente da droga" (classe 2), apesar do apoio, acompanhamento, não terem aparecido como palavras relevantes, considera-se importante expor a fala de um usuário que registra um pedido de ajuda.

Preciso de um acompanhamento para passar por isso, para dizer como estou me sentindo.

Isso sugere que quando o profissional não aborda o tema com o usuário, pode estar perdendo ou privando o usuário de uma oportunidade para expressar suas dificuldades em relação ao consumo ou às tentativas de supressão do mesmo.

No estudo de Field et al. (2013) os participantes expressaram, sentimentos de medo, resentimento ou embaraço como reações negativas que os impediram de levar o uso de álcool para uma discussão com os profissionais. Mas, considera-se que os usuários podem superar tais sentimentos quando observam um profissional com postura empática e conhecimento técnico.

Mesmo bebedores pesados, sempre relatados como pessoas de difícil acesso, podem ser estimulados a refletir críticamente sobre o consumo de álcool, conforme mostrou um estudo (ROSE et al., 2015), para determinar as características desses usuários na APS, que receberam intervenção breve de seus provedores de cuidado. Os resultados evendenciaram que 50\% deles iniciaram a reflexão sobre o seu consumo habitual, prerrogativa esta considerada como um fator protetivo.

Embora o estudo de Rose et al. (2015) traga o dado da discussão sobre o consumo com o usuário, faz-se necessário pensar como se pode de fato, sensibilizar os usuários de álcool para que eles próprios iniciem uma discussão com médico ou outros profissionais da APS, sobre a redução 
do consumo de álcool.

Outro aspecto relevante como sugestão de próximos estudos, é avaliar o quanto as caracteristicas pessoais dos usuários se associam com as respostas às intervenções breves em estudos clínicos e, por consequencia, na prática clínica da APS (EWING; LaCHANCE; BRYAN; HUTCHISON, 2009).

Diante disso, dada a problemática do consumo de álcool não se pode pensar que no âmbito da saúde pública só a execução de intervenções breves resolveria a necessidade de reduzir os danos do consumo, há de se pensar em conjuntos de alternativas, discutidas localmente com a equipe de saúde e outros segmentos da população e inclusive incorporando na rede de atenção serviços especializados, com estratégias aparentemente, mais efetivas.

No que se refere às limitações do estudo, a amostra foi a mais preocupante e, embora tenham sido feitas todas as tentativas para aumentá-la, tais como coletas de dados nos fins de semanas para participantes que trabalhavam, coletas após os horários das 18 horas, contatos via telefone e a própria estratégia de realizar as intervenções breves no domicílio, ainda assim essa questão não foi superada a contento. Possivelmente, isso foi resultante da opção de recrutamento não ideal, embora tenha sido a única possível, dada a equipe para coleta e o tempo para finalização do estudo. Recrutar participantes por indicação dos profissionais e, após, por visita domiciliar tornou o estudo oneroso em termos de tempo e não mostrou grandes incrementos no número da amostra, ainda que tenha sido significativo para vínculo com os usuários de álcool, compreensão do território, envolvimento e mobilização dos profissionais do serviço com a temática de pesquisa.

Uma outra possível limitação, foi o fato do principal resultado quantitativo ser somente o escore do AUDIT como medida única para avaliação quantitativa do estudo. Nos futuros estudos, seria mais apropriado inserir a investigação de outros aspectos que podem ser modificados com a intervenção breve, como o bem-estar, as doses consumidas, o estágio motivacional e outras associações com parâmetros de saúde relacionados com a saúde dos usuários de álcool, acrescentando possivelmente indicadores biológicos de saúde.

Sobre alguns participantes serem usuários de álcool mais outras drogas, esse estudo não se concentrou em verificar a influência no uso das demais drogas na efetividade de intervenção. Outros estudos com amostragem maior seriam necessários para identificar essa questão. 


\section{CONCLISÕ̃ES}




\section{Conclusões}

A complexidade da realização de um estudo clínico, embora os pragmáticos tenham menos rigor em critérios de inclusão e exclusão de amostra, induz a pensar sobre a representatividade deste estudo, por possibilitar ser um reflexo da atenção primária no que se refere à atenção aos usuários de drogas onde, a necessidade de estabelecimento de vínculos é premente, contudo difícil de estabelecer e manter.

Realizar um estudo dessa natureza mostrou-se uma tarefa árdua, que provavelmente representa a prática cotidiana dos profissionais da atenção primária que tentam realizar intervenções ou seguimento com usuários de álcool. O uso do método de visitas domiciliares foi positivo, mas para fins de pesquisa apresentou dificuldades numa população tão móvel dentro do território e ainda de difícil acesso por via telefônica. Contudo, entende-se que incluir somente uma amostra mais "fácil" de contatar provocaria um viés e não traria o aspecto pragmático que se objetivou desde a concepção do estudo.

$\mathrm{O}$ conhecimento de aspectos qualitativos mostrou que, na amostra, o consumo ligado ao hábito cotidiano parece se relacionar a padrões de consumo de doses mensais altos e, por isso, mais danosos, embora tenha se observado que possivelmente, o consumo seja alto também devido a carência de orientações e diálogos com os profissionais sobre o hábito de beber. As vivências sociais foram relacionadas ao consumo e o incentivo a pensar em como prover espaços e momentos de lazer sem álcool poderia auxiliar na diminuição ou abstinência dessa substância.

A necessidade de seguimento dessa população foi simulada pelo caráter longitudinal das avaliações e, ante esse segmento, outra questão emergiu: os horários de funcionamento dos serviços; por mais que se tentasse agendar encontros no horário de funcionamento normal do serviço, os participantes estavam envolvidos em outras atividades, sobretudo àqueles que possuíam vínculo empregatício ou que realizavam alguma atividade remunerada.

Diante disso, coloca-se o seguinte questionamento: como dentro do contexto da APS os profissionais podem pensar em seguir, intervir e avaliar usuários de álcool com uso problemático e mesmo de outras substâncias psicoativas, que estão inseridos no mercado de trabalho e por isso, com jornadas de trabalho em horários diferentes dos serviços?

A forma de recrutamento dos participantes foi um fator que aumentou o tempo necessário para finalização do estudo e, de certa forma, os recursos necessários. Como recomendação a parceria ou realização de intervenções pela própria equipe de saúde dos serviços de atenção primária, talvez 
pudesse prover uma amostra maior e uma proximidade mais real ainda do cotidiano de cuidado desses serviços.

A falta de evidência estatística na diferença de escores dos grupos após a intervenção (grupo controle e grupo intervenção) remete a que as intervenções com propósito de mudança comportamental, nessa população devem ser realizadas com mais frequência. Esse dado se fundamentou na verificação do efeito da intervenção no GI. Sobre o fato GC apresentar diminuição no primeiro mês de medida AUDIT, demonstrou que não apenas a intervenção breve direta pode ser usada no contexto comunitário, mas os folhetos podem ser ferramentas usadas numa primeira tentativa de sensibilização para diminuição no padrão.

Contudo, como mimetizado no atual estudo, é a intervenção breve que proveria uma mudança de comportamento com relação ao consumo de álcool mais substancial, duradoura e estável, pois, após os seis meses esse grupo manteve diminuição no consumo e, embora se discutam os valores estatísticos, como valor de p, não se pode negar o ganho clínico direto de participantes que ingeriam altas doses de álcool e, dado o tempo de reflexão e compressão (postulado na terapia cognitivo comportamental para mudança) reduziram o nível de consumo de álcool.

Entende-se que prolongar o período de avaliação nos grupos que recebem intervenção breve apontaria avanços para se predizer por quanto tempo esse tipo de intervenção tem efetividade, quando necessitaria de reforço para a manutenção da mudança ou mesmo a possível associação com outros tipos de intervenção para obter maior sucesso.

Como no atual estudo os contatos foram longitudinais e as entrevistas realizadas no grupo controle ainda em visita domiciliar, isso pode ter favorecido a autencidade das falas no que se refere aos dados qualitaivos. Além disso, a postura empática e o vínculo possibilitou uma relação de confiança, que permitiu a discussão e incluir o consumo de álcool como um tema possível dentro do contexto dos encontros com os participantes.

Poucos estudos qualitativos com pacientes usuários de álcool dentro desse contexto foram realizados e julga-se que os apontamentos resultantes de dados qualitativos acrescentaram aspectos relevantes aos resultados sobre os usuários de atenção primária, por mostrarem o quão imbricado está o consumo na relações sociais dos usuários e ao mesmo tempo nas suas características individuais. Essa condição complexa, denota a necessidade de promover políticas sociais de prevenção ao uso de álcool, fora dos padrões já estabelecidos de promoção e prevenção, comumente centrados só nas questões de restrições e promoção de tratamento.

Cabe ressaltar que alguns aspectos do desenho desse estudo são inovadores dentro da temática de APS no Brasil, tais como a implantação de visitas domiciliares (VD) para realização 
das intervenções em uso de álcool e a possibilidade de percepção de uma rotina semanal de uso identificada durante o mês de intervenção. Destaque-se que as ações de intervenção são viáveis de serem desenvolvidas pelos serviços componentes da APS, permitindo inferir que os resultados encontrados serão próximos aos obtidos pelas equipes de APS, que tentarem realizar seguimentos com usuários de álcool.

A execução de um roteiro de intervenção claro e o uso de ferramentas condizentes com o referencial cognitivo comportamental, como o Diário de consumo de álcool, mostrou-se de utilidade, pois possibilitou iniciar diálogos focados no consumo e pode facilitar aos profissionais que possuem dificuldades, ao oferecer um norte para lidar com os usuários de álcool. As entrevistas com os participantes do grupo intervenção também acrescentaram conhecimento às avaliações qualitativas do estudo, embora para pesquisas subsequentes recomende-se que as mesmas sejam feitas por etapas, a exemplo das medidas de follow up e que tenham o intuito maior de avaliação qualitativa para triangulação com os resultados quantitativos.

Destaca-se ainda o caráter inovador da tentativa de prover resultados tanto quantitativos quanto qualitativos no que se refere ao processo de mudança no comportamento de beber, visto que essa abrangência ainda não havia sido executada - pelo menos em estudos publicados até a recente data com usuários de álcool. 


\section{Referências $^{12}$}

ABREU, A. M. M. et al. Consumo nocivo de bebidas alcoólicas entre usuários de uma Unidade de Saúde da Família. Acta Paul Enferm. v. 25, n. 2, 291-5. 2012.

AFSHAR, M. et al. Acute immunomodulatory effects of binge alcohol ingestion. Alcohol. v. 49, n. 1, feb . 2015. doi: 10.1016/j.alcohol.2014.10.002.

ALDRIDGE, A. P. et al. The Relationship Between End-of-Treatment Alcohol Use and Subsequent Healthcare Costs: Do Heavy Drinking Days Predict Higher Healthcare Costs? Alcohol Clin Exp Res. v. 40, n. 5, may, 1122-8. 2016. doi: 10.1111/acer.13054.

ALLEN, E. et al. The efficacy of a brief intervention in reducing hazardous drinking in working age men in Russia: the HIM (Health for Izhevsk men) individually randomised parallel group exploratory trial. Trials. v. 12, n. 238. 2011. doi: 10.1186/1745-6215-12-238.

ALTMAN, D. G.; BLAND, J. M. Absence of evidence is not evidence of absence. BMJ. v. 311, n. 7003, aug. 1995.

ANTHONY, J. C.; ECHEAGARAY-WAGNER, F. Epidemiologic analysis of alcohol and tobacco use. Alcohol Res Health. v. 24, n. 4, 201-8. 2000.

BABOR, T. E. et al. Alcohol screening and brief intervention in primary care settings: implementation models and predictors. J Stud Alcohol. v. 66, n. 3, 361-8. 2005.

BABOR, T. et al. Brief interventions for at-risk drinking: patient outcomes and cost-effectiveness in managed care organizations. Alcohol Alcohol. v. 41, 624-631, 2006.

BABOR, T. et at. El alcohol: un producto de consumo no ordinario. Investigación y políticas públicas. Washington D. C.: Organización Panamericana de la Salud (versión en inglés publicada por Oxford Univesity Press, 2010).

BABOR, T. F.; HIGGINS-BIDDLE, J. C.; SAUNDERS, J. et al. AUDIT The Alcohol Use Disorders Identification Test. Guidelines for use in Primary Care. 2. ed.

WHO/MSD/MSB/01.6, World Health Organization, Geneva, 2001.

BARBOSA, C. et al. Cost of Screening, Brief Intervention, and Referral to Treatment in Health Care Settings. Journal of Substance Abuse Treatment. v. 60, 54-61, 2016.

BARDIN, L. Análise de conteúdo. Lisboa: Edições 70. 2010.

BARROS, M. A.; PILLON, S. C. Programa Saúde da Família: desafios e potencialidades frente ao uso de drogas. Revista Eletrônica de Enfermagem, v. 08, n. 01, p. 144 - 149, 2006.

\footnotetext{
${ }^{12}$ De acordo com a Associação Brasileira de Normas Técnicas. NBR 6023.
} 
BECHELLI, L. P. C.; SANTOS, M. A. Psicoterapia de grupo e considerações sobre o paciente como agente da própria mudança. Rev. Latino-Am. Enfermagem, Ribeirão Preto, v. 10, n. 3 , jun. 2002 .

BECK, A.T. et al. Cognitive Therapy of Substance Abuse. New York, NY: Guilford; 1993.

BIEN, T. H.; MILLER, W. R.; TONIGAN, J. S. Brief interventions for alcohol problems: A review. Addiction, v. 88, n. 3, 315-335. 1993.

BRITTON, A.; McKEE M. The relation between alcohol and cardiovascular disease in Eastern Europe: Explaining the paradox. J Epidemiol Community Health. v. 54, 328 - 32. 2000.

BUEHLER, A. M. et al. Como avaliar criticamente um ensaio clínico de alocação aleatória em terapia intensiva. Rev. bras. ter. intensiva, São Paulo, v. 21, n. 2, June. 2009.

CHAN, B. C. et al. The impact of a team-based intervention on the lifestyle risk factor management practices of community nurses: outcomes of the community nursing SNAP trial. BMC Health Serv Res. v.13, n. 54. 2013. doi: 10.1186/1472-6963-13-54

CHAN, Y.F. et al. Substance screening and referral for substance abuse treatment in an integrated mental health care program. Psychiatr Serv. v. 64, n. 1, 88-90. 2013.

CHASTAIN, G. Alcohol, neurotransmitter systems, and behavior. J Gen Psychol. v. 133, n. 4, Oct, 329-35. 2006.

COHEN, J. Statistical power analysis for the behavioral sciences. Second edition. Lawrence Erlbaum Associates Inc. London. 1988.

CONNOR, J. Alcohol consumption as a cause of cancer. Addiction. Version of Record online: 21 jul 2016. doi: 10.1111/add.13477

COUTINHO, E. S.; HUF, G.; BLOCH, K. V. Ensaios clínicos pragmáticos: uma opção na construção de evidências em saúde. Cad. Saúde Pública, Rio de Janeiro, v. 19, n. 4, p. 1189-1193, Aug. 2003. doi: 10.1590/S0102-311X2003000400039.

COX, W. M. et al. Attentional bias modification for addictive behaviors: clinical implications. CNS Spectrums. v. 19, 215-224. 2014. doi: 10.1017/S1092852914000091

CRAIG, P. et al. Developing and evaluating complex interventions: the new Medical Research Council guidance. BMJ. v. 337, sep, a1655. 2008. doi: 10.1136/bmj.a1655.

CUNNINGHAM, J. A. et al. Twelve-month follow-up results from a randomized controlled trial of a brief personalized feedback intervention for problem drinkers. Alcohol Alcohol. v. 45, n.3, mayjun, 258-62. 2010. doi: 10.1093/alcalc/agq009.

CUNNINGHAM, J. A. et al. Ultra-Brief Intervention for Problem Drinkers: Results from a Randomized Controlled Trial. Addiction Science \& Clinical Practice. 7 (Suppl 1): A17. 2012. 
DAVOUDI, M.; RAWSON, R. A. Screening, brief intervention, and referral to treatment (SBIRT) initiatives in California: notable trends, challenges, and recommendations. J Psychoactive Drugs. Sep; Suppl 6:239-48. 2010.

DAWSON, D. A. et al. Effectiveness of the derived Alcohol Use Disorders Identification Test (AUDIT-C) in screening for alcohol use disorders and risk drinking in the US general population. Alcohol Clin Exp Res. v. 29, n. 5, 844-54. 2005.

DE MICHELI, D.; FISBERG, M.; FORMIGONI, M.L.O.S. Estudo da efetividade da intervenção breve para o uso de álcool e outras drogas em adolescentes atendidos num serviço de assistência primária à saúde. Rev. Assoc. Med. Bras., São Paulo, v. 50, n. 3, Sept. 2004.

DOBKIN, P. L. et al. The role of functional social support in treatment retention and outcomes among outpatient adult substance abusers. Addiction. v. 97, 347-356. 2002. doi:10.1046/j.13600443.2002.00083.x.

DOLMAN, J. M.; HAWKES, N. D. Combining the AUDIT questionnaire and biochemical markers to assess alcohol use and risk of alcohol withdrawal in medical inpatients. Alcohol Alcohol. v. 40, n. 6, nov-dec, 2005.

DONABEDIAN, A.; WHEELER, J. R. C.; WYSZEWLANSKI, L. Quality, cost and health: An integrative model. Medical Care, v. 20, n. 10, 975-992. 1982.

EDWARDS, A. G. K.; ROLLNICK, S. Outcome studies of brief alcohol intervention in general practice: the problem of lost subjects. Addiction. v. 92, 1699-1704. 1997.

Ewing, S. et al. Do genetic and individual risk factors moderate the efficacy of motivacional enhacement therapy? Drinking outcomes with an emerging adult sample. Addiction Biology. v. 14, n. 3, 356-365. 2009.

FLEMING, M. F. et al. Brief physician advice for problem drinkers: Long-term efficacy and benefitcost analysis. Alcoholism: Clinical and Experimental Research. v. 26, n. 1, 36-43. 2002.

FONTANELLA, B. J. B. et al. Os usuários de álcool, Atenção Primária à Saúde e o que é "perdido na tradução". Interface. v.15, n.37, jun, 573-585. 2011.

FOULDS, J. et al. Harmful drinking and talking about alcohol in primary care: New Zealand population survey findings. Acta Psychiatr Scand. v. 126, n. 6, 434-9, dec. 2012. doi: 10.1111/j.1600-0447.2012.01871.x.

GONÇALVES, A.M.S. et al. Estratégias de rastreamento e intervenções breves como possibilidades para a prática preventiva do enfermeiro. Revista Eletrônica de Enfermagem, v. 13, p. 355-360, 2011.

GUAL, A. et al. Cribado precoz e intervención breve en el consumo perjudicial de alcohol para mejorar el tratamiento de la hipertensión arterial en atención primaria. Med Clin (Barc). v. 146, n. 2, jan. 2016. doi:10.1016/j.medcli.2015.07.014 
HALLGREN, K. A.; WITKIEWITZ, K. Missing data in alcohol clinical trials: a comparison of methods. Alcohol Clin Exp Res. v. 37, n. 12, 2152-60, dec, 2013. doi: 10.1111/acer.12205.

HANSEN, M. B. et al. "A welfare recipient may be drinking, but as long as he does as told--he may drink himself to death": a qualitative analysis of project implementation barriers among Danish job consultants. BMC Public Health. v. 18, mar, 15:264. 2015. doi: 10.1186/s12889-015-1620-x.

HEATHER, N. Can screening and brief intervention lead to population-level reductions in alcoholrelated harm? Heather Addiction Science \& Clinical Practice. v. 7, n. 15, 2012.

HENRIQUE, I. F. S. et a l. Validação da versão brasileira do teste de triagem do envolvimento com álcool, cigarro e outras substâncias (ASSIST). Rev Assoc Med Bras. v.50, n.2, p. 199-206, 2004.

HINGSON, R.; COMPTON, W. M. Screening and Brief Intervention and Referral to Treatment for Drug Use in Primary Care. Back to the Drawing Board. JAMA. v. 312, n. 5, august. 2014.

HUMENIUK, R.; DENNINGTON, V.; ALI, R. The effectiveness of a brief intervention for illicit drugs linked to the alcohol, smoking and substance involvement-screening test (ASSIST) in primary health care settings: a technical report of phase III findings of the WHO ASSIST randomized controlled trial. World Health Organization; Geneva: 2008.

ILGEN, M.A. et al. Therapeutic alliance and the relationship between motivation and treatment outcomes in patients with alcohol use disorder. Journal of Substance Abuse Treatment. v.31, 157-162. 2006.

INSTITUTE OF MEDICINE. Small Clinical Trials: Issues and Challenges. Washington, DC: The National Academies Press, 2001. doi: 10.17226/10078.

JOHNSON, M., et al. Barriers and facilitators to implementing screening and brief intervention for alcohol misuse: a systematic review of qualitative evidence. J Public Health (Oxf). v. 33, n. 3, sep, 412-21. 2011. doi: 10.1093/pubmed/fdq095.

JOMAR, R. T. et al. Perfil do consumo de álcool de usuários de uma unidade de Atenção Primária à Saúde. J. bras. psiquiatr. v. 64, n. 1, mar, 55-62, 2015. doi:10.1590/0047-2085000000057.

KAHAN, M.; WILSON, L.; BECKER, L. Effectiveness of physician-based interventions with problem drinkers: a review. CMAJ. v. 152, 851-859. 1995.

KANER, E. et al. Effectiveness of screening and brief alcohol intervention in primary care (SIPS trial): pragmatic cluster randomised controlled trial. BMJ. 346. 2013. doi: ttp://dx.doi.org/10.1136/bmj.e8501

KANER, E. F. et al. Effectiveness of brief alcohol interventions in primary care populations. Cochrane Database Syst Rev. v. 18, n. 2. 2007.

KNAPP, P.; BECK, A.T. Fundamentos, modelos conceituais, aplicações e pesquisa da terapia cognitiva. Rev. Bras. Psiquiatr. v .30, suppl.2 oct. 2008. 
KNOTT, C. S., et al. All-cause mortality and the case for age specific alcohol consumption guidelines: pooled analyses of up to 10 population based cohorts. BMJ. 350:h384. 2015. doi: http://dx.doi.org/10.1136/bmj.h384

KOSKI-JÄNNES, A.; PENNONEN, M.; SIMMAT-DURAND, L. Treatment professionals' basic beliefs about alcohol use disorders: the impact of different cultural contexts. Substance Use \& Misuse. v. 51, n. 4, 479-88. 2016. doi: 10.3109/10826084.2015.1126736

KOUIMTSIDIS, C. et al. Extended brief intervention to address alcohol misuse in people with mild to moderate intellectual disabilities living in the community (EBI-ID): study protocol for a randomised controlled trial. Trials. v. 16, n. 114, marc. 2015. doi: 10.1186/s13063-015-0629-X.

KRISTENSON, H. et al. Identification and Intervention of heavy drinking in middle-aged men: results and follow-up of 24 - 60 months of long-term study with randomized controls. Alcohol Clin Exp Res. v. 7, n. 2, 203-9. 1983.

KUERBIS, A. N. et al. Testing the initial efficacy of a mailed screening and brief feedback intervention to reduce at-risk drinking in middle-aged and older adults: the comorbidity alcohol risk evaluation study. J Am Geriatr Soc. v. 63, n. 2, 321-6, feb. 2015. doi: 10.1111/jgs.13237.

LAATIKAINEN, T. et al. Increased mortality related to heavy alcohol intake pattern. J Epidemiol Community Health. v. 57, 379-384. 2003. doi:10.1136/jech.57.5.379

LAC, A.; DONALDSON, C. D. Alcohol attitudes, motives, norms, and personality traits longitudinally classify nondrinkers, moderate drinkers, and binge drinkers using discriminant function analysis. Addictive Behaviors. v. 61, october, 91-98. 2016.

doi:10.1016/j.addbeh.2016.05.006

LACHENMEIERA, D. W.; REHM, J. Comparative risk assessment of alcohol, tobacco, cannabis and other illicit drugs using the margin of exposure approach. Sci Rep. v. 5, n. 8126. 2015.

LARANJEIRA, et al. Alcohol use patterns among Brazilian adults. Rev Bras Psiquiatr. v. 32, n. 3, sep, 231-41. 2010.

LARANJEIRA, R. et al. II Levantamento Nacional de Álcool e Drogas. 2012.

Disponível em: http://inpad.org.br/wp-content/uploads/2014/03/Lenad-II-Relat\%C3\%B3rio.pdf Acesso em jan de 2015.

LIM, S. S. et al. A comparative risk assessment of burden of disease and injury attributable to 67 risk factors and risk factor clusters in 21 regions, 1990 - 2010: a systematic analysis for the Global Burden of Disease Study 2010. The Lancet. v. 380, n. 9859, 2224-2260, December. 2012. doi:10.1016/S0140-6736(12)61766-8.

LITT, M. D.; KADDEN, R. M.; TENNEN, H. Network Support treatment for alcohol dependence: gender differences in treatment mechanisms and outcomes. Addict Behav. v. 45, jun, 87-92. 2015. doi: 10.1016/j.addbeh.2015.01.005.

LOPEZ, A. D. et al. Global and regional burden of disease and risk factors, 2001: systematic analysis of population health data. Lancet. v. 27, n. 367, may, 2006. 
LUDMAN, E.; CURRY, S. J. Perspectives in Implementing a Primary Care-Based Intervention to Reduce Alcohol Misuse. Am J Prev Med. v. 49, n. 302, sep, 194-199. 2015.

doi: 10.1016/j.amepre.2015.05.016

LUIS, M. A. V. et al. Patterns of Alcohol Use among Patients Who Visited Community Emergency Care Services in Southwestern Brazil. British Journal of Medicine \& Medical Research. v. 4, n. 35, 5689-5698, 2014.

MAHONEY, M.J. Human change processes: the scientific foundations of psychotherapy. New York: Basic Books; 1995.

MANGIONE, T. W. et al. Employee drinking practices and work performance. J Stud Alcohol. v. 60, n. 2, mar, 261-70. 1999.

MARQUES, A. C. P.; SILVA, E. A. Cognitivo-comportamental. In: Dependência de drogas. Alfredo Toscano Jr., Sergio Dario Seibel São Paulo: Editora Atheneu, $1^{\text {a }}$ Edição, 2000.

MAVANDADI, S. et al. The Moderating Role of Perceived Social Support on Alcohol Treatment Outcomes. J Stud Alcohol Drugs. v. 76, n. 5, sep, 818-22. 2015.

MAY, T. Pesquisa social: questões, métodos e processos. Porto Alegre: Artmed, 2004.

McCAMBRIDGE J. Brief intervention content matters. Drug Alcohol Rev. v. 32, 339 -4. 2013.

McCAMBRIDGE, J.; CUNNINGHAM, J. A. The early history of ideas on brief interventions for alcohol. Addiction. v. 109, 538-546. 2014.

McCORMICK, S. P., et al. Coping and social problem solving correlates of asthma control and quality of life. Chron Respir Dis. v.11, n. 1, 15-21, feb, 2014. doi: 10.1177/1479972313516878.

McHUGH, R. K.; HEARON, B. A.; OTTO, M. W. Cognitive-Behavioral Therapy for Substance Use Disorders. Psychiatr Clin North Am. v. 33, n. 3, sep, 511-525. 2010.

doi: $10.1016 /$ j.psc.2010.04.012

McLELLAN, A. T.; LEWIS, D. C.; O'BRIEN, C. P.; KLEBER, H. D. Drug dependence, a chronic medical illness: implications for treatment, insurance, and outcomes evaluation. JAMA. v. 284, n. 13, out, 1689-95. 2000.

MENDOZA, A. Z. O uso de álcool na adolescência, uma expressão de masculinidade [tese]. Ribeirão Preto: Escola de Enfermagem de Ribeirão Preto, Universidade de São Paulo; 2004.

MENESES-GAYA, C. et al. Alcohol Use Disorders Identification Test (AUDIT): an updated systematic review of psychometric properties. Psychol Neurosci. v. 2, n. 1, 83-97. 2009.

MILLER, W. R.; ROLLNICK, S. La entrevista motivacional. Preparar para el cambio de conductas adictivas. Barcelona: Paidós, 1991.

MINISTERIO DE SALUD DE LA NACIÓN. Dirección Nacional de Capital Humano y Salud Ocupacional La construcción de la matriz mínima de datos de profesionales de la salud del 
MERCOSUR desde sus inicios hasta el 2014 en Argentina, Brasil y Uruguay; compilado por María Del Carmen Cadile; coordinación de Maria Isabel Duré; Guillermo I. Williams. 1a ed. - Ciudad Autónoma de Buenos Aires: Ministerio de Salud de la Nación. Dirección Nacional de Capital Humano y Salud Ocupacional, 2015

MITCHELL, A. J., et al. Clinical recognition and recording of alcohol disorders by clinicians in primary and secondary care: meta-analysis. Br J Psychiatry. v. 201, n. 2, 93-100. 2012.

MONTEIRO, M. G. Alcohol and public health in Latin America: how to prevent a health disaster? Adicciones. v. 25, n. 2, 99-105. 2013.

MORETTI-PIRES, R. O.; CORRADI-WEBSTER, C. M.; FURTADO, E. F. Consumo de álcool e atenção primária no interior da Amazônia: sobre a formação de médicos e enfermeiros para assistência integral. Rev. bras. educ. med. v. 35, n. 2, june. 2011.

MURPHY, J. G. et al. Behavioral economic predictors of brief alcohol intervention outcomes. J Consult Clin Psychol. v. 83, n. 6, dec, 1033-43. 2015. doi: 10.1037/ccp0000032.

NAGGARA, O. et al. Analysis by categorizing or dichotomizing continuous variables is inadvisable: an example from the natural history of unruptured aneurysms. AJNR Am J Neuroradiol. v. 32, n. 3, mar, 437-40. 2011. doi: 10.3174/ajnr.A2425.

NEMETH, L. S. et al. Organizational Attributes and Screening and Brief Intervention in Primary Care. Addict Behav. v. 38, n. 11, nov, 2639-2642, 2013. doi:10.1016/j.addbeh.2013.05.016.

NIRENBERG, T. et al. Treatment May Influence Self-Report and Jeopardize Our Understanding of Outcome. J Stud Alcohol Drugs. v. 74, n. 5, sep, 770 - 776. 2013.

NTOUVA, A. et al. Assessing the feasibility of screening and providing brief advice for alcohol misuse in general dental practice: a clustered randomised control trial protocol for the DART study. BMJ. v. 5, n. 10. 2015. doi: 10.1136/bmjopen-2015-008586.

NUTT, D. J.; KING, L.A; PHILLIPS, L.D. Independent Scientific Committee on Drugs. Drug harms in the UK: a multicriteria decision analysis. Lancet. v. 376, n. 9752, 1558-65. 2010. doi: 10.1016/S0140-6736(10)61462-6.

NYAMATHI, A. et al. Effect of motivational interviewing on reduction of alcohol use. Drug Alcohol Depend. v. 107, n. 1, feb, 23-30. 2010. doi: 10.1016/j.drugalcdep.2009.08.021.

ORGANIZACIÓN MUNDIAL DE LA SALUD. Global status report on alcohol and health. Ginebra, Suiza: Organización Mundial de la Salud. 2011.

PENA, A. P. S.; GONCALVES, J. R. L. Assistência de enfermagem aos familiares cuidadores de alcoolistas. SMAD, Rev. Eletrônica Saúde Mental Álcool Drog. v. 6, n. 1, 2010.

PNUD, 2015. Relatório do Desenvolvimento Humano 2015: O Trabalho como Motor do Desenvolvimento Humano. Disponível em:

http://hdr.undp.org/sites/default/files/2015_human_development_report_1.pdf Acesso em jan 2016. 
POMPILI, M. et al. Suicidal Behavior and Alcohol Abuse. Int J Environ Res Public Health. v. 7, n. 4, apr, 1392-1431. 2010. doi: 10.3390/ijerph7041392

PORTNEY, L. G.; WATKINS, M. P. Foundations of clinical research. 2a ed. New Jersey: Prentice Hall Health; 2009.

PRAUD, D. et al. Cancer incidence and mortality attributable to alcohol consumption. Int J Cancer. v. 138, n. 6, mar, 1380-7. 2016. doi: 10.1002/ijc.29890.

PROBST, C. et al. Alcohol use disorder severity and reported reasons not to seek treatment: a crosssectional in European primary care practices. Substance Abuse Treatment, Prevention, and Policy. v. 10, n. 1. 2015. doi:10.1186/s13011-015-0028-z.

RAHHALI N. et al. Modelling the consequences of a reduction in alcohol consumption among patients with alcohol dependence based on real-life observational data. BMC Public Health. v. 15, 1271. 2015. doi: 10.1186/s12889-015-2606-4

RASSOOL, G.H. Substance Use and Misuse: Nature, Context and Clinical Interventions. Substance use and misuse: nature, context and clinical interventions. Blackwell Science, 1998.

REHM, J. et al. Alcohol Use Disorders in Primary Health Care: What Do We Know and Where Do We Go? Alcohol Alcohol. v. 51, n. 4, jul, 422-7. 2016. doi: 10.1093/alcalc/agv127.

REHM, J. et al. Global burden of disease and injury and economic cost attributable to alcohol use and alcohol-use disorders. Lancet. v. 373, n. 9682, jun, 2223-33. 2009. doi: 10.1016/S01406736(09)60746-7.

REHM, J. et al. The relation between different dimensions of alcohol consumption and burden of disease: an overview. Addiction. v. 105, n. 5, may, 817-843. 2010.

REHM, J. How should prevalence of alcohol use disorders be assessed globally? Int J Methods Psychiatr Res. v. 25, n. 2, jun, 79-85. 2016. doi: 10.1002/mpr.1508

REYNAUD, M. et al. Alcohol is the main factor in excess traffic accident fatalities in France. Alcohol Clin Exp Res. v. 26, n. 12, dec, 1833-9. 2002.

RITTER, A. et al. The influence of the therapeutic relationship in treatment for alcohol dependency. Drug Alcohol Rev. v. 21, n. 3, sep, 261-8. 2002.

RONZANI, T. M.; MOTA, D. C. B.; SOUZA, I. C.W. Prevenção do uso de álcool na atenção primária em municípios do estado de Minas Gerais. Rev. Saúde Pública. v. 43, suppl.1, 51-61. 2009.

RONZANI, T.M. et al. Implantação de rotinas de rastreamento do uso de risco de álcool e de uma intervenção breve na atenção primária à saúde: dificuldades a serem superadas. Cad. Saúde

Pública. v. 21, n. 3, June. 2005. 
ROOM, R.; CALLINAN, S.; DIETZA, P. Influences on the drinking of heavier drinkers: Interactional realities in seeking to 'change drinking cultures'. Drug Alcohol. v. 35, Special Section: Alcohol policy. 2015. doi: 10.1111/dar.12283

ROY-BYRNE, P. et al. Brief Intervention for Problem Drug Use in Safety-Net Primary Care Settings: A Randomized Clinical Trial. JAMA. v. 312, n. 5, 492-501. 2014. doi:10.1001/jama.2014.7860.

SALONSALMI, A. et al. Drinking habits and disability retirement. Addiction. v. 107, n. 12, dec, 2128-36. 2012. doi: 10.1111/j.1360-0443.2012.03976.x.

SCHULER, M.S. et al. Perceived barriers to treatment for alcohol problems: a latent class analysis. Psychiatric Services. v. 66, n. 11, 1221-1228. 2015. doi: 10.1176/appi.ps.201400160.

SEGATTO, M. L. et al. Triagem e intervenção breve em pacientes alcoolizados atendidos na emergência: perspectivas e desafios. Cad. Saúde Pública. v. 23, n. 8, aug. 2007.

SHIELD, K. D. et al. Alcohol consumption and burden of disease in the Americas in 2012: implications for alcohol policy. Rev Panam Salud Publica. v. 38, n. 6, dec, 442-449, 2015.

SILVA, L M. V.; FORMIGLI, V. L. A. Avaliação em saúde: limites e perspectivas. Cad. Saúde Pública, Rio de Janeiro, v. 10, n. 1, mar. 1994.

SILVEIRA, C. M. et al. Drinking Patterns and Alcohol Use Disorders in São Paulo, Brazil: The Role of Neighborhood Social Deprivation and Socioeconomic Status. PLoS ONE. v. 9, n. 10. 2014. doi: 10.1371/journal.pone.0108355.

SOUZA, J. et al. The social network of alcohol users undergoing treatment in a mental health service. Revista Latino-Americana de Enfermagem. v. 19, n. 1, 140-147, 2011.

SPEAR, S. et al. Another way of talking about substance abuse: substance abuse screening and brief intervention in a mental health clinic. Journal of human behavior in the social environment, v.19, 959-977. 2009.

STROBBE, S. Prevention and Screening, Brief Intervention, and Referral to Treatment for Substance Use in Primary Care. Primary Care: Clinics in Office Practice. v. 41, n. 2, june. 185 213. 2014.

TAUFICK, M. L. C. et al. Perfis de consumo alcoólico entre pacientes da atenção primaria a saúde e seu reconhecimento pelos profissionais de saúde. Cad. Saúde Pública. v. 30, n. 2, feb, 2014.

VAN DE WIEL, A.; DE LANGE, D. W. Cardiovascular risk is more related to drinking pattern than to the type of alcoholic drinks. Neth J Med. v. 66, n. 11, 467 - 73. 2008.

VARGAS, D.; BITTENCOURT, M. N.; BARROSO, L. P. Padrões de consumo de álcool de usuários de serviços de atenção primaria a saúde de um município brasileiro. Ciênc. saúde coletiva. v. 19, n. 1, jan. 2014. 
WATSON, J. M. et al. AESOPS: a randomised controlled trial of the clinical effectiveness and costeffectiveness of opportunistic screening and stepped care interventions for older hazardous alcohol users in primary care. Health Technol Assess. v. 17, n. 25, jun, 1-158. 2013. doi:

10.3310/hta17250.

WECHSLER, H. et al. A gender-specific measure of binge drinking among college students.

American Journal Public Health. v. 85, 982-985, 1995.

WHITLEY, E.; BALL, J. Statistics review 6: Nonparametric methods. Crit Care. v. 6, n. 6, 509513. 2002.

WORDEN, B. L.; McCRADY, B. S. Effectiveness of a feedback-based brief intervention to reduce alcohol use in community substance use disorders treatment. Alcoholism Treatment Quarterly. 31, 186-205. 2013.

WORLD HEALTH ORGANISATION (WHO). Global status report on alcohol and health. Geneva. 2014. Disponível em:<http://apps.who.int/iris/bitstream/10665/112736/1/9789240692763_eng.pdf > Acesso em: Jan/2015.

WORLD HEALTH ORGANISATION (WHO). Reducing Risks, promoting healthy life. World Health Organization, Geneva, Switzerland. 2002. Disponível em:

http://www.who.int/whr/2002/en/whr02_en.pdf Acesso em fevereiro de 2015.

WORLD HEALTH ORGANIZATION (WHO). Problems related to alcohol consumption. Geneva: Health Organization, Geneva, Switzerland. 1980. (Technical Report Series, 650). 
ANEXOS 


\section{Anexo I}
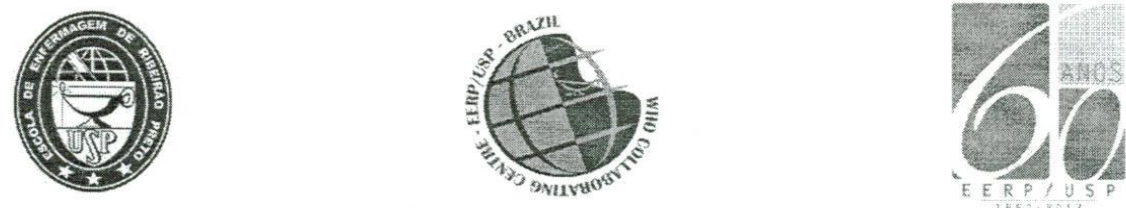

ESCOLA DE ENFERMAGEM DE RIBEIRÃO PRETO DA UNIVERSIDADE DE SÃO PAULO Centro Colaborador da Organiżação Mundial da Saúde para o Desenvolvimento da Pesquisa em Enfermagem Avenida Bandeirantes, 3900 - Ribeirão Preto - Sâo Paulo - Brasil - CEP 14040-902 - Fone: 55163602.3382 - 55163602.3381 - Fax: 55163602.0518 www.eerp.usp.br - eerpeedu.usp.br

\section{COMITÊ DE ÉTICA EM PESQUISA DA EERPIUSP}

Of.CEP-EERP/USP - 152/2013

Ribeirão Preto, 04 de junho de 2013

Prezada Senhora,

Comunicamos que o projeto de pesquisa, abaixo especificado, foi analisado e considerado APROVADO AD REFERENDUM pelo Comitê de Ética em Pesquisa da Escola de Enfermagem de Ribeirão Preto da Universidade de São Paulo, em 04 de junho de 2013.

Protocolo CAAE: 11343213.9 .0000 .5393

Projeto: Identificação das necessidades e proposta de intervenção nos problemas de saúde mental e uso de drogas psicoativas em população usuária de Programa Saúde da Família (PSF) do Município de Ribeirão Preto - SP.

Pesquisadores: Margarita Antonia Villar Luis

Em atendimento à Resolução 196/96, deverá ser encaminhado ao CEP o relatório final da pesquisa e a publicação de seus resultados, para acompanhamento, bem como comunicada qualquer intercorrência ou a sua interrupção.

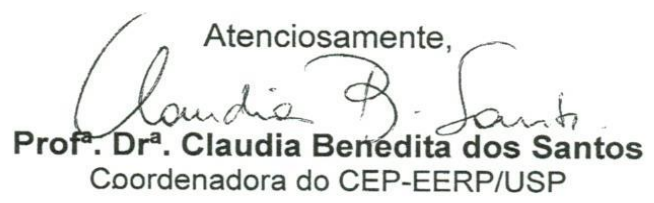

IIma. Sra.

Profa. Dra. Margarita Antonia Villar Luis

Departamento de Enfermagem Psiquiátrica e Ciências Humanas

Escola de Enfermagem de Ribeirão Preto - USP 


\section{Anexo II}

AUDIT

\begin{tabular}{|c|c|c|c|c|c|}
\hline $\begin{array}{l}\text { 1.Com que frequência você consome } \\
\text { bebidas alcoólicas? }\end{array}$ & $\begin{array}{l}\text { Nunca } \\
\square 0\end{array}$ & $\begin{array}{c}\text { 1x por mês ou } \\
\text { menos } \\
\square 1\end{array}$ & $\begin{array}{c}\text { 2-4x por mês } \\
\square 2\end{array}$ & $\begin{array}{c}\begin{array}{c}2-3 x \text { por } \\
\text { semana }\end{array} \\
\square 3\end{array}$ & $\begin{array}{c}4 \text { ou mais } x \\
\text { por semana } \\
\quad \square 4\end{array}$ \\
\hline \multirow{2}{*}{$\begin{array}{l}\text { 2.Quantas doses de álcool você consome } \\
\text { num dia normal? }\end{array}$} & 0 ou 1 & 2 ou 3 & 4 ou 5 & 6 ou 7 & 8 ou mais \\
\hline & $\square 0$ & $\square 1$ & $\square 2$ & $\square 3$ & $\square 4$ \\
\hline \multirow{2}{*}{$\begin{array}{l}\text { 3.Com que frequência você consome } \\
\text { cinco ou mais doses em uma única } \\
\text { ocasião? }\end{array}$} & Nunca & $\begin{array}{l}<1 \mathrm{x} \text { vez por } \\
\text { mês }\end{array}$ & $\begin{array}{l}\text { Uma vez por } \\
\text { mês }\end{array}$ & $1 x$ por semana & $\begin{array}{l}\text { Quase todos os } \\
\text { dias }\end{array}$ \\
\hline & $\square 0$ & $\square 1$ & $\square 2$ & $\square 3$ & $\square 4$ \\
\hline \multirow{2}{*}{$\begin{array}{l}\text { 4.Quantas vezes ao longo dos últimos } \\
\text { doze meses você achou que não } \\
\text { conseguiria parar de beber uma vez } \\
\text { tendo começado? }\end{array}$} & Nunca & $\begin{array}{l}<1 \mathrm{x} \text { vez por } \\
\text { mês }\end{array}$ & $\begin{array}{l}\text { Uma vez por } \\
\text { mês }\end{array}$ & $1 \mathrm{x}$ por semana & $\begin{array}{l}\text { Quase todos os } \\
\text { dias }\end{array}$ \\
\hline & $\square 0$ & $\square 1$ & $\square 2$ & $\square 3$ & $\square 4$ \\
\hline \multirow{2}{*}{$\begin{array}{l}\text { 5.Quantas vezes ao longo dos últimos } \\
\text { doze meses você não conseguiu fazer o } \\
\text { que era esperado de você por causa do } \\
\text { álcool? }\end{array}$} & Nunca & $\begin{array}{l}<1 \mathrm{x} \text { vez por } \\
\text { mês }\end{array}$ & $\begin{array}{l}\text { Uma vez por } \\
\text { mês }\end{array}$ & $1 x$ por semana & $\begin{array}{l}\text { Quase todos os } \\
\quad \text { dias }\end{array}$ \\
\hline & $\square 0$ & $\square 1$ & $\square 2$ & $\square 3$ & $\square 4$ \\
\hline \multirow{2}{*}{$\begin{array}{l}\text { 6. Quantas vezes ao longo dos últimos } \\
\text { doze meses você precisou beber pela } \\
\text { manhã para poder se sentir bem ao longo } \\
\text { do dia após ter bebido bastante no dia } \\
\end{array}$} & Nunca & $\begin{array}{l}<1 \mathrm{x} \text { vez por } \\
\text { mês }\end{array}$ & $\begin{array}{l}\text { Uma vez por } \\
\text { mês }\end{array}$ & $1 x$ por semana & $\begin{array}{l}\text { Quase todos os } \\
\text { dias }\end{array}$ \\
\hline & $\square 0$ & $\square 1$ & $\square 2$ & $\square 3$ & $\square 4$ \\
\hline \multirow{2}{*}{$\begin{array}{l}\text { 7.Quantas vezes ao longo dos últimos } \\
\text { doze meses você se sentiu culpado ou com } \\
\text { remorso após ter bebido? }\end{array}$} & Nunca & $\begin{array}{l}<1 \mathrm{x} \text { vez por } \\
\text { mês }\end{array}$ & $\begin{array}{l}\text { Uma vez por } \\
\text { mês }\end{array}$ & $1 x$ por semana & $\begin{array}{l}\text { Quase todos os } \\
\quad \text { dias }\end{array}$ \\
\hline & $\square 0$ & $\square 1$ & $\square 2$ & $\square 3$ & $\square 4$ \\
\hline \multirow{2}{*}{$\begin{array}{l}\text { 8.Quantas vezes ao longo dos últimos } \\
\text { doze meses você foi incapaz de lembrar } \\
\text { o que aconteceu devido à bebida? }\end{array}$} & Nunca & $\begin{array}{l}<1 \mathrm{x} \text { vez por } \\
\text { mês }\end{array}$ & $\begin{array}{l}\text { Uma vez por } \\
\text { mês }\end{array}$ & $1 x$ por semana & $\begin{array}{l}\text { Quase todos os } \\
\quad \text { dias }\end{array}$ \\
\hline & $\square 0$ & $\square 1$ & $\square 2$ & $\square 3$ & $\square 4$ \\
\hline \multirow{2}{*}{$\begin{array}{l}\text { 9.Você já causou ferimentos ou } \\
\text { prejuízos a você mesmo ou a outra } \\
\text { pessoa após ter bebido? }\end{array}$} & Não & & $\begin{array}{l}\text { Sim, mas não } \\
\text { no último ano }\end{array}$ & & $\begin{array}{l}\text { Sim, durante o } \\
\text { último ano }\end{array}$ \\
\hline & $\square 0$ & & $\square 2$ & & $\square 4$ \\
\hline \multirow{2}{*}{$\begin{array}{l}\text { 10.Alguém ou algum parente, amigo ou } \\
\text { médico, já se preocupou com o fato de } \\
\text { você beber ou sugeriu que você } \\
\text { parasse? }\end{array}$} & Não & & $\begin{array}{l}\text { Sim, mas não } \\
\text { no último ano }\end{array}$ & & $\begin{array}{l}\text { Sim, durante o } \\
\text { último ano }\end{array}$ \\
\hline & $\square 0$ & & $\square 2$ & & $\square 4$ \\
\hline
\end{tabular}

Consumo de baixo risco ou abstêmico $=0$ a 7 pontos

Consumo de risco $=8$ a 15 pontos

Uso nocivo ou consumo de alto risco $=15$ a 19 pontos

Provável dependência $=20$ ou mais pontos ( máximo $=40$ pontos $)$. 


\section{Anexo III}

Nome:

Registro

\section{Entrevistador: DATA:}

\section{ASSIST - OMS}

\begin{tabular}{|l|c|c|}
\hline $\begin{array}{l}\text { 1. Na sua vida qual(is) } \\
\text { dessa(s) substâncias } \\
\text { você já usou? } \\
\text { (somente uso não } \\
\text { prescrito pelo médico) }\end{array}$ & NÃo & SIM \\
\hline a. derivados do tabaco & 0 & 3 \\
\hline b. bebidas alcoólicas & 0 & 3 \\
\hline c. maconha & 0 & 3 \\
\hline d. cocaína, crack & 0 & 3 \\
\hline e. anfetaminas ou êxtase & 0 & 3 \\
\hline f. inalantes & 0 & 3 \\
\hline g.hipnóticos/sedativos & 0 & 3 \\
\hline h. alucinógenos & 0 & 3 \\
\hline i. opióides & 0 & 3 \\
\hline j. outras, especificar & 0 & 3 \\
\hline
\end{tabular}

- SE "NÃO" em todos os itens investigue:

Nem mesmo quando estava na escola?

- $\quad$ Se "NÃO" em todos os itens, pare a entrevista

- Se "SIM" para alguma droga, continue com as demais questões

3. Durante os três últimos meses, com que freqüência você teve um forte desejo ou urgência em consumir?

(primeira droga, segunda

droga, etc))

a. derivados do tabaco

b. bebidas alcoólicas

c. maconha

d. cocaína, crack

e. anfetaminas ou êxtase

f. inalantes

g.hipnóticos/sedativos

h. alucinógenos

i. opióides

j. outras, especifica

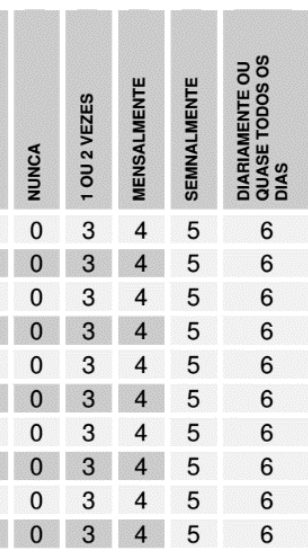

QUESTIONÁRIO PARA TRIAGEM DO USO DE ÁLCOOL, TABACO E OUTRAS SUBSTÂNCIAS.

\begin{tabular}{|c|c|c|c|c|c|}
\hline $\begin{array}{l}\text { 2. Durante os três últimos } \\
\text { meses, com que } \\
\text { freqüência você utilizou } \\
\text { essa(s) substância(s) } \\
\text { que mencionou? } \\
\text { (primeira droga, depois a } \\
\text { segunda droga, etc) }\end{array}$ & $\begin{array}{l}\text { d } \\
\text { ż } \\
\mathbf{z}\end{array}$ & 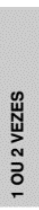 & 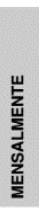 & 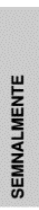 & 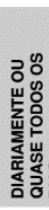 \\
\hline a. derivados do tabaco & 0 & 2 & 3 & 4 & 6 \\
\hline b. bebidas alcoólicas & 0 & 2 & 3 & 4 & 6 \\
\hline c. maconha & 0 & 2 & 3 & 4 & 6 \\
\hline d. cocaína, crack & 0 & 2 & 3 & 4 & 6 \\
\hline e. anfetaminas ou êxtase & 0 & 2 & 3 & 4 & 6 \\
\hline f. inalantes & 0 & 2 & 3 & 4 & 6 \\
\hline g.hipnóticos/sedativos & 0 & 2 & 3 & 4 & 6 \\
\hline h. alucinógenos & 0 & 2 & 3 & 4 & 6 \\
\hline i. opióides & 0 & 2 & 3 & 4 & 6 \\
\hline j. outras, especificar & 0 & 2 & 3 & 4 & 6 \\
\hline
\end{tabular}

- $\quad$ Se "NUNCA" em todos os itens da questão 2 pule para a questão 6 , com outras respostas continue com as demais questões

4. Durante os três últimos meses, com que freqüência o seu consumo de (primeira droga, depois a segunda droga, etc) resultou em problema de saúde, social, legal ou financeiro?

a. derivados do tabaco

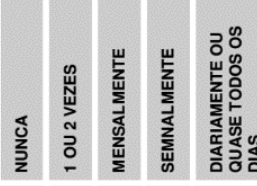

b. bebidas alcoólicas

c. maconha

$\begin{array}{llllll}0 & 4 & 5 & 6 & 7\end{array}$

d. cocaína, crack

e. anfetaminas ou êxtase

$\begin{array}{lllllll}0 & 4 & 5 & 6 & 7\end{array}$

f. inalantes

g.hipnóticos/sedativos

h. alucinógenos

i. opióides

j. outras, especificar

NOMES POPULARES OU COMERCIAIS DAS DROGAS

a. produtos do tabaco (cigarro, charuto, cachimbo, fumo de corda)

b. bebidas alcóolicas (cerveja, vinho, champagne, licor, pinga uísque, vodca, vermutes, caninha, rum tequila, gin)

c. maconha (baseado, erva, liamba, diamba, birra, fuminho, fumo, mato, bagulho, pango, manga-rosa, massa,

haxixe, skank, etc)

d. cocaína, crack (coca, pó, branquinha, nuvem, farinha, neve, pedra, caximbo, brilho)

e. estimulantes como anfetaminas (bolinhas, rebites, bifetamina, moderine, MDMA)

f. inalantes (solventes, cola de sapateiro, tinta, esmalte, corretivo, verniz, tinner, clorofórmio, tolueno, gasolina, éter, lança perfume, cheirinho da loló)

g.hipnóticos, sedativos (ansiolíticos, tranquilizantes, barbitúricos, fenobarbital, pentobarbital, benzodiazepínicos, diazepam)

h. alucinógenos (LSD, chá-de-lírio, ácido, passaporte, mescalina, peiote, cacto)

i. opiáceos (morfina, codeína, ópio, heroína elixir, metadona)

j. outras - especificar: 
5. Durante os três últimos meses, com que freqüência, por causa do seu uso de (primeira droga, depois a segunda droga, etc), você deixou de fazer coisas que eram normalmente esperadas de você?

a. derivados do tabaco

b. bebidas alcoólicas

c. maconha

d. cocaína, crack

e. anfetaminas ou êxtase

f. inalantes

g.hipnóticos/sedativos

h. alucinógenos

i. opióides

j. outras, especificar

7. Alguma vez você já Alguma vez você já
tentou controlar, diminuir ou parar o uso de ((primeira droga, depois a segunda droga, etc...) e não conseguiu?

a. derivados do tabaco

b. bebidas alcoólicas

c. maconha

d. cocaína, crack

e. anfetaminas ou êxtase

f. inalantes

g.hipnóticos/sedativos

h. alucinógenos

i. opióides

j. outras, especificar

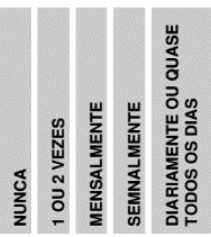

$\begin{array}{lllll}0 & 5 & 6 & 7 & 8\end{array}$

\begin{tabular}{l|l|l|l|l}
0 & 5 & 6 & 7 & 8
\end{tabular}

$\begin{array}{lllll}0 & 5 & 6 & 7 & 8\end{array}$

\begin{tabular}{l|l|l|l|l}
0 & 5 & 6 & 7 & 8
\end{tabular}

\begin{tabular}{ll|l|l|l}
0 & 5 & 6 & 7 & 8
\end{tabular}

\begin{tabular}{l|l|l|l|l}
0 & 5 & 6 & 7 & 8
\end{tabular}

$\begin{array}{llllll}0 & 5 & 6 & 7 & 8\end{array}$

\begin{tabular}{l|l|l|l|l}
0 & 5 & 6 & 7 & 8
\end{tabular}

$\begin{array}{lllll}0 & 5 & 6 & 7 & 8\end{array}$

\begin{tabular}{l|l|l|l|l}
0 & 5 & 6 & 7 & 8
\end{tabular}
- FAÇA as questões 6 e 7 para todas as substâncias mencionadas na questão 1

6. Há amigos, parentes ou outra pessoa que tenha demonstrado preocupação com seu uso de (primeira droga, depois a segunda droga, etc...)?

a. derivados do tabaco

b. bebidas alcoólicas

c. maconha

d. cocaína, crack

e. anfetaminas ou êxtase

f. inalantes

g.hipnóticos/sedativos

h. alucinógenos

i. opióides

j. outras, especificar

Nota Importante: Pacientes que tenham usado drogas injetáveis nos últimos 3 meses devem ser perguntados sobre seu padrão de uso injetável durante este periodo, para determinar seus níveis de risco e a melhor forma de intervenção.

\begin{tabular}{|c|c|c|}
\hline \multicolumn{3}{|c|}{$\begin{array}{l}\text { 8- Alguma vez você já usou drogas por injeção? } \\
\text { (Apenas uso não médico) }\end{array}$} \\
\hline $\begin{array}{l}\text { NÂO, } \\
\text { nunca }\end{array}$ & $\begin{array}{c}\text { SIM, nos } \\
\text { últimos } 3 \text { meses }\end{array}$ & $\begin{array}{l}\text { SIM, mas não nos } \\
\text { últimos } 3 \text { meses }\end{array}$ \\
\hline
\end{tabular}

Guia de Intervencão para Padrão de uso inietável

Uma vez por semana ou menos $\rightarrow$ Intervenção Breve incluindo cartão de Ou menos de três dias seguidos "riscos associados com o uso injetável"

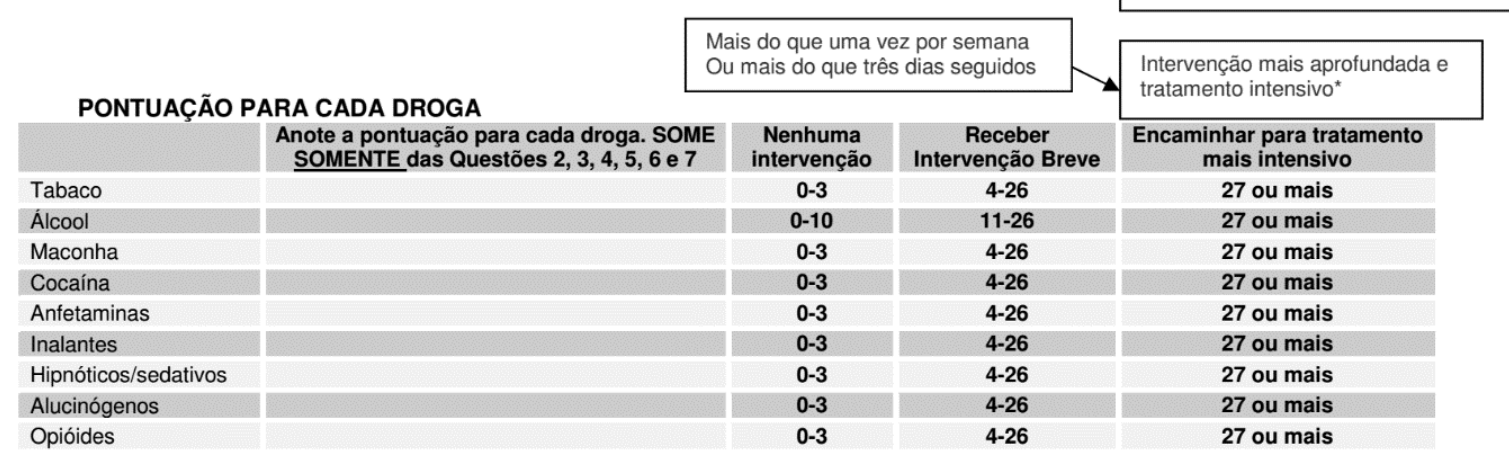

Cálculo do escore de envolvimento com uma substância específica.

Para cada substância (de 'a' a 'j') some os escores obtidos nas questões 2 a 7 (inclusive).

Não inclua os resultados das questōes 1 e 8 aqui.

Por exemplo, um escore para maconha deverá ser calculado do seguinte modo: Q2c + Q3c+Q4c+Q5c+Q6c+Q7c

Note que Q5 para tabaco não é codificada, sendo a pontuação para tabaco = Q2a + Q3a + Q4a + Q6a + Q7a 


\section{Apêndice I}

\section{Diário de consumo de álcool}

Indicar, de acordo com horário (manhã, tarde ou noite) o consumo de bebida alcoólica descrevendo a quantidade (ex.: um copo de cerveja, uma dose de pinga), o tipo de bebida (cerveja, pinga, vinho...) e uma palavra que descreva seu sentimento quando sentiu vontade de beber álcool (por exemplo: ansioso, alegre, agitado, triste...).

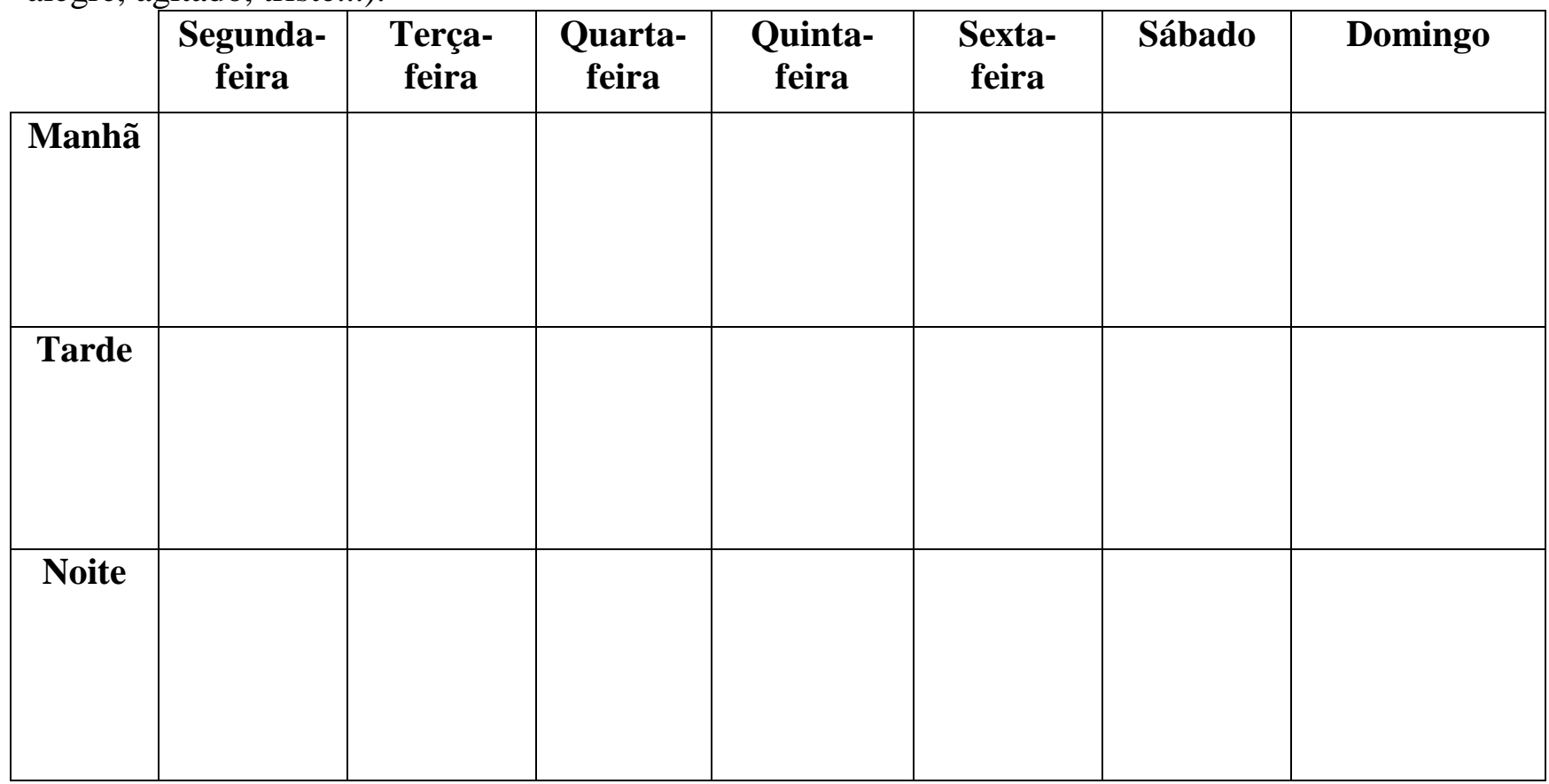




\section{Apêndice II}

\section{Protocolo de intervenção breve}

As intervenções deverão ser realizadas, preferencialmente, na casa das participantes e será realizada uma visita prévia para explicação e convite para participação no estudo após a aplicação do AUDIT. Participantes com AUDIT > 7 são elegíveis para ingresso do grupo do estudo de intervenção breve.

Abaixo segue os temas a serem abordados a cada encontro de intervenção breve.

Primeiro encontro: Identificação da rotina de consumo através da discussão do Diário de consumo de álcool; Identificação e discussão dos sentimentos relatados antes o consumo (exemplo: tristeza, raiva, ansiedade...). Caso o participante não consiga identificar os sentimentos, estimulá-lo a "se perceber" antes de iniciar o consumo de álcool.

Segundo encontro: Leitura do Diário de Consumo de álcool e exploração dos prós e contras do consumo de álcool, segundo a percepção do usuário e as situações ligadas ao uso (festas, encontros com amigos, trabalho);

Terceiro encontro: Leitura do Diário de Consumo de álcool e discussão sobre a capacidade do participante para efetuar mudanças e questionamento sobre planejamento de metas para mudança para a próxima semana;

Quarto encontro: Leitura do Diário de Consumo de álcool das últimas semanas e incentivo à reflexão sobre a capacidade de mudança. Realizado ainda o feedback da pesquisadora ao participante. Nesse encontro o feedback e a reflexão quanto à mudança são realizados no sentido de trazer o problema de beber no nível de outros problemas e na condição de hábito de saúde controlável e sai da seara da moralidade. 


\title{
Apêndice V
}

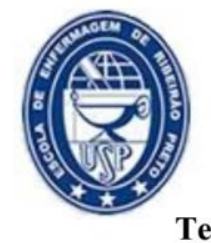

\author{
Universidade de São Paulo \\ “CAMPUS” DE RIBEIRÃO PRETO \\ Telefone: 3602-3391 - FAX: (16) 3633-3271/3630-2561
}

CEP: 14040-902 - Ribeirão Preto - SP - Brasil

Termo de Consentimento Livre e Esclarecido para Usuários

Convidamos o senhor/a a participar uma pesquisa cujo título é "Identificação das necessidades e proposta de intervenção nos problemas de saúde mental e uso de drogas psicoativas em população usuária de Programa Saúde da Família (PSF) do Município de Ribeirão Preto - SP” e que tem como objetivo identificar situação de saúde local, centralizando-se no levantamento de informações sobre problemas mentais e uso de álcool e outras drogas entre uma amostra de população da zona de abrangência da USP - Zona Oeste, planejar intervenções em usuários de álcool e avaliar o resultado das mesmas. Este estudo justifica-se por colaborar com alternativas de intervenção com os usuários de álcool. Caso aceite, sua participação se dará em dois momentos, um mês e seis meses após o primeiro, onde serão aplicados instrumentos para avaliar seu padrão de consumo de álcool, sendo isso parte da coleta de dados desta pesquisa. Esse instrumento contém perguntas referentes ao uso de álcool do/a senhor/a e objetiva avaliar o grau de risco que existe nesse consumo. Esses encontros serão realizados entre você e um/a pesquisador/a em data e local previamente agendados, conforme sua disponibilidade e terão duração de, em média, 30 minutos. Todos os nossos encontros serão gravados, caso concorde. Sua participação é voluntária, sendo garantido o sigilo das informações confidencias que por ventura o senhor/a venha a revelar ao pesquisador/a, bem como seu anonimato, ou seja, em nenhum momento da divulgação dos resultados desta pesquisa o senhor/a será identificado. Você poderá retirar-se do estudo a qualquer momento, caso julgue necessário, sem quaisquer prejuízos. Acreditamos ter tomado todas as providências para que você não sofra riscos, prejuízos, desconfortos, lesões, mas caso sinta desconforto devido falar do uso de drogas ou das situações que lhe levam a isso, orientamos a procurar o serviço do Núcleo de Saúde da Família e nos informar sobre seu desconforto. O senhor/a não terá gastos financeiros devido à sua participação na pesquisa, porém também não será beneficiado financeiramente. Sua participação poderá trazer benefício direto de pensar sobre o uso prejudicial de álcool ou outras drogas, o que pensamos que pode auxiliá-lo na diminuição ou na cessação do vício. Indiretamente sua participação contribui para avaliar estratégias possíveis de serem aplicadas em outras pessoas que usam de forma abusiva alguma droga. $\mathrm{O}$ senhor/a será informado sobre os resultados parciais da pesquisa, sempre que o desejar. Dúvidas poderão ser esclarecidas diretamente com os pesquisadores responsáveis. Este termo será confeccionado em duas vias, caso concorde em participar, uma original assinada deste termo de consentimento lhe será fornecida e outra fica com o pesquisador. Esclarecemos que esta pesquisa foi submetida ao Comitê de Ética em Pesquisa da Escola de Enfermagem de Ribeirão Preto - USP (Protocolo $\mathrm{n}^{\circ}$. 11343213.9.0000.5393).

$\mathrm{Eu}$ RG esclareço que em caso de dúvida, fui orientado a procurar a Prof ${ }^{a} \operatorname{Dr}^{\mathrm{a}}$ Margarita Antonia Villar Luis do Departamento de Enfermagem Psiquiátrica e Ciências Humanas da Escola de Enfermagem de Ribeirão Preto da Universidade de São Paulo (EERP-USP) pelo telefone (16) 3602-3477 ou e-mail: margarit@eerp.usp.br Declaro que tenho conhecimento dos direitos acima descritos, e consinto em participar deste estudo, realizado pela pesquisadora que assina este termo de consentimento.

De acordo, Ribeirão Preto, de de

Assinatura da pesquisadora

Assinatura do Participante 


\title{
Apêndice III
}

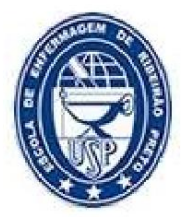

\author{
Universidade de São Paulo \\ Escola de Enfermagem de Ribeirão Preto \\ “CAMPUS” DE RIBEIRÃO PRETO \\ Telefone: 3602-3391 - FAX: (16) 3633-3271/3630-2561 \\ CEP: 14040-902 - Ribeirão Preto - SP - Brasil
}

Termo de Consentimento Livre e Esclarecido para Usuários

Convidamos o senhor/a a participar uma pesquisa cujo título é "Identificação das necessidades e proposta de intervenção nos problemas de saúde mental e uso de drogas psicoativas em população usuária de Programa Saúde da Família (PSF) do Município de Ribeirão Preto - SP” e que tem como objetivo identificar situação de saúde local, centralizando-se no levantamento de informações sobre problemas mentais e uso de álcool e outras drogas entre uma amostra de população da zona de abrangência da USP - Zona Oeste, planejar intervenções em usuários de álcool e avaliar o resultado das mesmas. Este estudo justifica-se por colaborar com alternativas de intervenção com os usuários de álcool. Caso aceite, sua participação se dará em quatro encontros baseados na técnica de atendimento de Intervenção Breve sobre uso de álcool e outros dois encontros de avaliação, onde se realizará a coleta de dados desta pesquisa. A técnica de Intervenção Breve consiste numa conversa focada na orientação sobre os riscos a saúde associada ao uso do álcool, questionando as coisas boas e as coisas não tão boas propiciadas pelo uso. Esses encontros serão realizados entre você e um/a pesquisador/a em data e local previamente agendados, conforme sua disponibilidade e terão duração de, em média, 30 minutos. Os encontros de avaliação serão realizados um mês e seis meses após nosso último encontro de intervenção e terão duração média de 60 minutos. Todos os nossos encontros serão gravados, caso concorde. Sua participação é voluntária, sendo garantido o sigilo das informações confidencias que por ventura o senhor/a venha a revelar ao pesquisador/a, bem como seu anonimato, ou seja, em nenhum momento da divulgação dos resultados desta pesquisa o senhor/a será identificado. Você poderá retirar-se do estudo a qualquer momento, caso julgue necessário, sem quaisquer prejuízos. Acreditamos ter tomado todas as providências para que você não sofra riscos, prejuízos, desconfortos, lesões, mas caso sinta desconforto devido falar do uso de drogas ou das situações que lhe levam a isso, orientamos a procurar o serviço do Núcleo de Saúde da Família 5 e nos informar sobre seu desconforto. O senhor/a não terá gastos financeiros devido à sua participação na pesquisa, porém também não será beneficiado financeiramente. Sua participação poderá trazer benefício direto de pensar sobre o uso prejudicial de álcool ou outras drogas, o que pensamos que pode auxiliá-lo na diminuição ou na cessação do vício. Indiretamente sua participação contribui para avaliar estratégias possíveis de serem aplicadas em outras pessoas que usam de forma abusiva alguma droga. O senhor/a será informado sobre os resultados parciais da pesquisa, sempre que o desejar. Dúvidas poderão ser esclarecidas diretamente com os pesquisadores responsáveis. Este termo será confeccionado em duas vias, caso concorde em participar, uma original assinada deste termo de consentimento the será fornecida e outra fica com o pesquisador. Esclarecemos que esta pesquisa foi submetida ao Comitê de Ética em Pesquisa da Escola de Enfermagem de Ribeirão Preto - USP (Protocolo $n^{\circ}$. 11343213.9.0000.5393).

$\mathrm{Eu}$ $R G$ , esclareço

que em caso de dúvida, fui orientado a procurar a $\operatorname{Prof}^{\mathrm{a}} \operatorname{Dr}^{\mathrm{a}}$ Margarita Antonia Villar Luis do Departamento de Enfermagem Psiquiátrica e Ciências Humanas da Escola de Enfermagem de Ribeirão Preto da Universidade de São Paulo (EERP-USP) pelo telefone (16)

3602-3477 ou e-mail: margarit@usp.br

Declaro que tenho conhecimento dos direitos acima descritos, e consinto em participar deste estudo, realizado pela pesquisadora que assina este termo de consentimento.

De acordo, Ribeirão Preto, de de

Assinatura da pesquisadora

Assinatura do Participante 


\section{Apêndice VII}

\section{Perfil Sócio demográfico}

N ${ }^{\circ}$ FICHA:

Grupo de alocação do participante:

ID do participante:

Entrevistador:

Data:

Serviço de saúde que é vinculado:

Informações fornecidas por: ( ) participante

( ) familiar

1. Sexo:

1. ( ) Feminino 2. ( ) Masculino

2. Data de Nascimento: ___________ Idade:____ ( ) não sabe

3. Cidade e Estado de origem:

4. Você mora com quem? ( ) sozinho. Se sozinho, recebe visitas?
(1) $\mathrm{Sim}$
(2) Não

( ) família

( ) abrigo/casa de repouso/Residência Terapêutica

5. Você trabalha atualmente?
1. ( ) Sim. No quê?
2. ( ) Não
3. ( ) Aposentado

6. Você estudou até que série?

Anos de estudo:

7. Você realiza alguma atividade para ganhar dinheiro?

1. ( ) sim. Qual? ( ) trabalho formal

( ) esmolar/ pedir dinheiro

( ) atividades informais (bicos)

2. ( ) não

( ) outra. Qual?

8. Você já utilizou algum tipo de droga alguma vez na vida?

1. ( ) sim Qual?
( ) álcool
( ) maconha
( ) cola
( ) cocaína inalada
( ) droga injetável.Qual?
( ) crack
( ) remédio Qual?
( ) tabaco
( ) outras
Qual?

2. ( ) não 
9. Você tem algum problema de saúde?

1. ( ) sim. Qual?

2. ( ) não

10. Você já teve alguma internação hospitalar?

1. ( ) Sim. Por quê?

2. ( ) Não

11. Você tem alguma queixa de saúde frequente? (dores no estômago, enxaqueca, fraqueza...)

1. ( ) Sim. Qual?

2. ( ) Não

12. Você acha que a álcool representa um problema para você?

1. ( ) sim

2. ( ) não

13. Algum familiar costuma tomar bebidas alcóolicas com muita frequência (a ponto de causar problemas em casa, no trabalho ou com amigos)?

1. ( ) Sim. Quem?

2. ( ) Não

14. Algum familiar faz uso de drogas ilícitas?

1. ( ) Sim. Quem?

2. ( ) Não

15. Algum familiar costuma fazer uso de drogas ilícitas com muita freqüência (a ponto de causar problemas em casa, no trabalho ou com amigos)?

1. ( ) Sim. Quem?

2. ( ) Não

16. Atualmente você tem algum parceiro sexual?

1. ( ) Sim. Quantos?

2. ( ) Não

17. Você costuma estar "alto" (ter usado álcool ou drogas) quando tem relações?

1. ( ) sim

2. ( ) não 


\section{Apêndice VIII}

\section{Folheto informativo para grupo controle}

Vamos falar sobre consumo de álcool?

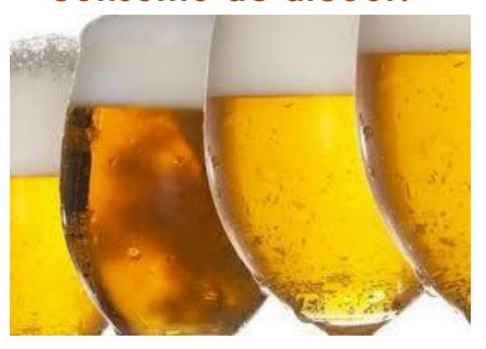

\author{
Pensar e falar \\ antes de \\ beber...
}

PORQUE ISSO ME AJUDA A CONSUMIR ÁLCOOL DE FORMA MAIS ADEQUADA?

\section{Quanto estou bebendo?}

Você já parou para pensar no quanto de bebida alcoólica consume por semana? Já refletiu como se sente antes de beber (triste, alegre, chateado)?

Pode parecer ser que não, mas pensar sobre essas questões pode te ajudar a entender o porquê você bebe e quando você tem uma tendência maior para beber.

\section{Como saber se meu consumo de álcool está elevado?}

O álcool, como qual quer substância que causa dependência, precisa ser monitorado quanto ao consumo e para isso é sempre aconselhado se procurar algum serviço ou profissional de saúde quando se percebe que está se indo "além da conta" no consumo.

$\mathrm{Na}$ atenção primária à saúde procure a enfermeira ou médico da estratégia de saúde da família, eles estão preparados com conversa e intervir nesses casos.

Existem também grupos na comunidade que podem auxiliar a pensar e planejar a diminuição do consumo de álcool, como o Alcoólicos Anônimos (AA). Você já ouviu falar?

\section{Exisłe "beber saudável" ou "social"?}

Existem pessoas que conseguem beber certa quantidade de bebida sem ter a necessidade de beber todo dia. Porém, as pessoas são diferentes quanto ao consumo de álcool e o corpo também responde diferente em cada pessoa e dependendo de cada consumo.

Fique atento a como você reage a quantidade de álcool que anda bebendo ultimamente. Você tem sentido a necessidade de beber mais para sentir o mesmo efeito? Tem se esquecido do que acontece quando bebe muito? Tem bebido logo pela manhã? Tem faltado no trabalho para beber?

Se respondeu sim a essas questões, fique atento!

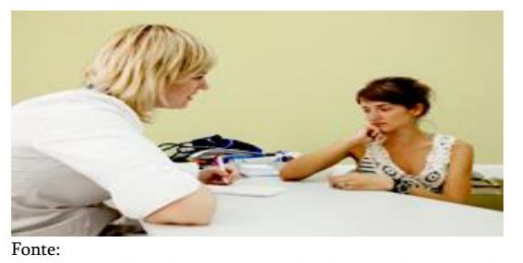

http://www.nih.gov/researchmatters/october2011/10172011alco 


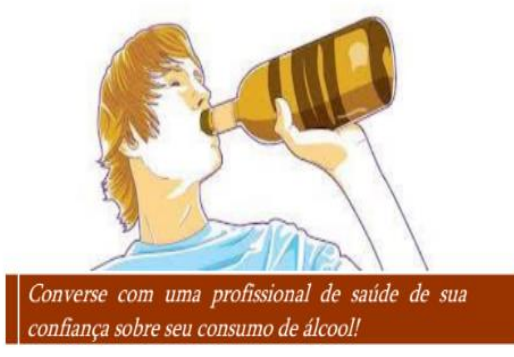

SE ESTOU COM PROBLEMAS DEVIDO CONSUMO DE ÁLCOOL, QUAL SERVICCO DEVO PROCURAR?

Procure o serviço do Núcleo de Saúde da Família ou outro serviço de saúde.

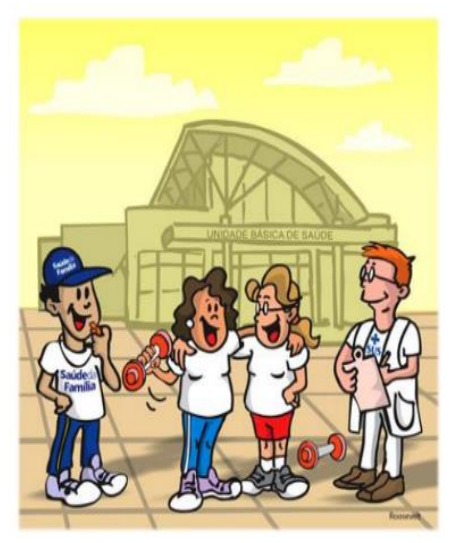

Perigos de beber excessivamente

Consequencias do uso abusivo de alcool

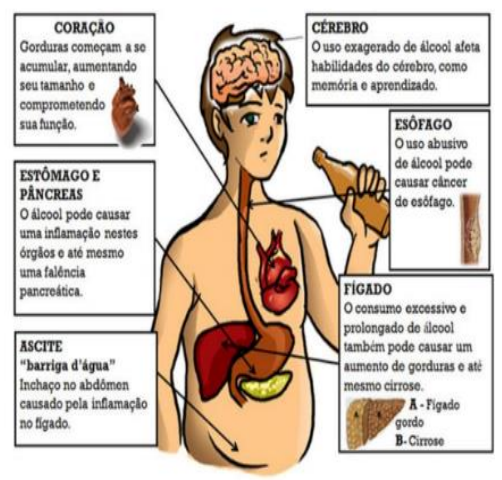

Fonte:

HTTP:/LABIOSIGNAL.PAGINAS.UFSC.BR/2013/06/22/PROJETO-

DE-EXTENSAO-PREVENCAO-AO-USO-ABUSIVO-DE-ALCOOL-

ENTRE-CRIANCAS-E-ADOLESCENTES-DO-ENTORNO-DA-UFSC

FIQUE ATENTO!!
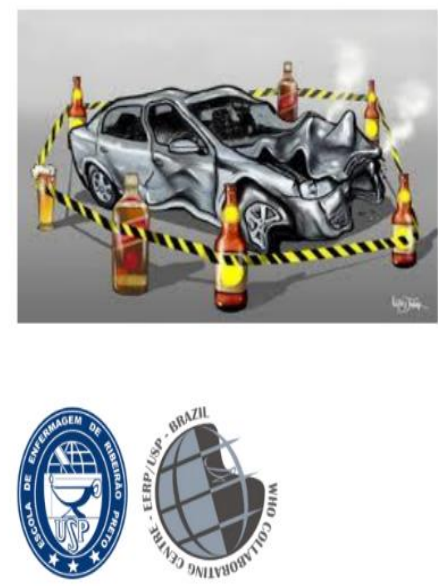

Criação

Enfo Sara Pinto Barbosa Prof: Margarita Antonia Villar Luis Laboratório de Stress, Álcool e outras

$$
\text { Drogas }
$$

Telefone (16) 3602-3477 